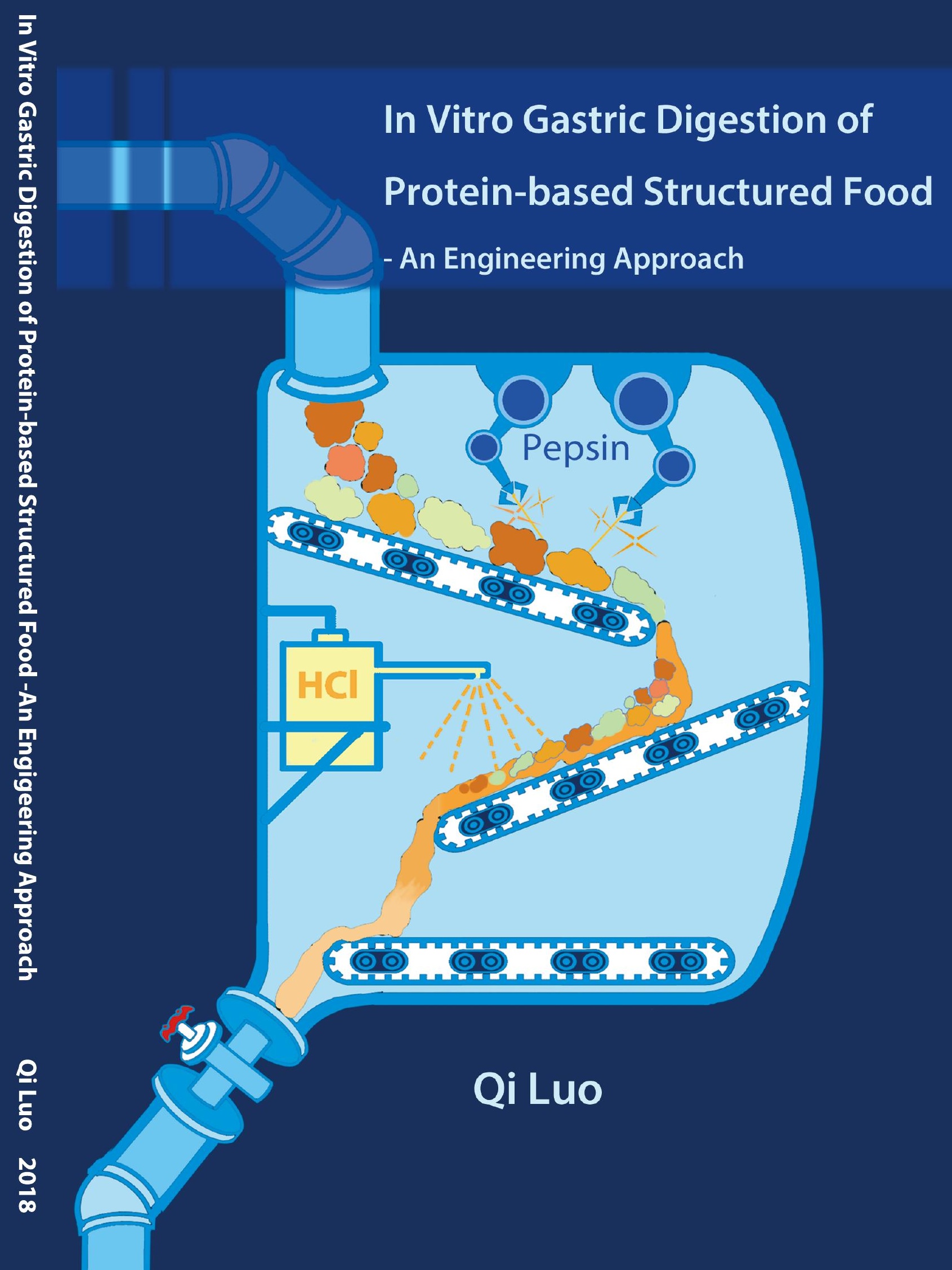




\section{Propositions}

1. Pepsin has evolved to allow us maximum use of scarce protein sources; understanding its mechanism allows us to balance our food uptake.

(this thesis)

2. The reaction mechanism of pepsin can only be properly understood when the complex and variable structure of food matrix is considered.

(this thesis)

3. From an engineer's perspective on the stomach, 'eat little and often' is more efficient than consuming big meals.

4. The gap between science disciplines is as disconcerting as the gap between science and general public.

5. An 'Open discussion' platform will provide more scientific progress than 'Open Access'.

6. Creative jobs will be just as suitable for automation and robotization as other jobs.

7. There is more diversity among individuals from the same culture than there is difference between cultures.

Propositions belonging to the thesis, entitled

"In vitro gastric digestion of protein-based structured food - an engineering approach"

Qi Luo

Wageningen, 25 June 2018 


\section{IN VITRO GASTRIC DIGESTION OF PROTEIN-BASED STRUCTURED FOOD \\ - AN ENGINEERING APPROACH}




\section{Thesis committee}

\section{Promotor}

Prof. Dr R.M. Boom

Professor of Food Process Engineering

Wageningen University \& Research

\section{Co-promotor}

Dr A.E.M Janssen

Associate Professor, Food Process Engineering

Wageningen University \& Research

\section{Other members}

Prof. Dr E. van der Linden, Wageningen University \& Research

Prof. Dr C. de Graaf, Wageningen University \& Research

Dr L. Cornacchia, Danone Research, Utrecht

Prof. Dr S. Bakalis, University of Nottingham, UK

This research was conducted under the auspices of Graduate School VLAG (Advanced studies in Food Technology, Agrobiotechnology, Nutrition, and Health Sciences). 


\title{
IN VITRO GASTRIC DIGESTION OF PROTEIN-BASED STRUCTURED FOOD \\ - AN ENGINEERING APPROACH
}

\author{
Qi Luo
}

Thesis

submitted in fulfilment of the requirements for the degree of doctor at Wageningen University

by the authority of the Rector Magnificus,

Prof. Dr A.P.J. Mol,

in the presence of the

Thesis Committee appointed by the Academic Board

to be defended in public

on Monday 25 June 2018

at 4 p.m. in the Aula. 
Qi Luo

In vitro gastric digestion of protein-based structured food

- an engineering approach

174 pages.

PhD thesis, Wageningen University, Wageningen, the Netherlands (2018) With references, with summary in English

ISBN: 978-94-6343-770-7

DOI: https://doi.org/10.18174/445829 




\section{Contents}

Page

Chapter 1 Introduction

Chapter 2 Digestion of protein and protein gels in simulated gastric environment

Chapter 3 Pepsin diffusivity in whey protein gels and its effect on gastric digestion

Chapter 4 Analysis and modeling of enhanced green fluorescent protein diffusivity in whey protein gels

Chapter 5 Revisiting the enzymatic kinetics of pepsin using isothermal titration calorimetry

Chapter 6 Interactions between acid and proteins under in vitro gastric condition - a theoretical and experimental quantification

Chapter 7 General Discussion 

Chapter 1

Introduction 


\subsection{Food and health}

The global prevalence of overweight (generally defined by a body mass index (BMI) over 25) and obesity (generally defined by a BMI over 30) continues to rise at an alarming rate over the past decades, in developed and developing countries, regardless of gender, age, race and educational level (World Health Organization 2000; Heymsfield and Wadden 2017). In the United States, $17.2 \%$ of children and adolescents aged 2 to 19 and $37.8 \%$ of adults aged 20 and over were obese in 2013-2014 (National Center for Health Statistics 2017). Among all the causes, one explanation for obesity is over-consumption of food, as people are exposed to high-calorie foods that are readily available, relatively affordable, and appealing (Whitney, Cataldo, and Sharon 1998). The various health consequences of overweight and obesity range from an increased risk of premature death to non-fatal but adverse effects on quality of life. Other related health risks include increased incidence of type II diabetes, hypertension, cardiovascular disease, some cancers, kidney stones and respiratory problems (World Health Organization 2000; Heymsfield and Wadden 2017). Despite the abundance of foods in many countries, nutritional deficiencies can still be found in both normal-weight and obese population, due to unbalanced dietary intake (Kaidar-Person et al. 2008). Moreover, the aging of the population raises new challenges. The elderly are more vulnerable to nutritional deficiencies, due to reduced appetite, higher prevalence of chronic diseases, as well as changes in the gastrointestinal function (Salles 2007; Levi and Lesmes 2014).

Food does not only just sustain our survival, but is also essential in our quality of life. We need to better understand the relation between the digestion process and the properties of the foods that are digested, to design foods foods that provide balanced nutrition for specific groups of consumers. For instance, food that provides better and faster satiety may reduce over-consumption, and food that offers better digestibility and nutrient delivery may alleviate malnutrition in the aging consumers. 


\begin{tabular}{|c|c|}
\hline The complexity of food \\
\hline $\begin{array}{c}\text { Composition } \\
\text {-Structure } \\
\text {-Diversity }\end{array}$
\end{tabular}

Figure 1.1: The complexity of food digestion

The first research on the process of digestion dates back more than one hundred years ago. These studies mainly focus on the metabolic and physiological aspects of digestion. The measurements in of these studies are mostly end-point measurements such as blood glucose response, plasma amino acids, etc., while the processes that happen between ingestion and absorption received less attention. In recent years, food scientists started to consider the fate of food after consumption, as they realized that the impact of food on health is more than just the sum of the ingredients (Mackie 2017). Attention to the influence of the food structure on the digestion process is needed.

However, the food digestion is a challenging subject, due to the complexity of both the structured food and the digestion process. The complexity of foods lies in their multicomponent nature, as well as their diverse and multiscale structure. The complexity of digestion lies in the dynamic and multi-scale processes, in the reaction kinetics under complex and dynamic conditions, in the release of nutrients from heterogeneous matrices, and in the physiological response of the human body. The combined complexity of the food and the digestion process results in a large range of challenges (Fig. 1.1).

\subsection{Overview of the digestive system}

The digestion of food starts in the mouth, where the solid food is masticated by teeth, mixed with saliva and formed into a cohesive mass, 
i.e. the food bolus. The mastication breaks down solid foods to particles ranging from lower than $1 \mathrm{~mm}$ to approximately $3 \mathrm{~mm}$ in size, depending on the texture of the food (Kong and R. P. Singh 2008b). The collection of these particles, the bolus, is then swallowed and undergoes a process of swelling, hydrolysis, disintegration, and dissolution in the stomach (Bornhorst and R. P. Singh 2012; Kozu et al. 2014), which mostly destroys the original structure of the food. The chemical and mechanical actions of the stomach produce the chyme. The chyme is transferred to the duodenum, which is the first part of the small intestine. In the duodenum, the chyme is mixed with secretions from the liver, the exocrine pancreas and the duodenum itself. These secretions contain protease, lipase, amylase, emulsifier, hormones, etc. In addition, the sodium bicarbonate from the pancreatic juice alters the $\mathrm{pH}$ of the acidic chyme to neutral or slightly alkaline. The chyme slowly traverses throughout the small intestine and is further digested and absorbed. The unabsorbed and unusable food residues arrive in the large intestine (the colon), where electrolyte and water absorption occurs (Pocock, C. D. Richards, and D. Richards 2013). The large intestine is heavily colonized by bacteria. Through fermentation of the food residues, the colonic bacteria produce compounds that can affect gut physiology both positively and negatively.

\subsection{Physiology of gastric digestion}

Food digestion research is an interdisciplinary field. Although we focused on the physicochemical processes of the digestion, to thoroughly understand the mechanism of digestion, the physiology related to the gastric digestion should be discussed.

The functions of the stomach include storage, mixing of the food and gastric fluid to produce chyme; mechanical breakdown and chemical digestion of food; secretion of acid, enzymes, mucus and intrinsic factor; and regulating the exit of processed food into the small intestine (Pocock, C. D. Richards, and D. Richards 2013). The stomach is divided into three regions: the fundus, the body, and the antrum (Fig. 


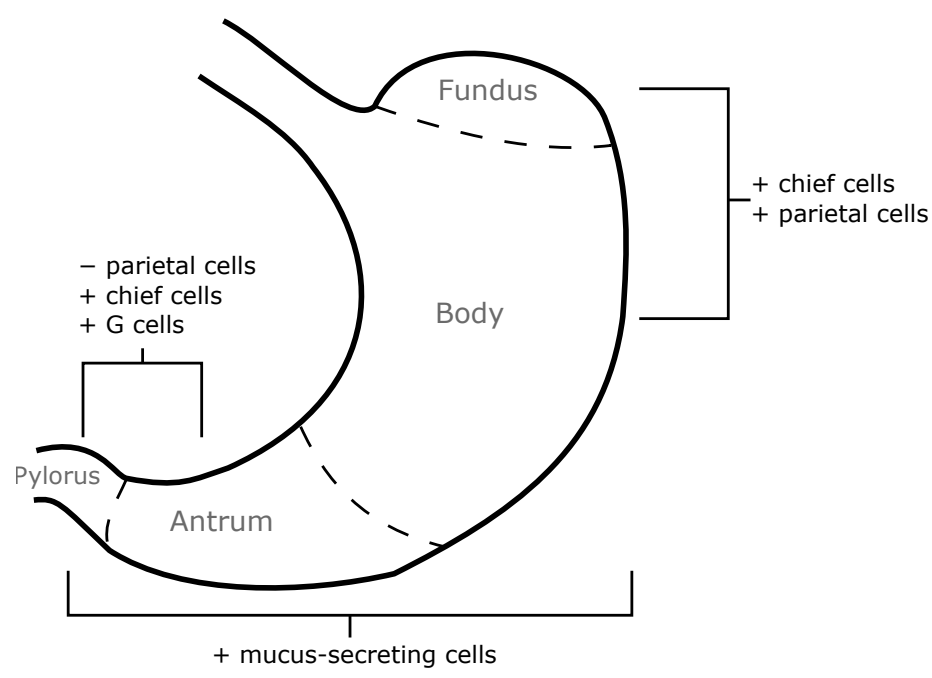

Figure 1.2: A schematic diagram of a human stomach. Three regions and the prevalence of secretory cells in the regions are shown. The + or - signs indicate the high or low prevalences.

Table 1.1: Secretory cells in gastric glands

\begin{tabular}{cc}
\hline Cell type & Secretion \\
\hline Surface mucous cell & Mucus \\
Mucous neckcell & Mucus \\
Parietal cell & $\mathrm{HCl}$, intrinsic factor \\
Chief cell & Pepsinogen \\
G cell & Gastrin \\
\hline
\end{tabular}

1.2). The fundus is the domed portion in the top of the stomach. The wall of the fundus is thin, which can expand easily. In the body of the stomach, the gastric mucosa folds into rugae which can flatten when required. The fundus and body both allow the stomach to expand to accommodate increases in volume after a meal, providing a reservoir. The antrum is the lower region. It is narrower and smaller in volume. The antrum has the strongest muscle layer and is responsible for the major part of gastric motility (Stanfield 2017). 


\subsubsection{Gastric Secretions}

The gastric mucosa contains numerous gastric glands, where a variety of secretory cells are located. These cells are highly specialized, with different contributions to gastric secretion (Table 1.1). The mucussecreting cells are distributed in all regions of the stomach. In the fundus and body of the stomach, the glands contain numerous chief and parietal cells which secrete pepsinogen, $\mathrm{HCl}$ and intrinsic factor. In the antral and pyloric regions, there are much less parietal cells, while the secretions of pepsinogens and gastrin are predominant (Del Valle and Todisco 2008; Pocock, C. D. Richards, and D. Richards 2013).

The secretion of the gastric glands forms the gastric fluid, which contains water, salt, $\mathrm{HCl}$, pepsinogens, intrinsic factor, etc. The exact composition and flow rate varies according to the phase of food ingestion and digestion. Adults secrete $2 \mathrm{~L}-3 \mathrm{~L}$ of gastric fluid each day (Pocock, C. D. Richards, and D. Richards 2013).

Pepsin (EC 3.4.23.1) is the major enzyme in gastric fluid. It is secreted as pepsinogen and activated in low pH (Kageyama 2014). Compare to other proteases, pepsin has a broad specificity with a preference to hydrophobic residues (Rawlings and Salvesen 2012). As an aspartic protease, pepsin has a optimum $\mathrm{pH}$ of around 2.0 (Kondjoyan, Daudin, and Santé-Lhoutellier 2015; Pletschke, Naudé, and Oelofsen 1995). Therefore, the secretion rate of gastric fluid does not only affect the amount of pepsin in the stomach, but also affects the activity of pepsin by determining the gastric $\mathrm{pH}$.

\subsubsection{Gastric Motility}

The gastric motility, i.e. the coordinated contractions of the stomach muscle layers, has an important role in gastric digestion. The stomach performs a wide variety of movements including grinding, churning, kneading as well as propulsion, which enhances the disintegration and digestion of food. The predominant type of gastric motility is the reg- 
ular peristalses that originate from the middle of the stomach and develops towards the bottom (M. Ferrua and R. P. Singh 2010). In vivo data shows that these peristaltic waves have a frequency of 3 times per minute and create a local relative pressure that approximately peaks at $50 \mathrm{mmHg}$ or $6.7 \mathrm{kPa}$ (Cassilly et al. 2008; Marciani et al. 2001; Vassallo et al. 1992)

\subsubsection{Gastric Emptying}

The gastric emptying is carefully regulated by altering the contraction forces in different regions of the stomach (Kelly 1980). The pyloric sphincter acts as a valve and sieve to limit the passage of gastric content to the duodenum. Liquid emptying is rapid compared to solid emptying. Solid food can only be emptied after being disintegrated into particles smaller than a few millimeters (Holt et al. 1982). The caloric content and volume both affect the rate of gastric emptying (Kong and R. P. Singh 2008b). The presence of acid, digested protein and fatty acids in the duodenum triggers hormonal and neural reflexes that regulate gastric emptying (Pocock, C. D. Richards, and D. Richards 2013).

Gastric emptying rate influences the development satiety. Satiety is defined as the post-meal inhibitory processes that suppress the motivation to eat, and it is closed related to dietary signals in the stomach and small intestine (Corstens, Berton-Carabin, Vries, et al. 2015). Since over-consumption is one of the major causes of obesity, appetite control through delayed gastric emptying or induced satiety has been considered as a tool to fight obesity.

\subsection{Methods to study food digestion}

Different aspects of the gastric digestion of food have been explored. Studies on food digestion include the breakdown kinetics of structured food (Kong, Oztop, et al. 2011; A. Ye et al. 2016; Floury et al. 
2018), the digestive products released by foods (Kopf-Bolanz et al. 2014; Denis et al. 2016), the bio-accessibility of micro-nutrients and functional ingredients (Fogliano et al. 2011; Roman, Burri, and R. P. Singh 2012; Papillo et al. 2014; Lorieau et al. 2018), structure design for tailored release of nutrients (McClements 2015; van Leusden et al. 2016; Corstens, Berton-Carabin, Elichiry-Ortiz, et al. 2017), etc. The digestion of food has been investigated using various methods including In vivo, in vitro, and in silico methods. The advantages and disadvantages of these methods and some representative studies are discussed in this sections.

\subsubsection{In vivo methods}

In vivo methods provide direct data on human subjects. The techniques include nasogastric tube sampling (Sullivan et al. 2014) and blood sampling (Boirie et al. 1997) to study the physiological and metabolic response of human subjects. However, these methods are end-point measurements which cannot yield much information about the dynamic processes during the food digestion. Moreover, variations between individual human subjects lead to large differences in the responses (Bornhorst, Gouseti, et al. 2016). More recently, Magnetic resonance imaging (MRI) technique has been applied to monitor the realtime events occurring in gastric digestion. Using MRI, Steingoetter et al. (2015) studied the structural transformation of lipid emulsion in the stomach, Camps and coworkers studied the relative effects of the energy density and viscosity on gastric emptying and satiety. In these studies, MRI provides new insight on the fate of food in the stomach (Camps et al. 2016), but still cannot clarify the detailed processes taking place with and around the food itself.

In vivo, intrusive animal experiments are an alternative to human experiments. Zebrowska and coworkers surgically fitted a re-entrant cannula in the duodenum of growing pigs to study the gastric digestion of protein and carbohydrate, gastric secretion and exocrine pancreatic secretion (T. Zebrowska, Low, and H. Zebrowska 1983). Barbé et al. used multi-canulated mini-pigs to study the kinetics of 
milk protein digestion and amino acid bioavailability (Barbé, Ménard, Gouar, et al. 2014). Bornhorst and coworkers sacrificed and dissected pigs to study the gastric emptying rate and chyme characteristics of cooked rice meals, and gastric protein hydrolysis of almonds (Bornhorst, Chang, Rutherfurd, Moughan, and R. P. Singh 2013; Bornhorst, M. J. Ferrua, et al. 2013; Bornhorst, Drechsler, et al. 2016).

Both human and animal methods are useful but also have limitations, e.g. technical difficulty, cost, and ethical constraints. Furthermore, the difference between human and animal digestion should also be taken into account, although the digestive system of the pig is closely similar to that of the human. In addition, the full physiological system includes all complexity and therefore makes it sheer impossible to elucidate specific, individual mechanisms that underlie the overall digestive process. Thus, they have only limited relevance for more detailed, mechanistic studies. Therefore, researchers are seeking other means to study the digestion of food.

\subsubsection{In vitro methods}

Compared to in vivo methods, in vitro methods are less resourceintensive and ethically controversial, but their most important aspect is the possibility to exclude most complexity of the system and perform systematic studies into individual underlying mechanisms of gastric digestion. In vitro models can be categorized into static and dynamic studies.

Static studies reproduce the gastric digestion using pepsin hydrolysis under fixed $\mathrm{pH}$ and temperature for a set duration (Guerra et al. 2012). These static systems are very suited for studying the digestion of single substrates or simple meals under specific conditions. Appropriate applications include benchmarking the digestibility of different products or studying specific aspects of the gastric digestion mechanism. Minekus et al. (2014), together with the COST Infogest network, proposed a standardized static in vitro digestion method which provides the composition of the simulated gastric fluid (SGF), the $\mathrm{pH}$ and the 
food to SGF ratio. This standardized method allows comparison of different results and studies. However, static models cannot reproduce the dynamic aspect of gastric digestion such as the peristaltic force, the gastric emptying or the change of gastric $\mathrm{pH}$.

Dynamic studies aim to reproduce the secretion of gastric fluid, the peristaltic movement, the gastric emptying, and other dynamic aspects. Reviews by Guerra et al. (2012) and Dupont et al. (2018) summarized and assessed these dynamic models, and discussed their limitations. Overall, dynamic in vitro digestion models can better mimic the complexity of the digestive system but their complexity also limits the mechanistic understanding that one can obtain from these systems, without having been preceded by more detailed static studies.

\subsubsection{In silico methods}

Many in silico models have been developed to describe and predict different aspects of digestion processes. M. Ferrua and R. P. Singh (2010) modeled the fluid dynamics in a human stomach using computational fluid dynamics, and demonstrated the flow patterns induced by the peristaltic movement of the stomach. Kong and R. P. Singh (2009b) studied the disintegration of solid foods in a simulated gastric environment, and used a linear-exponential equation to describe the disintegration profiles of different food materials. Drechsler and M. J. Ferrua (2016) modeled the breakdown mechanics of solid foods during gastric digestion, taking the mechanical properties of food into account. Tonda and coworkers used Monte-Carlo simulation to predict the peptide distribution of pepsin-catalyzed hydrolysis of bovine lactoferrin, based on the subsite specificity of pepsin (Tonda et al. 2017). Current in silico models are limited to very specific condition and food type, some are empirical models that depend on experimental data. Only with a better understanding of the digestion processes, mechanistic in silico models can be developed and applied to universal situations. 


\subsection{Food structure and digestion}

Studies have shown that the food structure is of great influence on the digestion of food and the delivery of nutrients (Turgeon and Rioux 2011; Bornhorst and R. P. Singh 2014; H. Singh, A. Ye, and M. J. Ferrua 2015). Generally, the food disintegration rate decreases when the food hardness increases (H. Singh, A. Ye, and M. J. Ferrua 2015). Kong and R. P. Singh (2009a) studied the gastric disintegration of raw and roasted almonds, and disintegration kinetics of the almonds demonstrated the involvement of the food structure in some physicochemical processes, including the swelling and uptake of acidic gastric juice, the gradual increase of porosity and loss of mechanical stability, and the mechanical attrition and collapse of the matrices (Fig. 1.3). In the gastric digestion of white and brown rice in an in vitro dynamic stomach model, the bran layer on brown rice affects the digestion by decreasing the ingression of gastric juice (Kong, Oztop, et al. 2011). Barbé, Ménard, Le Gouar, et al. (2013) and Guo, A. Ye, Lad, M. Ferrua, et al. (2015) and Nyemb-Diop et al. (2016) studied gastric digestion of different protein gels, and all found that microstructure plays an important role in the food disintegration and emptying rate in the stomach.

The food structure that is left after being processed by the stomach can also influence subsequent intestinal digestion. Gouseti et al. (2014) studied the digestion in an in vitro intestinal models, and found that hydrocolloids have a significant effect in retarding simulated glucose accessibility. Casein has dramatically slower absorption than whey protein (Boirie et al. 1997), because casein gels under gastric condition which leads to slower gastric emptying (Lambers, Bosch, and Jong 2013).

Despite the increasing number of studies in the area of food digestion, few have yet provided a mechanistic, quantitative descriptions of the digestion processes. Because of the complexity of food digestion, researchers have proposed to regard food digestion as a combination of processes at multiple, interrelated length scales (Bornhorst, Gouseti, 


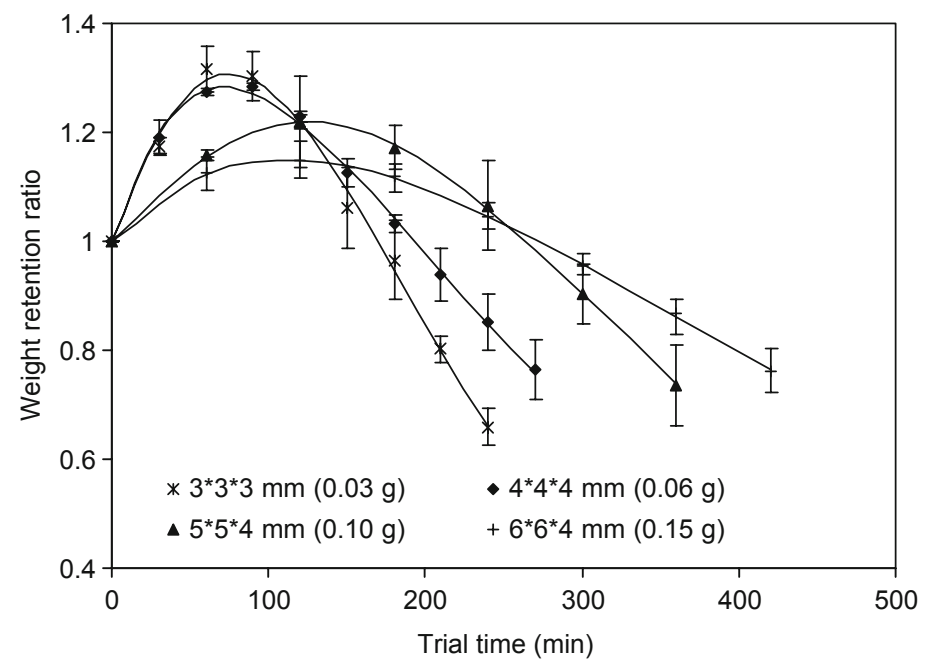

Figure 1.3: Static digestion of fragments of almonds with different sizes, showing primary swelling and ingression of gastric fluid, subsequent hydrolysis and mechanical attrition of the partially hydrolysed matrix (Kong and R. P. Singh 2009a).

et al. 2016). For instance, mastication in the mouth and peristalsis in the stomach both occur at macro-scales ( $\mathrm{cm}$ to $\mathrm{mm}$ ), while enzymatic hydrolysis in the gastro-intestinal tract occurs at micro-scales $(\mu \mathrm{m})$. Similarly, food structures are highly heterogeneous, with arrangements ranging across several orders of magnitude. The digestion processes at multiple scales have to be analyzed individually under simplified experimental conditions, and then systematically related in coupling models or experiments.

\subsection{Objective and outline of this thesis}

We aim to study the physicochemical processes in the gastric digestion of protein-based food matrices, to gain quantitative characterization and mechanistic understanding of the gastric digestion of protein food as function of the state and structure of the proteins. We envisage that this will ultimately ultimately give us the possibility to predict the digestion kinetics and design new food matrices based on the char- 
acteristics of the food. We focus on the gastric digestion of proteinbased food matrices, because a large part of food structure transformation occurs in the stomach, and protein is both the key component to build food structures and one of the most important macronutrients. The predominant enzyme in the stomach, pepsin, is a protease, which emphasizes the important role of proteins in food structure digestion.

We consider the stomach as a complex bioreactor and interpret the digestion processes as a combination of texture/structure transformation, enzymatic/chemical reactions, and mass transfer processes. With quantitative knowledge of these processes, in combination with the known physical and chemical properties of the foods, we may be able to predict the digestion kinetics of foods regardless of their diversity.

Chapter 2 explores the digestion of protein in solution and in gels in a static simulated environment. The results show that the performance of pepsin is an important factor in the disintegration of protein gel. The effect of the food structure on the digestion of the protein gels was shown to be considerable.

In Chapter 3, we then determine the diffusivity of pepsin in whey protein gels by fluorescence correlation spectroscopy (FCS). In combination with the observation from scanning electron microscopy image and gel composition analysis, we demonstrate the mutual influence between pepsin diffusion and food microstructure. To quantitatively characterize the hindrance by the microstructure in the diffusive mobility of the enzyme, we analyzed the diffusivity in varied protein gel matrices (Chapter 4). Models for interpreting this hindrance of solute diffusion in hydrogels were applied to describe and predict diffusion in protein gel matrices.

In Chapter 5, we then explored the enzymatic kinetics of pepsin with bovine serum albumin at varying $\mathrm{pH}$ and ionic strengths. The buffering capacity of the protein was quantified, and the relation between this buffer capacity and acid diffusion in protein gel is explored (Chapter 6). 
The final chapter (Chapter 7) reviews and reflects on the previous chapters. The connection between the physicochemical processes studied was discussed, and integrated in an qualitative overall model. A discussion is given on the influence of the state and structure of proteins in foods, on their gastric digestion.

\section{References}

Barbé, F., O. Ménard, Y. L. Gouar, C. Buffière, M.-H. Famelart, B. Laroche, S. L. Feunteun, D. Rémond, and D. Dupont (Jan. 15, 2014). "Acid and Rennet Gels Exhibit Strong Differences in the Kinetics of Milk Protein Digestion and Amino Acid Bioavailability." In: Food Chemistry 143, pp. 1-8. Dor: 10.1016/ j . foodchem.2013.07.100.

Barbé, F., O. Ménard, Y. Le Gouar, C. Buffière, M.-H. Famelart, B. Laroche, S. Le Feunteun, D. Dupont, and D. Rémond (Feb. 1, 2013). "The Heat Treatment and the Gelation Are Strong Determinants of the Kinetics of Milk Proteins Digestion and of the Peripheral Availability of Amino Acids." In: Food Chemistry. ASSET 2011 136.3, pp. 1203-1212. Dor: 10.1016/ j . foodchem.2012.09.022.

Boirie, Y., M. Dangin, P. Gachon, M.-P. Vasson, J.-L. Maubois, and B. Beaufrere (Dec. 23, 1997). "Slow and Fast Dietary Proteins Differently Modulate Postprandial Protein Accretion." In: Proceedings of the National Academy of Sciences of the United States of America 94.26, pp. 14930-14935. pmid: 9405716.

Bornhorst, G. M., L. Q. Chang, S. M. Rutherfurd, P. J. Moughan, and R. P. Singh (Sept. 1, 2013). "Gastric Emptying Rate and Chyme Characteristics for Cooked Brown and White Rice Meals in Vivo." In: Journal of the Science of Food and Agriculture 93.12, pp. 2900-2908. DoI: 10.1002 / jsfa.6160.

Bornhorst, G. M., K. C. Drechsler, C. A. Montoya, S. M. Rutherfurd, P. J. Moughan, and R. P. Singh (Nov. 15, 2016). "Gastric Protein Hydrolysis of Raw and Roasted Almonds in the Growing Pig." In: Food Chemistry 211, pp. 502-508. DoI: 10.1016/ j . foodchem. 2016 . 05. 085. 
Bornhorst, G. M., M. J. Ferrua, S. M. Rutherfurd, D. R. Heldman, and R. P. Singh (June 1, 2013). "Rheological Properties and Textural Attributes of Cooked Brown and White Rice During Gastric Digestion in Vivo." In: Food Biophysics 8.2, pp. 137-150. Dor: 10.1007/s 11483013-9288-1.

Bornhorst, G. M., O. Gouseti, M. S. Wickham, and S. Bakalis (Jan. 2016). "Engineering Digestion: Multiscale Processes of Food Digestion: Engineering Food Digestion..." In: Journal of Food Science, R534-R543. DoI: 10.1111/1750-3841.13216.

Bornhorst, G. M. and R. P. Singh (Mar. 2012). "Bolus Formation and Disintegration during Digestion of Food Carbohydrates." In: Comprehensive Reviews in Food Science and Food Safety 11.2, pp. 101-118. DoI: $10.1111 /$ j.1541-4337.2011.00172.x.

Bornhorst, G. M. and R. P. Singh (Feb. 28, 2014). "Gastric Digestion In Vivo and In Vitro: How the Structural Aspects of Food Influence the Digestion Process." In: Annual Review of Food Science and Technology 5.1, pp. 111-132. DoI: 10.1146/annurev-food-030713-092346.

Camps, G., M. Mars, C. de Graaf, and P. A. Smeets (July 1, 2016). "Empty Calories and Phantom Fullness: A Randomized Trial Studying the Relative Effects of Energy Density and Viscosity on Gastric Emptying Determined by MRI and Satiety," in: The American Journal of Clinical Nutrition 104.1, pp. 73-80. Dor: 10 . 3945/a jcn . 115. 129064.

Cassilly, D., S. Kantor, L. C. Knight, A. H. Maurer, R. S. Fisher, J. Semler, and H. P. Parkman (2008). "Gastric Emptying of a NonDigestible Solid: Assessment with Simultaneous SmartPill pH and Pressure Capsule, Antroduodenal Manometry, Gastric Emptying Scintigraphy." In: Neurogastroenterology \& Motility 20.4, pp. 311319. Dor: 10.1111/ j . 1365-2982.2007.01061.x.

Corstens, M. N., C. C. Berton-Carabin, P. T. Elichiry-Ortiz, K. Hol, F. J. Troost, A. A. M. Masclee, and K. Schroën (July 1, 2017). "EmulsionAlginate Beads Designed to Control in Vitro Intestinal Lipolysis: Towards Appetite Control." In: Journal of Functional Foods 34, pp. 319328. DoI: $10.1016 /$ j.jff. 2017.05 .003$. 
Corstens, M. N., C. C. Berton-Carabin, R. D. Vries, F. J. Troost, A. A. M. Masclee, and K. Schroën (Aug. 7, 2015). "Food-Grade Micro-Encapsulation Systems That May Induce Satiety via Delayed Lipolysis: A Review." In: Critical Reviews in Food Science and Nutrition 0.10, pp. 2218-2244. DoI: 10 . $1080 / 10408398$. 2015.1057634. pmid: 26252442.

Del Valle, J. and A. Todisco (2008). “Gastric Secretion.” In: Textbook of Gastroenterology. Ed. by T. Yamada. Oxford, UK: Blackwell Publishing Ltd., pp. 284-329. Dor: 10. 1002/9781444303254 .ch13.

Denis, S., T. Sayd, A. Georges, C. Chambon, S. Chalancon, V. SantéLhoutellier, and S. Blanquet-Diot (June 15, 2016). "Digestion of Cooked Meat Proteins Is Slightly Affected by Age as Assessed Using the Dynamic Gastrointestinal TIM Model and Mass Spectrometry." In: Food E Function 7.6, pp. 2682-2691. DoI: 10. 1039/C6F000120C.

Drechsler, K. C. and M. J. Ferrua (Oct. 1, 2016). "Modelling the Breakdown Mechanics of Solid Foods during Gastric Digestion." In: Food Research International. The 4th International Conference on Food Digestion 88, pp. 181-190. DoI: 10.1016/ j . foodres.2016.02.019. Dupont, D., M. Alric, S. Blanquet-Diot, G. Bornhorst, C. Cueva, A. Deglaire, S. Denis, M. Ferrua, R. Havenaar, J. Lelieveld, A. R. Mackie, M. Marzorati, O. Menard, M. Minekus, B. Miralles, I. Recio, and P. Van den Abbeele (Jan. 23, 2018). "Can Dynamic in Vitro Digestion Systems Mimic the Physiological Reality?" In: Critical Reviews in Food Science and Nutrition, pp. 1-17. Dor: 10 . 1080 / 10408398.2017. 1421900.

Ferrua, M. and R. P. Singh (Sept. 2010). "Modeling the Fluid Dynamics in a Human Stomach to Gain Insight of Food Digestion.” In: Journal of Food Science 75.7, R151-R162. Dor: 10.1111/ j . 1750-3841. 2010. 01748.x.

Floury, J., T. Bianchi, J. Thévenot, D. Dupont, F. Jamme, E. Lutton, M. Panouillé, F. Boué, and S. Le Feunteun (Jan. 15, 2018). "Exploring the Breakdown of Dairy Protein Gels during in Vitro Gastric Digestion Using Time-Lapse Synchrotron Deep-UV Fluorescence Microscopy.” In: Food Chemistry 239, pp. 898-910. Dor: 10 . 1016 / j . foodchem. 2017.07.023. 
Fogliano, V., M. L. Corollaro, P. Vitaglione, A. Napolitano, R. Ferracane, F. Travaglia, M. Arlorio, A. Costabile, A. Klinder, and G. Gibson (May 1, 2011). "In Vitro Bioaccessibility and Gut Biotransformation of Polyphenols Present in the Water-Insoluble Cocoa Fraction." In: Molecular Nutrition E Food Research 55 (S1), S44-S55. DoI: 10. 1002 /mnfr. 201000360.

Gouseti, O., M. R. Jaime-Fonseca, P. J. Fryer, C. Mills, M. S. J. Wickham, and S. Bakalis (Dec. 15, 2014). "Hydrocolloids in Human Digestion: Dynamic in-Vitro Assessment of the Effect of Food Formulation on Mass Transfer." In: Food Hydrocolloids. Special Issue: Bridging the Divide between Food and Pharma 42, pp. 378-385. Dor: 10 . 1016 / j . foodhyd.2014.06.004.

Guerra, A., L. Etienne-Mesmin, V. Livrelli, S. Denis, S. Blanquet-Diot, and M. Alric (Nov. 2012). "Relevance and Challenges in Modeling Human Gastric and Small Intestinal Digestion." In: Trends in Biotechnology 30.11, pp. 591-600. Dor: 10 . 1016/ j . tibtech. 2012 . 08.001.

Guo, Q., A. Ye, M. Lad, M. Ferrua, D. Dalgleish, and H. Singh (Jan. 6, 2015). "Disintegration Kinetics of Food Gels during Gastric Digestion and Its Role on Gastric Emptying: An in Vitro Analysis." In: Food E Function 6, pp. 756-764. Dor: 10.1039/C4F000700J.

Heymsfield, S. B. and T. A. Wadden (Jan. 19, 2017). "Mechanisms, Pathophysiology, and Management of Obesity." In: New England Journal of Medicine 376.3. Ed. by D. L. Longo, pp. 254-266. Dor: 10. 1056 / NE JMra 1514009.

Holt, S., J. Reid, T. V. Taylor, P. Tothill, and R. C. Heading (Apr. 1, 1982). “Gastric Emptying of Solids in Man.” In: Gut 23.4, pp. 292296. Dor: 10.1136/gut.23.4.292. pmid: 7076006.

Kageyama, T. (Apr. 30, 2014). "Pepsinogens, Progastricsins, and Prochymosins: Structure, Function, Evolution, and Development." In: Cellular and Molecular Life Sciences CMLS 59.2, pp. 288-306. Dor: 10. 1007/s00018-002-8423-9.

Kaidar-Person, O., B. Person, S. Szomstein, and R. J. Rosenthal (Aug. 1, 2008). "Nutritional Deficiencies in Morbidly Obese Patients: A New 
Form of Malnutrition?" In: Obesity Surgery 18.8, pp. 1028-1034. DoI: 10. 1007/s11695-007-9350-5.

Kelly, K. A. (Aug. 1, 1980). "Gastric Emptying of Liquids and Solids: Roles of Proximal and Distal Stomach." In: American Journal of Physiology-Gastrointestinal and Liver Physiology 239.2, G71-G76. DoI: 10.1152/ajpgi. 1980.239.2.G71.

Kondjoyan, A., J.-D. Daudin, and V. Santé-Lhoutellier (Apr. 2015). "Modelling of Pepsin Digestibility of Myofibrillar Proteins and of Variations Due to Heating." In: Food Chemistry 172, pp. 265-271. Dor: $10.1016 / \mathrm{j}$. foodchem. 2014.08.110.

Kong, F., M. H. Oztop, R. P. Singh, and M. J. McCarthy (Aug. 2011). "Physical Changes in White and Brown Rice during Simulated Gastric Digestion." In: Journal of Food Science 76.6, E450-E457. Dor: 10. 1111 / j . 1750-3841.2011.02271.x.

Kong, F. and R. P. Singh (2008b). "Disintegration of Solid Foods in Human Stomach.” In: Journal of Food Science 73.5, R67-R80. Dor: 10 . 1111 / j . 1750-3841.2008.00766.x.

Kong, F. and R. P. Singh (Oct. 22, 2009a). "Digestion of Raw and Roasted Almonds in Simulated Gastric Environment." In: Food Biophysics 4.4, pp. 365-377. DoI: 10. 1007/s11483-009-9135-6.

Kong, F. and R. P. Singh (Sept. 1, 2009b). "Modes of Disintegration of Solid Foods in Simulated Gastric Environment." In: Food Biophysics 4.3, pp. 180-190. DoI: 10.1007/s11483-009-9116-9.

Kopf-Bolanz, K. A., F. Schwander, M. Gijs, G. Vergères, R. Portmann, and L. Egger (Apr. 2014). "Impact of Milk Processing on the Generation of Peptides during Digestion." In: International Dairy Journal 35.2, pp. 130-138. Dor: 10.1016/ j . idairy j .2013.10.012.

Kozu, H., Y. Nakata, M. Nakajima, M. A. Neves, K. Uemura, S. Sato, I. Kobayashi, and S. Ichikawa (2014). "Development of a Human Gastric Digestion Simulator Equipped with Peristalsis Function for the Direct Observation and Analysis of the Food Digestion Process." In: Food Science and Technology Research 20.2, pp. 225-233. Dor: 10 . 3136 / fstr.20.225.

Lambers, T. T., W. G. Bosch, and S. Jong (Mar. 23, 2013). "Fast and Slow Proteins: Modulation of the Gastric Behavior of Whey and Casein In 
Vitro." In: Food Digestion 4.1, pp. 1-6. Dor: 10. 1007 / s13228-0120028-7.

Levi, C. S. and U. Lesmes (Sept. 24, 2014). "Bi-Compartmental Elderly or Adult Dynamic Digestion Models Applied to Interrogate Protein Digestibility." In: Food E Function 5.10, pp. 2402-2409. DoI: 10. 1039/C4F000478G.

Lorieau, L., L. Le Roux, F. Gaucheron, A. Ligneul, E. Hazart, D. Dupont, and J. Floury (Apr. 15, 2018). "Bioaccessibility of Four Calcium Sources in Different Whey-Based Dairy Matrices Assessed by in Vitro Digestion.” In: Food Chemistry 245, pp. 454-462. Dor: 10 . 1016/ j . foodchem. 2017. 10. 108.

Mackie, A. (July 21, 2017). "Food: More than the Sum of Its Parts." In: Current Opinion in Food Science. DoI: 10 . 1016/ j . cofs . 2017 . 07 . 004.

Marciani, L., P. Young, J. Wright, R. Moore, N. Coleman, P. A. Gowland, and R. C. Spiller (2001). "Antral Motility Measurements by Magnetic Resonance Imaging." In: Neurogastroenterology \& Motility 13.5, pp. 511-518. Dor: 10.1046/ j . 1365-2982 .2001.00285 . x.

McClements, D. J. (June 1, 2015). "Nanoscale Nutrient Delivery Systems for Food Applications: Improving Bioactive Dispersibility, Stability, and Bioavailability." In: Journal of Food Science, n/a-n/a. DoI: 10.1111/1750-3841.12919.

Minekus, M., M. Alminger, P. Alvito, S. Ballance, T. Bohn, C. Bourlieu, F. Carrière, R. Boutrou, M. Corredig, D. Dupont, C. Dufour, L. Egger, M. Golding, S. Karakaya, B. Kirkhus, S. Le Feunteun, U. Lesmes, A. Macierzanka, A. Mackie, S. Marze, D. J. McClements, O. Ménard, I. Recio, C. N. Santos, R. P. Singh, G. E. Vegarud, M. S. J. Wickham, W. Weitschies, and A. Brodkorb (2014). "A Standardised Static in Vitro Digestion Method Suitable for Food - an International Consensus." In: Food E Function 5.6, p. 1113. Dor: 10.1039/c3fo60702 j.

National Center for Health Statistics (2017). Health, United States, 2016: With Chartbook on Long-Term Trends in Health. Hyattsville, MD.

Nyemb-Diop, K., D. Causeur, J. Jardin, V. Briard-Bion, C. GuérinDubiard, S. M. Rutherfurd, D. Dupont, and F. Nau (2016). "Inves- 
tigating the Impact of Egg White Gel Structure on Peptide Kinetics Profile during in Vitro Digestion." In: Food Research International 88, pp. 302-309. DoI: 10.1016/ j . foodres.2016.01.004.

Papillo, V. A., P. Vitaglione, G. Graziani, V. Gokmen, and V. Fogliano (May 7, 2014). "Release of Antioxidant Capacity from Five Plant Foods during a Multistep Enzymatic Digestion Protocol." In: Journal of Agricultural and Food Chemistry 62.18, pp. 4119-4126. DoI: 10. 1021/ jf500695a.

Pletschke, B. I., R. J. Naudé, and W. Oelofsen (Dec. 1995). "Ostrich Pepsins I and II: A Kinetic and Thermodynamic Investigation." In: The International Journal of Biochemistry \& Cell Biology 27.12, pp. 1293-1302. Dor: 10.1016/1357-2725(95)00092-4.

Pocock, G., C. D. Richards, and D. Richards (2013). Human Physiology. Oxford university press.

Rawlings, N. D. and G. S. Salvesen (Oct. 30, 2012). Handbook of Proteolytic Enzymes. Academic Press. 3988 pp.

Roman, M. J., B. J. Burri, and R. P. Singh (Sept. 26, 2012). "Release and Bioaccessibility of $\beta$-Carotene from Fortified Almond Butter during in Vitro Digestion." In: Journal of Agricultural and Food Chemistry 60.38, pp. 9659-9666. DoI: 10.1021/ jf302843w.

Salles, N. (2007). "Basic Mechanisms of the Aging Gastrointestinal Tract." In: Digestive diseases 25.2, pp. 112-117.

Singh, H., A. Ye, and M. J. Ferrua (June 2015). "Aspects of Food Structures in the Digestive Tract." In: Current Opinion in Food Science. Sensory Sciences and Consumer Perception • Food Physics and Material Science 3, pp. 85-93. DoI: 10.1016/ j . cofs.2015.06.007.

Stanfield, C. L. (2017). “The Gastrointestinal System.” In: Principles of Human Physiology, Global Edition. Vol. Sixth edition. Global edition. Boston: Pearson.

Steingoetter, A., T. Radovic, S. Buetikofer, J. Curcic, D. Menne, M. Fried, W. Schwizer, and T. J. Wooster (Jan. 4, 2015). "Imaging Gastric Structuring of Lipid Emulsions and Its Effect on Gastrointestinal Function: A Randomized Trial in Healthy Subjects." In: The American Journal of Clinical Nutrition 101.4, pp. 714-724. Dor: 10.3945 / a jcn.114.100263. pmid: 25833970. 
Sullivan, L. M., J. J. Kehoe, L. Barry, M. J. M. Buckley, F. Shanahan, K. H. Mok, and A. Brodkorb (Aug. 2014). "Gastric Digestion of $\alpha-$ Lactalbumin in Adult Human Subjects Using Capsule Endoscopy and Nasogastric Tube Sampling." In: British Journal of Nutrition 112.4, pp. 638-646. DoI: 10.1017/S0007114514001196.

Tonda, A., A. Grosvenor, S. Clerens, and S. Le Feunteun (Oct. 11, 2017). "In Silico Modeling of Protein Hydrolysis by Endoproteases: A Case Study on Pepsin Digestion of Bovine Lactoferrin." In: Food $\mathcal{E}$ Function. DoI: 10.1039/C7F000830A.

Turgeon, S. L. and L.-E. Rioux (Dec. 2011). "Food Matrix Impact on Macronutrients Nutritional Properties.” In: Food Hydrocolloids 25.8, pp. 1915-1924. Dor: 10.1016/ j . foodhyd.2011.02.026.

Van Leusden, P., G. J. M. den Hartog, A. Bast, M. Postema, E. van der Linden, and L. M. C. Sagis (Aug. 10, 2016). "Structure Engineering of Filled Protein Microbeads to Tailor Release of Oil Droplets in Gastric Digestion." In: Food E Function 7.8, pp. 3539-3547. DoI: 10. 1039/C6F000405A.

Vassallo, M. J., M. Camilleri, C. M. Prather, R. B. Hanson, and G. M. Thomforde (Jan. 8, 1992). "Measurement of Axial Forces during Emptying from the Human Stomach." In: American Journal of Physiology - Gastrointestinal and Liver Physiology 263.2, G230-G239.

Whitney, E. N., C. B. Cataldo, and R. R. Sharon (1998). Understanding Normal and Clinical Nutrition. 5th ed. Wadsworth Publishing Company, Inc.

World Health Organization (2000). Obesity: Preventing and Managing the Global Epidemic. 894. World Health Organization.

Ye, A., J. Cui, D. Dalgleish, and H. Singh (Jan. 2016). "Formation of a Structured Clot during the Gastric Digestion of Milk: Impact on the Rate of Protein Hydrolysis." In: Food Hydrocolloids 52, pp. 478-486. DoI: 10.1016/ j . foodhyd.2015.07.023.

Zebrowska, T., A. G. Low, and H. Zebrowska (1983). "Studies on Gastric Digestion of Protein and Carbohydrate, Gastric Secretion and Exocrine Pancreatic Secretion in the Growing Pig." In: Br. J. Nutr 49, pp. 401-410. 



\section{Chapter 2}

\section{Digestion of protein and protein gels in simulated gastric environment}

This chapter has been published as:

Q. Luo, R. M. Boom, and A. E. M. Janssen (Sept. 2015). "Digestion of Protein and Protein Gels in Simulated Gastric Environment." In: LWT - Food Science and Technology 63.1, pp. 161-168. Dor: 10.1016/ j . lwt . 2015.03 .087 


\section{Abstract}

Despite the increasing attention to food digestion research, food scientists still need to better understand the underlying mechanisms of digestion. Most in vitro studies on protein digestion are based on experiments with protein solutions. In this study, the digestion of egg white protein and whey protein isolate in solution and in gels was investigated using simulated gastric conditions. The digestion process was followed via the dry matter loss, degree of hydrolysis and peptide distribution. We showed that the performance of pepsin is an important factor in protein digestion, and hydrodynamic force effectively disintegrated the gel particles and enhance the hydrolysis of protein. The gel microstructure had shown to be a hindrance for the digestion of protein. However, the hindrance is not simply slowing down the hydrolysis, but also altering the apparent enzyme kinetics to some extent: while the dissolved proteins were hydrolysed through a 'zipper' type mechanism, the gels showed a slower 'one-by-one' mechanism. Overall, we believe that the digestion of the protein gels is influenced by the microstructure of food matrices, caused by the immobilisation of the substrate in the network, and the steric hindrance in the diffusive ingression of pepsin and egression of peptides. 


\subsection{Introduction}

The gastric digestion of food into dissolved or dispersed nutrients is an essential step in human nutrition and health. However, regarding the digestion of solid food, limited knowledge is available, especially on the underlying mechanism of the process (Bornhorst and R. P. Singh 2014). By understanding the disintegration dynamics of solid food in the stomach, the digestion process can be better pictured. As a result, food products may be better designed towards the targeted consumer group.

In the mouth, the solid food is masticated, mixed with saliva and formed into a cohesive mass, i.e. the food bolus. The bolus is then swallowed and undergoes a process of swelling, hydrolysis, disintegration, and dissolution in the stomach (Bornhorst and R. P. Singh 2012; Kozu et al. 2014). In the stomach, the peristaltic waves promote the disintegration of the bolus by grinding and mixing, which reduces diffusion distances and enlarges the interfacial area. The disintegration of the matrix is dependent on the physical and chemical condition of the digestion environment as well as the density and coherence of the food matrix (Bornhorst and R. P. Singh 2012).

When the particles in the bolus are able to pass the pylorus which acts as a sieve, they are selectively emptied to the duodenum (Guerra et al. 2012). The food is then further digested and absorbed in the small intestine (Whitney, Cataldo, and Sharon 1998).

Protein is one of the most important macronutrients in food. The digestion of protein is mostly facilitated by the acid and pepsin in the stomach and subsequently by the pancreatic and intestinal enzymes in the small intestine (Whitney, Cataldo, and Sharon 1998).

Pepsin (EC 3.4.23.1) is the major enzyme in gastric fluid. It is an aspartic protease and has a broad specificity with a preference for hydrophobic residues(Rawlings and Salvesen 2012), especially the aromatic amino acid residues tyrosine and phenylalanine (Fruton and Bergmann 1939). 
The enzymatic hydrolysis of proteins, including the peptic hydrolysis, has been extensively studied. With regard to the kinetics of the enzymatic hydrolysis, some models are proposed to characterize the reaction during the proteolysis, including the widely used LinderstrømLang's model.

Linderstrøm-Lang introduced two extreme types of reactions for native globular proteins: the "one-by-one" type and the "zipper" type (Adler-Nissen 1976; Linderstrøm-Lang 1952), also see supplementary material). In the "one-by-one" type, as soon as a protein is attacked by a protease, the protein tends to be hydrolyzed in one sequence to the final products, and thus intermediate products can scarcely be detected. In the "zipper" type, the initial stage of hydrolysis is fast, but the subsequent steps are much slower, which results in a wide range of peptides in solution (Ortiz and An 2000). Most proteases will act in between the two extreme models (Adler-Nissen 1976). Choisnard et al. (2002) observed a 'one-by-one' mechanism for the peptic hydrolysis of native hemoglobin and a 'zipper' type reaction for the hydrolysis of denatured hemoglobin.

Generally, studies into the kinetics and mechanism of enzymatic proteolysis are mostly based on the reaction in solutions, whereas most of the proteins in our food are present in solid foods (even casein in milk tends to precipitate and form a solid mass in the stomach (Lambers, Bosch, and Jong 2013)). It is interesting to study the effect of the solid matrix on the digestion and thus on the behaviour of pepsin. Barbé, Ménard, Gouar, et al. (2014) found that acid and rennet gels show different bioavailability and kinetics in digestion. Guo, A. Ye, Lad, Dalgleish, et al. (2014b) made simulated boluses of soft and hard gels and studied the gastric digestion. In this study we aim at the digestion of well-defined solid, protein matrices in a simulated gastric environment. Protein gels were used for this. We focus on the role of pepsin and its interaction with other factors (e.g., $\mathrm{pH}$ and matrix properties). 


\subsection{Material and methods}

\subsubsection{Materials}

Pepsin from porcine gastric mucosa( $\geq 400$ activity units/mg protein), mucin from porcine stomach (Type III) and all other chemicals were purchased from SigmaeAldrich, Inc. (St. Louis, USA). Milli-Q water (resistivity $18.2 \mathrm{M} \Omega \mathrm{cm}$ at $25^{\circ} \mathrm{C}$, Merck Millipore, Billerica, USA) was used in all experiments. Whey Protein Isolate (WPI) (Bipro, lot no. JE 034-70-440-6) was purchased from Davisco Food International, Inc. (Le Sueur, USA) This batch of WPI was reported to have a protein content of $97.9 \mathrm{~g} / 100 \mathrm{~g}$ dry solid. Chicken fresh shell eggs were purchased from a local supermarket. The egg white was separated from the whole egg and gently mixed. Afterward, the egg white was lyophilized and ground. The egg white protein (EWP) powder thus obtained was stored under dry conditions at room temperature. The protein content was $89.3 \mathrm{~g} / 100 \mathrm{~g}$ dry solid measured by DUMAS in duplicate.

\subsubsection{Preparation of gel and simulated digestion fluids}

Egg white gel and whey protein gel with 15 g protein/100 g gel or $20 \mathrm{~g}$ protein/100 g were made as follows: egg white protein powder and WPI were respectively dissolved in water (15 g protein/ $100 \mathrm{~g}$ or $20 \mathrm{~g}$ protein $/ 100 \mathrm{~g}$ ) and stirred at room temperature for at least $2 \mathrm{~h}$. The solutions were centrifuged at $1000 \mathrm{rpm}(1 \mathrm{rpm}=2 \pi \mathrm{rad} / \mathrm{min}$, approximately $200 \times$ g relative centrifuge force for the swing-bucket rotor) for $10 \mathrm{~min}$ to eliminate air bubbles, and were poured into Teflon tubes which were then sealed. The Teflon tubes were rotated at 50 $\mathrm{rpm}$ heated in a $90^{\circ} \mathrm{C}$ water bath for $30 \mathrm{~min}$ min. After that, they were immediately cooled in an ice-water bath. The gels were sealed with multiple layers of kitchen plastic wrap (cling foil) and stored at $4{ }^{\circ} \mathrm{C}$. Visual inspection showed that gel with a concentration of $20 \mathrm{~g}$ protein/100 $\mathrm{g}$ is much more compact than that gel with a concentra- 
tion of $15 \mathrm{~g}$ protein/100 g. The gels were stored 1 to 5 days prior to use.

The simulated gastric fluid (SGF) and simulated saliva were prepared based on the composition of human gastric juice and saliva, following Kong and R. P. Singh (2008a). The simulated saliva contained gastric mucin $\left(1 \mathrm{gL}^{-1}\right)$, a-amylase $\left(2 \mathrm{gL}^{-1}\right), \mathrm{NaCl}\left(0.117 \mathrm{gL}^{-1}\right), \mathrm{KCl}$ $\left(0.149 \mathrm{~g} \mathrm{~L}^{-1}\right)$, and $\mathrm{NaHCO} 3\left(2.1 \mathrm{~g} \mathrm{~L}^{-1}\right)$. The SGF comprised of pepsin $\left(1 \mathrm{~g} \mathrm{~L}^{-1}\right)$, mucin $\left(1.5 \mathrm{~g} \mathrm{~L}^{-1}\right), \mathrm{NaCl}\left(8.775 \mathrm{~g} \mathrm{~L}^{-1}\right)$, and $\mathrm{pH} 1.8$ to $2.0 \mathrm{ad}$ justed with $2 \mathrm{~mol} \mathrm{~L}^{-1} \mathrm{HCl}$. The SGF without pepsin had the same composition except that no pepsin was added. SGF prepared at $\mathrm{pH} 3$ were used to study the effect of $\mathrm{pH}$ in dry matter loss of WPI gel.

\subsubsection{Dry matter loss of WPI gel}

Static soaking system A based on the design of Kong and R. P. Singh (2008a) was built (Fig. 2.1A) to apply stirring and track the dry matter loss hourly. The system was kept at $37^{\circ} \mathrm{C}$, agitated at $100 \mathrm{rpm}$.

The gel samples (cylindrical, $\varnothing 7 \mathrm{~mm} \times 9 \mathrm{~mm}$ approximately, original weight $(0.25 \pm 0.01) \mathrm{g}$ (mean \pm standard deviation $(\mathrm{SD}), \mathrm{N}=24)$ ) were first dipped into simulated saliva at $37^{\circ} \mathrm{C}$ for $15 \mathrm{~s}$ to mimic the oral process, afterward they were fixed on the needles and soaked in $300 \mathrm{~mL}$ SGF so that direct contact of the gel and the magnetic bar was avoided. Four gel samples were tested in one batch, each time point was an individual experiment. This set-up was used to measure the effect of gel concentration and the effect of $\mathrm{pH}$.

\subsubsection{Study of peptic hydrolysis in simulated gastric fluid}

Protein solutions and protein gels in static soaking

The hydrolysis of protein solutions and protein gels in SGF was studied in static soaking system B (Fig. 2.1B).

For solution experiments, $0.1 \mathrm{~g}$ protein (EWP or WPI) was dissolved in 

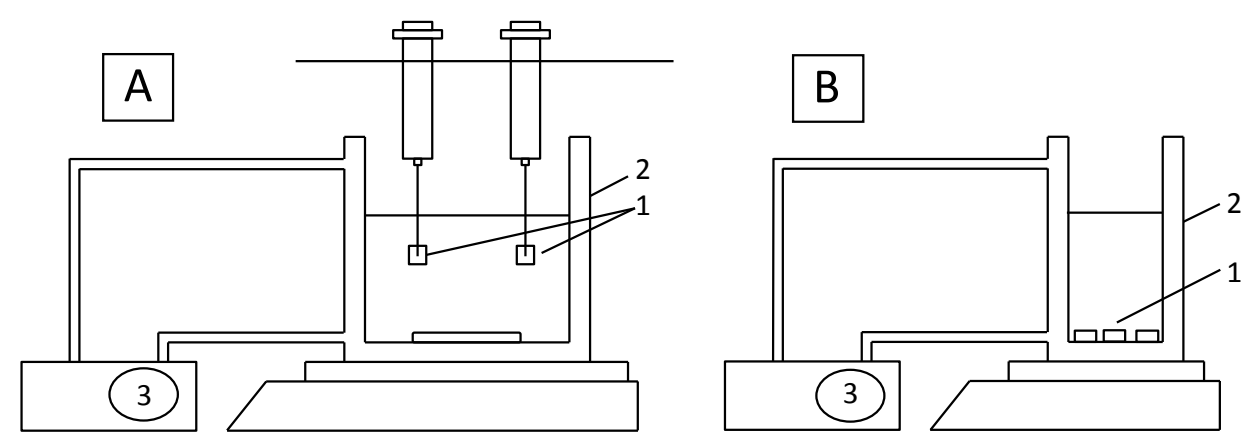

Figure 2.1: Static soaking systems. System A for studying the dry matter loss of whey protein isolate gel and system B for studying protein hydrolysis: 1 . Gel samples in simulated gastric juice (SGF) (System A: 4 of $\varnothing 7 \mathrm{~mm}$ $\times 9 \mathrm{~mm}$ cylindrical samples in $300 \mathrm{~mL}$ SGF, system B: 10 of $\varnothing 5 \mathrm{~mm} \times 5 \mathrm{~mm}$ cylindrical samples in $50 \mathrm{~mL} \mathrm{SGF)} \mathrm{2.} \mathrm{Water-jacketed} \mathrm{beaker} \mathrm{3.} \mathrm{Heat} \mathrm{circu-}$ lator.

$1.9 \mathrm{~mL}$ Milli-Q water. These solutions underwent the heat treatment at $90{ }^{\circ} \mathrm{C}, 30 \mathrm{~min}, 1400 \mathrm{rpm}$ in a pre-heated Eppendorf thermomixer (Eppendorf AG, Hamburg, Germany). Each heat-treated protein solution was added to one of the vessels containing $50 \mathrm{~mL}$ of SGF, stirring at $100 \mathrm{rpm}$.

For gel digestion experiments, 10 cylindrical particles $(\varnothing 5 \mathrm{~mm} \times 5 \mathrm{~mm}$ approximately) of egg white gel or WPI gel samples (15 g protein/100 g) were digested in $50 \mathrm{~mL}$ SGF. The weight was $(0.93 \pm 0.06) \mathrm{g}$ for 10 particles of egg white gel, and $(0.73 \pm 0.06) \mathrm{g}$ for WPI gel (mean $\pm \mathrm{SD}$, $\mathrm{N}=10$ ). The weighing procedure was done as fast as possible to reduce water evaporation. No agitation was applied in system B, mixing was done only before taking samples.

For solution experiments, $1 \mathrm{ml}$ sample was taken at $10 \mathrm{~min}, 20 \mathrm{~min}$, $30 \mathrm{~min}, 45 \mathrm{~min}, 1 \mathrm{~h}, 2 \mathrm{~h}$ and $3 \mathrm{~h}$; for gel digestion experiments $1 \mathrm{ml}$ sample was taken at $1 \mathrm{~h}, 2 \mathrm{~h}$, and $3 \mathrm{~h}$. To inactivate pepsin, the gastric juice samples taken from the vessels were heated by a pre-heated Eppendorf thermomixer at $90^{\circ} \mathrm{C}, 1400 \mathrm{rpm}$ for $5 \mathrm{~min}$.

Experiments using SGF without pepsin were done to compare the ef- 
fect of pepsin.

Protein gels in the simulated gastric system (U-stomacher)

In the interest of better simulation of the physical force induced by the peristaltic movement in the stomach, a simulated gastric system was designed.

Two plastic syringes $(50 \mathrm{~mL})$ were connected by silicon tubing (inner $\varnothing=8 \mathrm{~mm}$ ) and fixed on an iron stand. One piston was attached to a texture analyzer (Instron 5564, Norwood, USA), the texture analyzer can compress and extend the piston as expected and log the force. The other piston can move freely. The whole setup was kept in the environmental chamber set at $37^{\circ} \mathrm{C}$. This simulated gastric system is named U-stomacher (Fig. 2.2). Ten cylindrical particles $(\varnothing 5 \mathrm{~mm} \times 5 \mathrm{~mm}$ approximately) of egg white gel or WPI gel samples (15 g protein/100 g gel concentration) were tested in $50 \mathrm{~mL}$ SGF in this system. The gel sample can move freely in the syringes and tubes. Experiments using SGF without pepsin were done to compare the effect of pepsin.

The force applied by the texture analyzer is controlled as follows: Initially, the piston was pushed downward at a constant speed $(8 \mathrm{~mm} / \mathrm{s})$ for $10 \mathrm{~s}$ and then stopped for $3 \mathrm{~s}$. Next, the piston was returned to the original position. A single cycle takes $20 \mathrm{~s}$, which is comparable to the typical cycle time of stomach contractions (Marciani et al. 2001). The circulation was repeated for $3 \mathrm{~h}$, while the $1 \mathrm{ml}$ fluid sample was taken each hour from a side tube at the connection of the two syringes.

\subsubsection{Analysis methods}

\section{Determination of dry matter}

The gel samples were dried in an oven at $105^{\circ} \mathrm{C}$ overnight and weighed afterwards. Before every digestion experiment, 2 aliquots from the original gel were used to determine the percentage of dry 

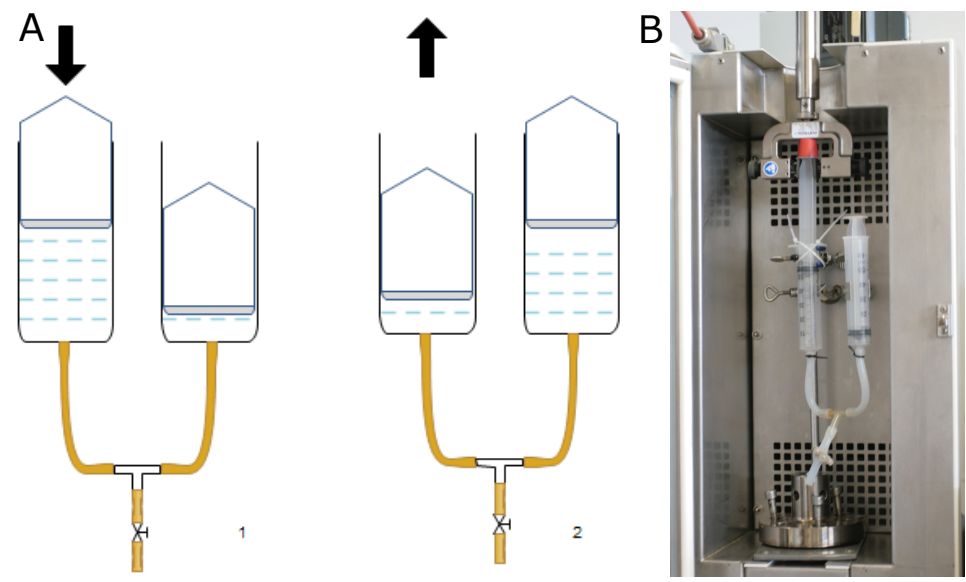

Figure 2.2: The U-stomacher. A: the schematic of the u-stomacher, compression step (1) and return step (2). B: picture of the U-stomacher.

matter $\left(x_{d m}\right)$ in duplicate, using

$$
x_{d m}=\frac{d m_{0}}{m_{0}}
$$

where $m_{0}$ is the weight of the aliquot, $d m_{0}$ is the dry weight of the aliquot.

The dry weight loss of the gel is calculated as follows:

$$
\text { Dry matter loss }=\frac{m_{1} x_{d m}-d m_{1}}{m_{1} x_{d m}}
$$

where $m_{1}$ is the weight of the gel sample before digestion and $d m_{1}$ is the dry weight of the gel sample after digestion.

Measurement of the degree of hydrolysis

The degree of hydrolysis (DH) is defined as the percentage of peptide bonds split in the total number of peptide bonds.

$$
D H=\frac{h}{h_{\text {tot }}} \times 100 \%
$$


where $\mathrm{h}$ is the number of peptide bonds split in $1 \mathrm{~kg}$ protein, htot is the total number of peptide bonds in $1 \mathrm{~kg}$ protein. htot has units of $\mathrm{eq} / \mathrm{kg}$ or $\mathrm{meq} / \mathrm{g}$ (eq stands for molar equivalent), and is found from the amino acid composition as the sum of the concentrations (in $\mathrm{mmol} \mathrm{g}^{-1}$ ) of each amino acid (Adler-Nissen 1993).

The degree of hydrolysis is measured using the OPAmethod. The OPA ( $\omega$-phthaldialdehyde) reagent was prepared as described by Nielsen et al. (Nielsen, Petersen, and Dambmann 2001): $3.81 \mathrm{~g}$ Borax and $100 \mathrm{mg}$ SDS were added in $80 \mathrm{~mL}$ Milli-Q water. After these reagents were completely dissolved, $80 \mathrm{mg}$ p-phthaldialdehyde was dissolved in $2 \mathrm{~mL}$ ethanol and added to the above-mentioned solution. $88 \mathrm{mg}$ of DL-dithiothreitol was added and further mixed. The solution was filled up to $100 \mathrm{~mL}$ with Milli-Q water and filtered using a $0.45 \mathrm{~mm}$ syringe filter. The solution was kept in the dark. A spectrophotometer DU 720 (Beckman Coulter Inc., Pasadena, USA) was set at $340 \mathrm{~nm}$ blanked with $1.5 \mathrm{~mL}$ OPA reagent $+0.2 \mathrm{~mL}$ Milli-Q water.

To make a calibration curve, $200 \mathrm{~mL}$ of $50 \mathrm{mg} / \mathrm{L}, 100 \mathrm{mg} / \mathrm{L}, 150 \mathrm{mg} / \mathrm{L}$ and $200 \mathrm{mg} / \mathrm{L}$ serine standard solutions were added to $1.5 \mathrm{~mL}$ OPA reagent in a semi-micro acrylic cuvette (optical pathway $10 \mathrm{~mm}$, Sarstedt AG\&Co., Nümbrecht, Germany), mixed by pipetting for $5 \mathrm{~s}$. The mixtures were measured by the spectrophotometer after standing for $3 \mathrm{~min}$. The same procedure was applied to samples from digestion experiments.

Due to the interference of the protein compounds from the gastric juice, a filtration step is necessary for all samples of digestion experiments. Centrifugal filtration was carried out as follows: $500 \mu \mathrm{L}$ of sample was pipetted into the Amicon Ultra-0.5 10K Centrifugal Filter Units (Millipore, USA) and was centrifuged at $14,000 \times$ g relative centrifugal force for $20 \mathrm{~min}$. Molecules larger than $10 \mathrm{kDa}$ were removed consequently. If relevant, the results were corrected for the blank simulated gastric fluid. 


\section{Size-exclusion chromatography}

Size-Exclusion Chromatography (SEC) was applied to observe the peptide profile during digestion. This was performed with a TSKgel G2000SWxl column (Tosoh Bioscience LLC, King of Prussia, USA) on an Ultimate 3000 UHPLC system (Thermo Scientific, Waltham, USA). $100 \mathrm{~mL}$ sample was injected each time. The eluent consisted of 30 $\mathrm{mL} / 100 \mathrm{~mL}$ Acetonitrile $(0.1 \mathrm{~mL} / 100 \mathrm{~mL}$ Trifluoro Acetic Acid) and $70 \mathrm{~mL} / 100 \mathrm{~mL}$ Milli-Q water $(0.1 \mathrm{~mL} / 100 \mathrm{~mL}$ Trifluoro Acetic Acid), the flow rate of the eluent was $1 \mathrm{~mL} / \mathrm{min}$. The UV-detector was set at $214 \mathrm{~nm}$.

Several standard solutions, including Carbonic Anhydrase, $\alpha$ Lactalbumin, Aprotinin, Insulin, Bacitracin, and Phenylalanine, were analyzed with the same method. By plotting the logarithm of the molecular weight (MW) and the respective retention time, a linear MW-retention time calibration curve was made.

The peptide profiles were quantified and compared as follows: The complete peptide profile was separated into four sections: MW > $10 \mathrm{kDa}, 10 \mathrm{kDa}-4 \mathrm{kDa}, 4 \mathrm{kDa}-2 \mathrm{kDa}$, and $<2 \mathrm{kDa}$. The last peak with a retention time of $11.25 \mathrm{~min}(\mathrm{MW} \approx 88 \mathrm{Da}$ ) was not included in the calculation, since it already existed in the simulated gastric juice and had little change during the digestion. The peak area (mAU.min) of each section was calculated by the Dionex ${ }^{\mathrm{TM}}$ Chromeleon ${ }^{\mathrm{TM}}$ 7.1 Chromatography Data System (Thermo Scientific, USA). Since the total peak areas varied over time, absolute values were used instead of relative peak areas. One example of size-exclusion chromatogram is shown in the Supplementary material. 

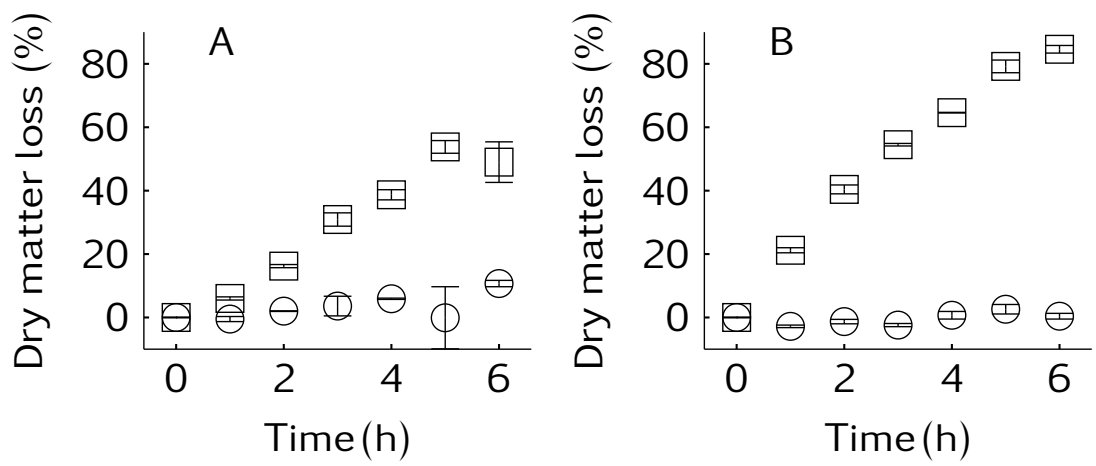

Figure 2.3: Dry matter loss of whey protein isolate (WPI) gels underwent static soaking in simulated gastric fluid at $37^{\circ} \mathrm{C}$, agitated at $100 \mathrm{rpm}$. A: comparison of different concentration at $\mathrm{pH} 1.8(\bigcirc: 15 \mathrm{~g}$ protein/100 g gel, $\square: 20 \mathrm{~g}$ protein $/ 100 \mathrm{~g}$ gel). B: comparison of $15 \mathrm{~g}$ protein $/ 100 \mathrm{~g}$ WPI gel at $\mathrm{pH} 1.8(\bigcirc)$ and $\mathrm{pH} 3(\square)$. The values are the mean values of 4 samples with standard deviation error bars.

\subsection{Results and discussion}

\subsubsection{Dry matter loss of WPI gel at different concentration and pH}

Gels made of WPI were soaked in gastric juice and the dry matter loss of the gels with different concentration was measured during $6 \mathrm{~h}$ (Fig. 2.3A). The dry matter loss of gel with $15 \mathrm{~g}$ protein/ $100 \mathrm{~g}$ reached approximately $50 \%$ at $6 \mathrm{~h}$. However, the gel with 20 g protein/100 $\mathrm{g}$ underwent distinctively lower dry matter loss, which grew steadily to $11 \%$ after $6 \mathrm{~h}$. It is clearly showing that even for the same protein substrate, the structural difference induced by the gel concentration has a significant effect on the disintegration of the protein structure. This is in line with the results of Guo et al. (2014a) who showed that a 'hard' gel structure can slow down disintegration, while a 'soft' gel structure was completely broken down during a certain time interval.

It is known that the $\mathrm{pH}$ in the stomach rises after ingestion of food. 
Table 2.1: Dry matter loss of $15 \mathrm{~g} / 100 \mathrm{~g}$ egg white protein (EWP) gel and $15 \mathrm{~g} / 100 \mathrm{~g}$ whey protein isolate (WPI) gel after $3 \mathrm{~h}$ of static soaking or Ustomacher digestion. The mean of 3 trials and the standard deviation are given.

\begin{tabular}{ccccc}
\hline & \multicolumn{2}{c}{ Quiescent conditions } & \multicolumn{2}{c}{ U-stomacher digestion } \\
\cline { 2 - 5 } & Without pepsin & With pepsin & Without pepsin & With pepsin \\
\hline EWP Gel & $7.1 \%(3.0 \%)$ & $18.2 \%(2.5 \%)$ & $17.3 \%(5.7 \%)$ & $33.9 \%(5.6 \%)$ \\
WPI Gel & $-3.6 \%(1.3 \%)$ & $33.2 \%(4.6 \%)$ & $61.6 \%(3.0 \%)$ & $69.3 \%(2.0 \%)$ \\
\hline
\end{tabular}

For this reason, we also studied the effect of $\mathrm{pH}$ on the static soaking of WPI gel with the concentration of $15 \mathrm{~g}$ protein $/ 100 \mathrm{~g}$, stirred at 100 rpm. Fig. 2.3B shows that the dry matter loss of the gel at $\mathrm{pH} 1.8$ reached $85 \%$ after $6 \mathrm{~h}$. While at $\mathrm{pH} 3$ the dry matter loss is negligible.

Experiments with simulated gastric juice without pepsin showed that the acid in gastric juice is ineffective for the disintegration of the protein structure, especially for WPI gel (Table 2.1). Thus, the difference in the dry matter loss between $\mathrm{pH} 1.8$ and $\mathrm{pH} 3$ most probably was due to the action of the pepsin. Previous research has shown that pepsin has a rather narrow optimum $\mathrm{pH}$ range, but should still be partially active at pH 3 (Christensen 1955; Piper and Fenton 1965). Thus, we may conclude that the nearly complete retention of the dry mass at $\mathrm{pH}$ 3 is due to the ineffectiveness of the acid to open the structure, plus the lower activity of pepsin resulted in the minor loss of dry matter. Notably, in vivo studies showed that the gastric $\mathrm{pH}$ increases towards neutral after the ingestion of a meal due to the buffering effect of the food, and then decreases gradually again to the original $\mathrm{pH}$ over a time period of $60 \mathrm{~min}-90 \mathrm{~min}$ (Cassilly et al. 2008; Dressman 1986). Thus the in vivo gastric $\mathrm{pH}$ after ingestion is far from optimum for pepsin during a considerable time span, which will have its effect on the digestion of solid protein foods. 

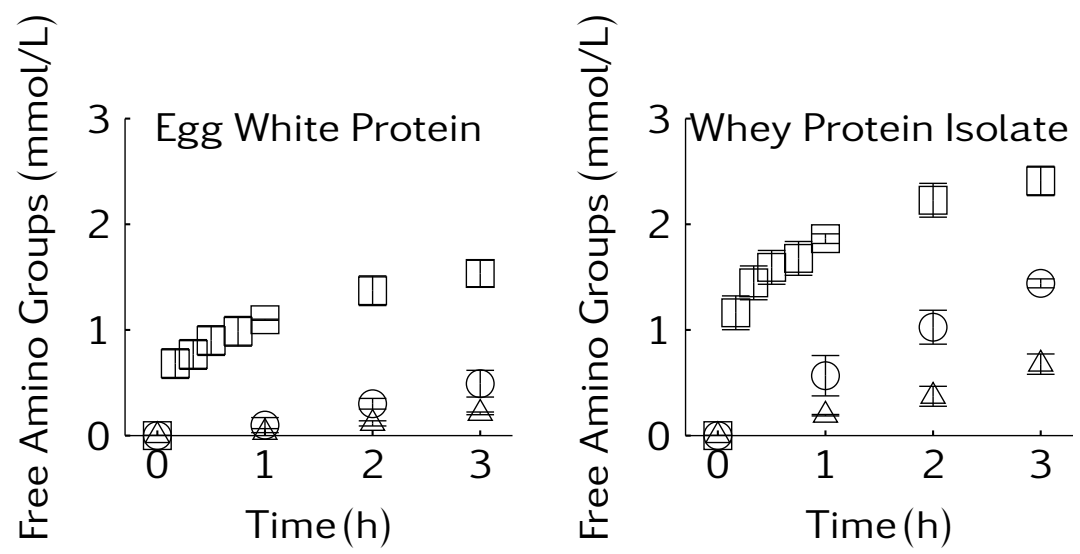

Figure 2.4: Hydrolysis profile of protein digestion measured by OPA method. $\square$ :solution, $\bigcirc$ :U-stomacher, $\triangle$ : static soaking, Error bars are based on the standard deviation of two or three experiments.

\subsubsection{Hydrolysis of protein solutions}

Degree of hydrolysis

Before continuing to study the digestion in protein gels, we first report on the hydrolysis of protein in solution, which is used as benchmark.

The hydrolysis profile of egg white protein and WPI proteins in simulated gastric juice is shown in Fig. 2.4. Results from the experiments without pepsin were omitted, since there was no increase in the amount of free amino groups even after $24 \mathrm{~h}$. The hydrolysis of the whey protein is somewhat faster; especially in the beginning one can see a quick increase of the amount of free amino acid groups; however one should realise that the solutions of whey protein and egg white protein did not have the same initial substrate molar concentration.

The hydrolysis profiles of both protein sources are typical for protein hydrolysis. Initially a rapid increase is observed, which is then followed by a steady increase over several hours. After $3 \mathrm{~h}$, the degree of hydrolysis for egg white protein solution was about $11 \%$, for WPI 
solution $15 \%$. In the study of Rocha (2008), the hydrolysis of whey protein concentrate by pepsin showed similar trend, reaching approximately a $\mathrm{DH}$ of $5 \%$ after $3 \mathrm{~h}$ hydrolysis when the enzyme: substrate ratio is $2: 40$. In our experiments where the protein is in solution, the enzyme: substrate ratio is 1:2 (weight/weight), which is higher than in other studies. This value was chosen to enable comparison with other experiments.

\section{Peptide profile}

The peptide distribution during hydrolysis of proteins in solution is shown in Table 2.2. The simulated gastric juice sample taken just before the addition of the protein solution was regarded as the start of the experiment. Since the gastric juice itself contains protein, it has an initial value in the category above $10 \mathrm{kDa}$; this level remained constant over the experiments. The peptide distribution for both egg white protein and WPI shows that larger peptides $(10 \mathrm{kDa}-4 \mathrm{kDa})$ accumulated at the beginning of the experiments decreased steadily afterward due to progressing hydrolysis. The peptides between $4 \mathrm{kDa}-2 \mathrm{kDa}$ followed a similar trend, while the small peptides below $2 \mathrm{kDa}$ increased throughout the whole process. The presence of a large amount of intermediate products suggests that the peptic hydrolysis of dissolved denatured egg white protein and WPI follow the "zipper-type" according to Linderstrøm-Lang's theory, which is also shown in other studies. 
Table 2.2: Peak area of peptides during digestion of egg white protein (EWP) and whey protein isolate (WPI), in solution and $15 \mathrm{~g} / 100 \mathrm{~g}$ gels. The gels were digested in $3 \mathrm{~h}$ of static soaking and U-stomacher. The mean of 2 trials and the standard deviation are given.

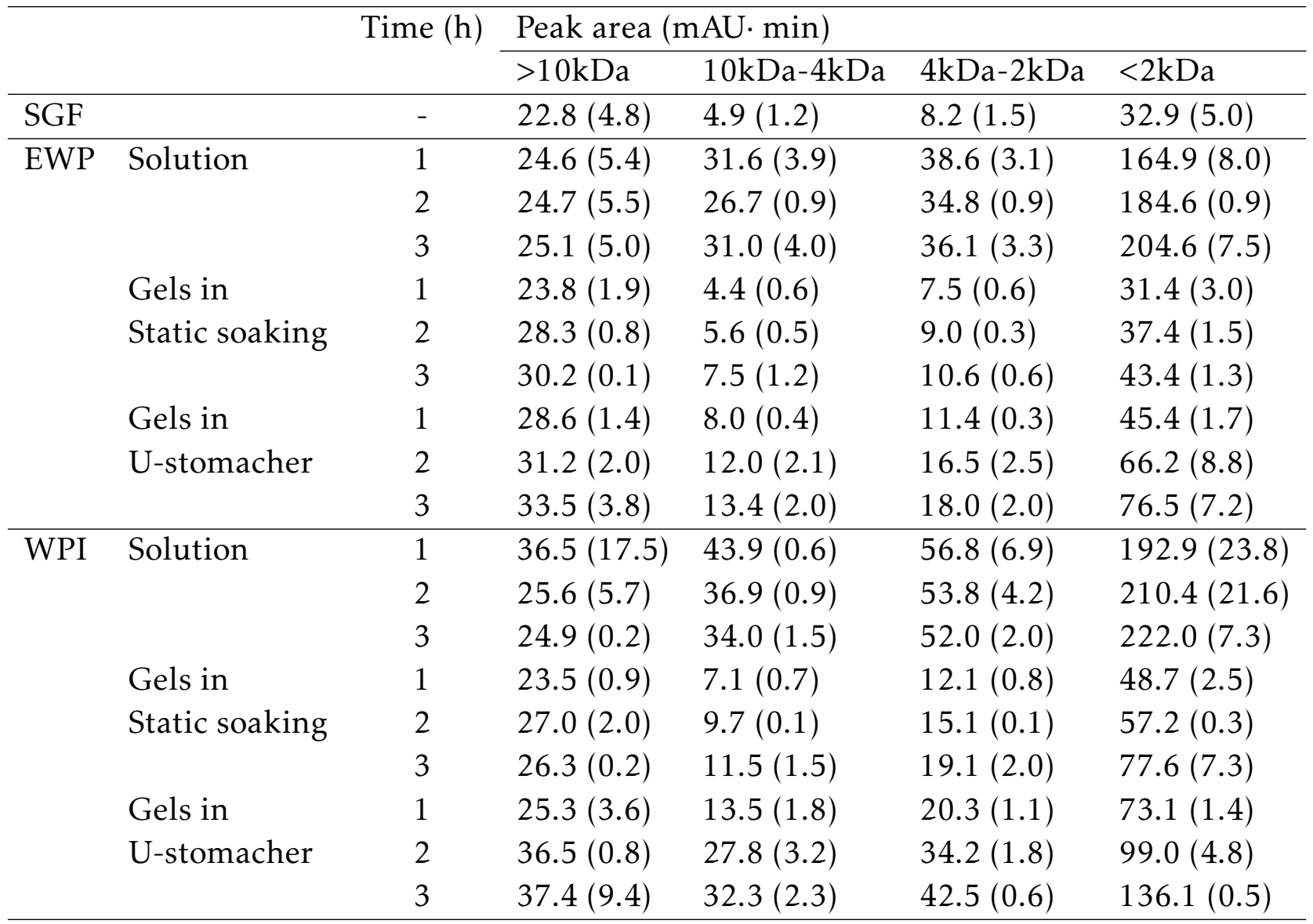




\subsubsection{Hydrolysis in protein gels}

The digestion of protein gels (15 g protein/100 g) was analyzed with a range of methods. The effect of pepsin was compared with control groups digested without pepsin and the effect of hydrodynamic force induced by the U-stomacher was compared with the static soaking conditions.

\section{Dry matter loss}

Table 2.1 shows the dry matter loss of the two kinds of protein gel after $3 \mathrm{~h}$ of digestion, in the presence or absence of pepsin. The dry matter loss of WPI gel after $3 \mathrm{~h}$ of static soaking was in agreement with previous tests in Section 2.3.1.

Kong and R. P. Singh (2009a) considered that both acid and enzyme may enhance the transfer of matter from the food matrix to the gastric fluid since their actions reduce the cohesiveness of solid. In this study, the pepsin is absent in the SGF. The dry matter loss, which is solely from the dissolution in water at low $\mathrm{pH}$, is rather low as compared to the effect of SGF with pepsin. For egg white gel, approximately $11 \%$ more dry matter was lost when pepsin was present. In accordance with our results as reported in Section 2.3.1, WPI gels that were soaking under quiescent conditions showed up to $33 \%$ dry matter loss. The WPI gel soaked in the SGF without pepsin had a negative dry matter loss, which can be explained by the infusion of gastric juice compounds into the gel matrix; similarly, the actual weight loss of the gel soaked in gastric juice with pepsin may be somewhat larger, since also here some gastric juice compounds may have ingressed.

The stress and deformation exerted on the samples during stomaching has a big effect: all samples saw a much larger dry matter loss than under quiescent conditions. This demonstrates that mechanical action can degrade solid foods without enzymatic reaction; one should realize however that dry matter loss does not imply that the matter that was released is also hydrolyzed into smaller peptides. When the 
hydrodynamic force was combined with pepsin, the yield of the dry matter loss was higher than each factor acting alone.

\section{Degree of hydrolysis}

The digestion of the gels yielded a lower increase of free amino groups than the digestion of the same amount of protein in solution (Fig. 2.4). The increases in the amount of free amino groups in the digestion of the gels followed a linear trend. Consistent with previous experiments, very little free amino acid was found in systems without pepsin present (data not shown); even though the previous section showed that a significant part of the solid was dispersed (shown by the high value of dry matter loss). If it is assumed that all protein in the gel particles was available in principle for hydrolysis, the DH after $3 \mathrm{~h}$ of $\mathrm{U}$ stomacher digestion was $2.5 \%$ for egg white gel, and $7.9 \%$ for the WPI gel. The Ustomacher digestion yielded a higher level of free amino groups compared to the static soaking. Therefore, as the mechanical stresses physically disintegrate the gel, a larger portion of protein becomes more accessible for the pepsin. Comparison with the dissolved proteins show that the total degree of hydrolysis is still much lower (2.5 compared to $11 \%$ in the case of EWP, and 7.9 compared to $15 \%$ in the case of WPI), with the EWP affected more strongly than the WPI.

\section{Peptide profile}

The simulated gastric fluid samples taken from the digestion of protein gel were analyzed by size-exclusion chromatography, and the peptide profiles were shown in Table 2.2.

Unlike the hydrolysis of the protein solutions, the big and medium sized peptides in the protein gel digestion monotonously increased in concentration trend. The molecules in solution that were larger than $10 \mathrm{kDa}$ and smaller than $2 \mathrm{kDa}$ had similar trend as the protein solution hydrolysis. 
The digestion of protein gel is much slower than the digestion of protein solution, as was also concluded before. For this reason, we do not only plot the peptide profile versus time, but we also made a graph in which the amount of free amino groups was plotted against the peak area of the peptides with different size. Thus it is possible to compare the peptide composition as related to the level of hydrolysis extent (Fig. 2.5).

The peak areas for peptides $<2 \mathrm{kDa}$ do not show difference between the gels and solutions. The small peptides are dominant in the total amount of free amino groups, given their low molecular weight, and thus the correlation between the horizontal and vertical axes is large. However, the trends for larger peptides $(10 \mathrm{kDa}-4 \mathrm{kDa}$ and $4 \mathrm{kDa}-2 \mathrm{kDa}$ ) differ significantly. In the digestion of dissolved protein, large peptides were rapidly formed at relatively low conversions, and then decreased in concentration as they were further hydrolyzed. The larger peptides tended to increase in concentration for the gels, regardless of whether mechanical action was applied, the big peptides had an increasing trend, but their concentration remained lower than those found in the digestion of dissolved protein at all times.

The model for protein hydrolysis in gels

We assume that pepsin is able to penetrate the protein gel matrix. This assumption is based on the dimensions of pepsin and the pore sizes of whey protein gels. The unit cell dimensions of pepsin crystal are $5.5 \mathrm{~nm} \times 3.6 \mathrm{~nm} \times 7.4 \mathrm{~nm}$ (Sielecki et al. 1989). For $13.5 \%$ whey protein concentrate gels (heated at $90^{\circ} \mathrm{C}$ for $60 \mathrm{~min}$, both at $\mathrm{pH} 4.6$ and $5.4)$, image analysis showed that they have mean pore diameters from $10 \mu \mathrm{m}-40 \mu \mathrm{m}$, if the pores are approximated to be spherical (Langton and Hermansson 1996). Moreover, the increase in dry matter of WPI gel in static soaking without pepsin also suggested the penetration of gastric juice compounds into the gel (Table 2.1). Based on these pieces of evidence and our results, we propose an enzymatic hydrolysis model for protein gels, derived from the Linderstrøm-Lang's theory (Fig. 2.6). 


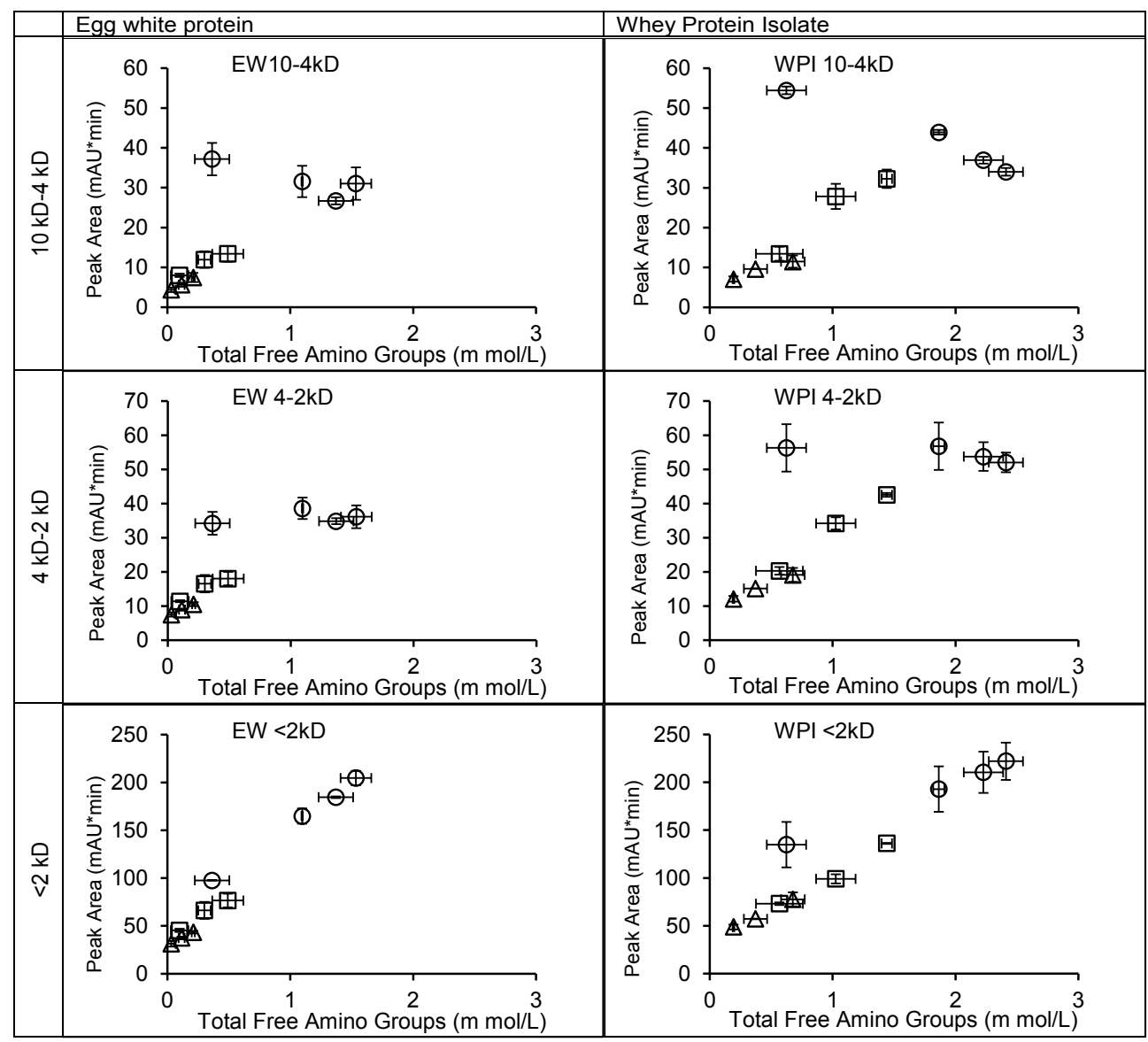

Figure 2.5: The correlation between total free amino group and peak area of peptides in egg white protein digestion and in whey protein isolate digestion. Error bars are based on the standard deviation of two or three experiments. $\bigcirc$ :solution ( 4 data points), $\square: U$-stomacher (3 data points), $\triangle$ : static soaking (3 data points). 


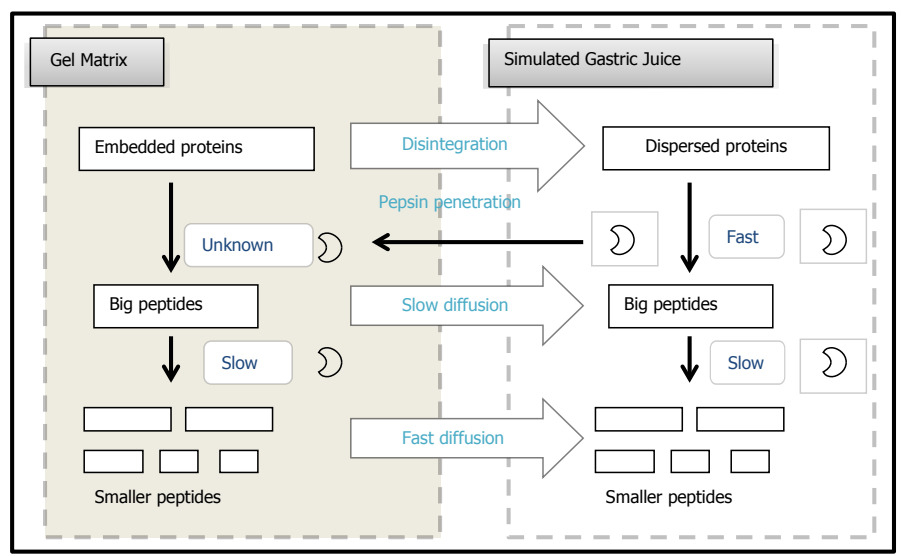

Figure 2.6: The hydrolysis model for protein gels in gastric digestion. The proteins and peptides are depicted by rectangles of different size. The proteases are denoted by crescents. The presumed relative reaction rates are in the rounded rectangles.

In gel matrices, the proteins are immobilized in the gel network. The pepsin needs to penetrate the gel matrix to access the major part of a protein that is not on the surface of the gel. After pepsin cleaves a peptide bond, the two resulting fragments generally are still bound to network. In addition, any larger fragment that is not bound anymore to the network will have to diffuse out. The diffusion takes time, and in this time the larger fragment can be further hydrolyzed by the pepsin inside the gel pores. The smaller the fragments are, the easier they will diffuse out of the pores, meanwhile, the number of bonds that keep the fragments to the network will also reduce. Therefore, the net effect is that the larger fragments will increase in time, but will never get to the levels that are present during digestion in solution. The ultimate freedom of diffusion can never be achieved as long as any form of network is still present.

In the meantime, the immobilized proteins may disintegrate from the network, and some of them are released into the simulated gastric fluid before being hydrolyzed. In the simulated gastric fluid, the situation is phenomenologically similar to the classic zipper type model of Linderstrøm-Lang (relatively slow initial hydrolysis followed fast 
subsequent hydrolysis) but the amount of free proteins is limited by the disintegration rate of proteins.

Overall, the differences between the digestion of protein gels and solutions may be the result of various causes: the immobilization of the substrate in the gel network, the steric hindrance for the ingression of pepsin and the egression of peptides.

\subsection{Conclusions}

Well-defined protein gels were successful models to study the digestion of protein in solid food matrices.

The performance of pepsin is an important factor in the disintegration of protein gels. By merely elevating the $\mathrm{pH}$ to 3 where pepsin has lower activity, the disintegration of protein gel was decelerated more than that can be expected on the basis of the residual activity of the pepsin. The hydrodynamic force applied by the simulated gastric system (U-stomacher) effectively disintegrated the gel particles and enhanced the hydrolysis of protein.

The gel microstructure was shown to hinder the digestion of protein. Relative to protein in solution, a protein gel is hydrolyzed more slowly and a higher concentrated gel leads to a slower loss of dry matter. The barrier of the gel structure does not simply lower the protein hydrolysis, but it may also be altering the type of enzyme kinetics. The gels were broken down according to a one-by-one type mechanism, in contrast to the zipper-type mechanism found with proteins in solution. This is thought to stem from immobilization of the substrate in the gel network, and steric hindrance in the diffusive ingression and egression of the larger macromolecules through the network pores. It has been assumed that pepsin is able to hydrolyze the proteins inside the gel, but further studies are needed to determine the affinity and kinetics of pepsin in embedded proteins. 


\subsection{Supplementary information}

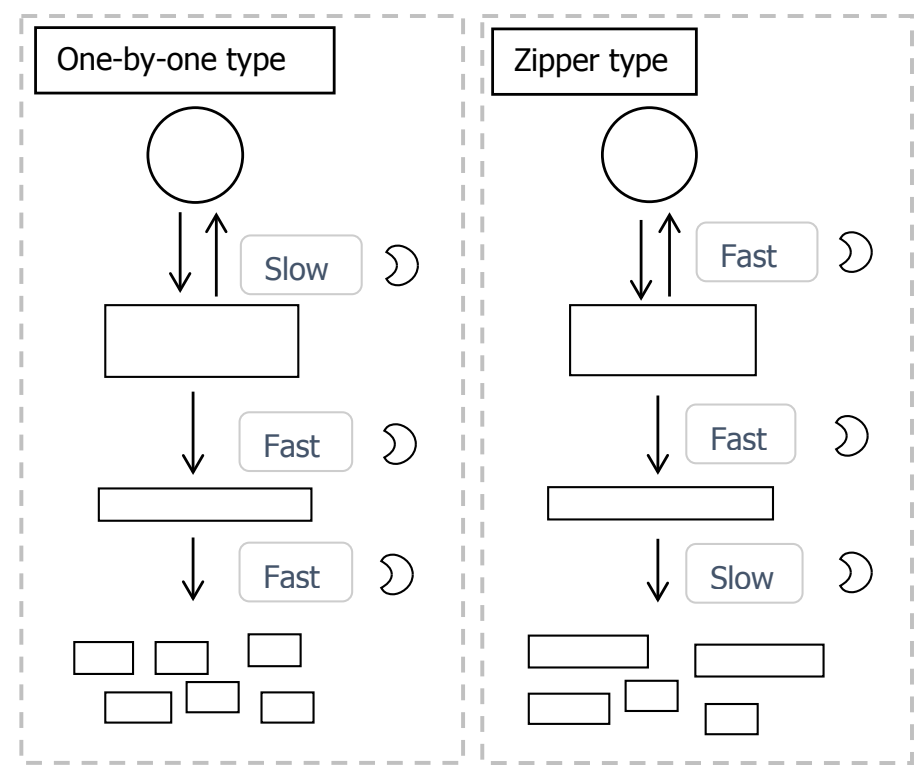

Figure 2.7: Supplementary information: the Linderstrøm-Lang hydrolysis model. Circles represent native protein, big rectangles represent denatured protein, small rectangles represent peptides with different length according to the peptide chain length. The crescents symbolize the enzymes. Adapted from Adler-Nissen' s figure (Adler-Nissen 1976). 


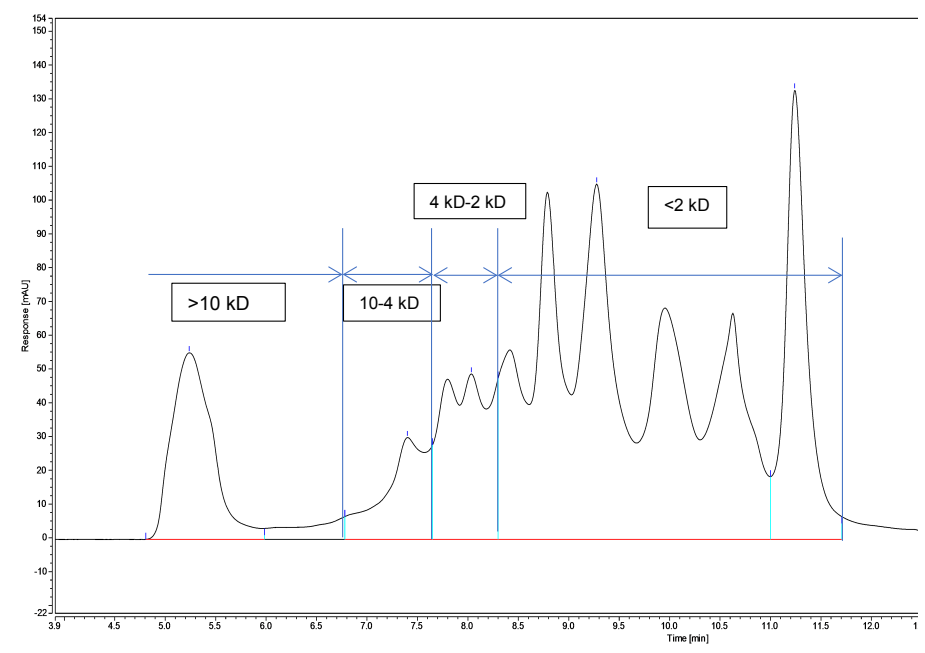

Figure 2.8: Supplementary information: one example of size-exclusion chromatogram. Sample was whey protein isolate solution hydrolyzed in simulated gastric juice after 3 hours. Sections of molecular weight ranges are indicated.

\section{References}

Adler-Nissen, J. (Nov. 1, 1976). "Enzymic Hydrolysis of Proteins for Increased Solubility." In: Journal of Agricultural and Food Chemistry 24.6, pp. 1090-1093. Dor: 10. 1021/ jf60208a021.

Adler-Nissen, J. (1993). “Chapter 7: Proteases.” In: Enzymes in Food Processing. Ed. by T. Nagodawithana and G. Reed. Academic Press, pp. 165-173.

Barbé, F., O. Ménard, Y. L. Gouar, C. Buffière, M.-H. Famelart, B. Laroche, S. L. Feunteun, D. Rémond, and D. Dupont (Jan. 15, 2014). "Acid and Rennet Gels Exhibit Strong Differences in the Kinetics of Milk Protein Digestion and Amino Acid Bioavailability." In: Food Chemistry 143, pp. 1-8. Dor: 10.1016/ j . foodchem.2013.07.100.

Bornhorst, G. M. and R. P. Singh (Mar. 2012). "Bolus Formation and Disintegration during Digestion of Food Carbohydrates." In: Comprehensive Reviews in Food Science and Food Safety 11.2, pp. 101-118. DoI: $10.1111 / \mathrm{j} .1541-4337.2011 .00172$.x. 
Bornhorst, G. M. and R. P. Singh (Feb. 28, 2014). "Gastric Digestion In Vivo and In Vitro: How the Structural Aspects of Food Influence the Digestion Process." In: Annual Review of Food Science and Technology 5.1, pp. 111-132. DoI: 10.1146/annurev-food-030713-092346.

Cassilly, D., S. Kantor, L. C. Knight, A. H. Maurer, R. S. Fisher, J. Semler, and H. P. Parkman (2008). "Gastric Emptying of a NonDigestible Solid: Assessment with Simultaneous SmartPill pH and Pressure Capsule, Antroduodenal Manometry, Gastric Emptying Scintigraphy." In: Neurogastroenterology \& Motility 20.4, pp. 311319. Dor: 10.1111/ j . 1365-2982.2007.01061.x.

Choisnard, L., R. Froidevaux, N. Nedjar-Arroume, B. Lignot, D. Vercaigne-Marko, F. Krier, P. Dhulster, and D. Guillochon (Dec. 1, 2002). "Kinetic Study of the Appearance of an Anti-Bacterial Peptide in the Course of Bovine Haemoglobin Peptic Hydrolysis." In: Biotechnology and Applied Biochemistry 36.3, pp. 187-194. Dor: 10 . 1042 /BA20010103.

Christensen, L. K. (July 1955). "Concerning the pH Optimum of Peptic Hydrolysis." In: Archives of Biochemistry and Biophysics 57.1, pp. 163-173. Dor: 10.1016/0003-9861(55)90189-2.

Dressman, J. B. (1986). "Comparison of Canine and Human Gastrointestinal Physiology.” In: Pharmaceutical Research 3.3, pp. 123-131.

Fruton, J. S. and M. Bergmann (Jan. 3, 1939). "The Specificity of Pepsin.” In: Journal of Biological Chemistry 127.3, pp. 627-641.

Guerra, A., L. Etienne-Mesmin, V. Livrelli, S. Denis, S. Blanquet-Diot, and M. Alric (Nov. 2012). "Relevance and Challenges in Modeling Human Gastric and Small Intestinal Digestion." In: Trends in Biotechnology 30.11, pp. 591-600. Dor: 10 . 1016/ j . tibtech . 2012 . 08.001.

Guo, Q., A. Ye, M. Lad, D. Dalgleish, and H. Singh (May 21, 2014a). "Behaviour of Whey Protein Emulsion Gel during Oral and Gastric Digestion: Effect of Droplet Size.” In: Soft Matter 10.23, pp. 41734183. DOI: 10.1039/C4SM00598H.

Guo, Q., A. Ye, M. Lad, D. Dalgleish, and H. Singh (Jan. 29, 2014b). "Effect of Gel Structure on the Gastric Digestion of Whey Protein 
Emulsion Gels.” In: Soft Matter 10.8, pp. 1214-1223. Dor: 10.1039/ C3SM52758A.

Kong, F. and R. P. Singh (June 2008a). “A Model Stomach System to Investigate Disintegration Kinetics of Solid Foods during Gastric Digestion." In: Journal of Food Science 73.5, E202-E210. Dor: 10.1111/ j . 1750-3841.2008.00745.x.

Kong, F. and R. P. Singh (Oct. 22, 2009a). "Digestion of Raw and Roasted Almonds in Simulated Gastric Environment." In: Food Biophysics 4.4, pp. 365-377. DoI: 10. 1007/s11483-009-9135-6.

Kozu, H., Y. Nakata, M. Nakajima, M. A. Neves, K. Uemura, S. Sato, I. Kobayashi, and S. Ichikawa (2014). "Development of a Human Gastric Digestion Simulator Equipped with Peristalsis Function for the Direct Observation and Analysis of the Food Digestion Process." In: Food Science and Technology Research 20.2, pp. 225-233. Dor: 10 . $3136 /$ fstr. 20.225.

Lambers, T. T., W. G. Bosch, and S. Jong (Mar. 23, 2013). "Fast and Slow Proteins: Modulation of the Gastric Behavior of Whey and Casein In Vitro." In: Food Digestion 4.1, pp. 1-6. DoI: 10 . 1007 / s13228-0120028-7.

Langton, M. and A.-M. Hermansson (Apr. 1996). "Image Analysis of Particulate Whey Protein Gels.” In: Food Hydrocolloids 10.2, pp. 179191. DoI: 10.1016/S0268-005X ( 96 ) 80033-6.

Linderstrøm-Lang, K. U. (1952). Lane Medical Lectures: Proteins and Enzymes. Stanford University Press. 132 pp.

Marciani, L., P. Young, J. Wright, R. Moore, N. Coleman, P. A. Gowland, and R. C. Spiller (2001). "Antral Motility Measurements by Magnetic Resonance Imaging." In: Neurogastroenterology \& Motility 13.5, pp. 511-518. Dor: 10. 1046/ j . 1365-2982 .2001.00285 . x.

Nielsen, P., D. Petersen, and C. Dambmann (2001). "Improved Method for Determining Food Protein Degree of Hydrolysis." In: Journal of Food Science 66.5, pp. 642-646. Dor: 10 . 1111/ j . 1365-2621. 2001. tb04614.x.

Ortiz, S. E. M. and M. C. An (Dec. 1, 2000). "Analysis of Products, Mechanisms of Reaction, and Some Functional Properties of Soy 
Protein Hydrolysates." In: Journal of the American Oil Chemists' Society 77.12, pp. 1293-1301. Dor: 10.1007/s11746-000-0204-4.

Piper, D. and B. H. Fenton (1965). "pH Stability and Activity Curves of Pepsin with Special Reference to Their Clinical Importance." In: Gut 6.5, pp. 506-508.

Rawlings, N. D. and G. S. Salvesen (Oct. 30, 2012). Handbook of Proteolytic Enzymes. Academic Press. 3988 pp.

Rocha, C. (2008). "Valorization of the Peptidic Fraction of Cheese Whey." PhD thesis. Universidade do Minho.

Sielecki, A. R., A. A. Fedorov, A. Boodhoo, N. S. Andreeva, and M. N. James (Dec. 18, 1989). "Molecular and Crystal Structures of Monoclinic Porcine Pepsin Refined at 1.8 A Resolution." In: J.Mol.Biol. 214, pp. 143-170. Dor: 10 . 1016 / 0022 - 2836 ( 90 ) 90153 -D. pmid: 2115087.

Whitney, E. N., C. B. Cataldo, and R. R. Sharon (1998). Understanding Normal and Clinical Nutrition. 5th ed. Wadsworth Publishing Company, Inc. 



\section{Chapter 3}

\section{Pepsin diffusivity in whey protein gels and its effect on gastric digestion}

This chapter has been published as:

Q. Luo, J. W. Borst, et al. (May 2017). "Pepsin Diffusivity in Whey Protein Gels and Its Effect on Gastric Digestion." In: Food Hydrocolloids 66, pp. 318-325. Dor: 10.1016/ j . foodhyd.2016.11.046 


\section{Abstract}

Protein is essential to human health, but its digestion kinetics in varied structures are not yet well understood. We previously found different kinetics of protein hydrolysis in solution and in gels, and we hypothesized that the difference stemmed from the steric hindrance of gel structure to the diffusion of pepsin and its hydrolysates. To better understand the pepsin diffusivity in food matrices and its effect on digestion, we determined the diffusivity of pepsin in water and in whey protein isolate (WPI) gels by fluorescence correlation spectroscopy (FCS).We estimated the pepsin concentration gradient during digestion based on the determined diffusivity, which showed that the pepsin is constrained within a thin layer from the gel surface. Gel composition analysis confirmed this constraint: peptides as protein fragments were observed only in the first $2 \mathrm{~mm}$ of the WPI gels after $6 \mathrm{~h}$ of in vitro gastric digestion. Scanning electron microscopy indicated that pepsin loosened the microstructure of whey protein gel surfaces, which may accelerate pepsin diffusion and consequently gel surface disintegration. We conclude that the mode of whey protein gel digestion is determined by the summed effect of diffusion limitation, hydrolysis rate and microstructure transformation. 


\subsection{Introduction}

Proteins in foods supply most of the amino acids for protein synthesis in human bodies (Whitney, Cataldo, and Sharon 1998). The digestion of protein starts in the stomach by the acidic environment and pepsincatalyzed hydrolysis (H. Singh, A. Ye, and M. J. Ferrua 2015). Pepsin is an aspartic protease with two aspartic acid residues at the catalytic site (Fersht 1985) and has maximum activity between $\mathrm{pH} 1.5$ and 2.5 (Piper and Fenton 1965). It prefers to cleave a peptide sequence containing phenylalanine, tyrosine, tryptophan and leucine residues (Inouye and Fruton 1967).

Food structure is important in the digestion and nutrient delivery (Bornhorst and R. P. Singh 2014; H. Singh, A. Ye, and M. J. Ferrua 2015); hence, the protein digestion differs in foods with different structures. For example, Nyemb-Diop et al. (2016) investigated the in vitro digestion of four different egg white gel matrices, and found that the gel structure greatly influences the digestion kinetics, resulting in different peptide profiles. (Guo, A. Ye, Lad, M. Ferrua, et al. 2015) found varied disintegration kinetics for two differently structured whey protein emulsion gels: the soft gel (hardness: 19.2 N) disintegrated faster, when both fragmentation and abrasion enacted in the disintegration; the hard gel (hardness 69.9 N) disintegrated slower, and abrasion was the predominant mechanism. Moreover, the abrasion process was accelerated by the presence of pepsin.

To better understand the role of pepsin in the digestion of protein in food structure, we previously studied the in vitro digestion of protein and protein gels by analyzing the peptide distribution after hydrolysis (Q. Luo, Boom, and Janssen 2015). We found that the kinetics of protein hydrolysis in solution and in gels are different: while the dissolved proteins were hydrolyzed through a 'zipper' -type mechanism, the gels followed a slower 'one-by-one' mechanism. We hypothesized that pepsin can penetrate the gel microstructure and hydrolyze proteins in gel matrices. Digestion kinetics may be limited by diffusion of pepsin in gel matrices, which can explain the differences in hydrolysis 
kinetics.

There are several methods to study the diffusivity of macromolecules in gel networks. Pulsed field gradient NMR has been used to study the diffusion of poly(ethylene glycol)s in whey protein solutions and gels (Colsenet, Söderman, and Mariette 2006b) and to study the selfdiffusion of native proteins and dextran during the heat-induced gelation of $\beta$-lactoglobulin (Croguennoc et al. 2001). Fluorescence recovery after photobleaching (FRAP) and fluorescence correlation spectroscopy (FCS) have been used to characterize the diffusions of pectin methylesterases in pectin solutions and gels (Videcoq et al. 2013).

FCS is based on the analysis of intensity fluctuations from some dynamic process, e.g. translational diffusion of a fluorophore through a small volume, using a confocal laser microscope. By autocorrelation analysis of the time-dependent fluorescence fluctuation, the diffusion coefficient of the fluorophore can be determined (Lakowicz 2006). While pulsed field gradient NMR requires a probe that is distinct from native proteins in the gel network (Croguennoc et al. 2001), the two fluorescence methods (FRAP and FCS) can measure any desired molecules that are fluorescent or fluorescently labeled. Compared with FRAP, FCS has a larger detection range of diffusion time ( $\mu \mathrm{s}-\mathrm{s})$, can be used at low fluorophore concentrations and can distinguish multicomponent diffusion (Kwaaitaal et al. 2011). In this study, we considered the possibility of interaction between pepsin and protein gel. Therefore, FCS was employed to investigate the diffusivity of pepsin in the protein gels.

In the FCS experiments, we used whey protein isolate (WPI) gel as a model for a protein-based food matrix. In addition to fluorescently labeled pepsin, enhanced green fluorescent protein (EGFP) was used as a reference molecule due to its intrinsic fluorescence and similar size to pepsin. EGFP is a variant of the wild-type green fluorescent protein, which has increased brightness and folding efficiency (Royant and Noirclerc-Savoye 2011). By combining the information from the diffusion study with that from gel composition analysis and scan- 
ning electron microscopy, we can better understand the role of pepsin diffusion in the digestive process, and thus better understand the role of the food microstructure in digestion.

\subsection{Material and methods}

\subsubsection{Material}

WPI (Bipro, lot no. JE 034-70-440-6) was purchased from Davisco Food International, Inc. (Le Sueur, MN, USA). This batch of WPI was reported to have a protein content of $97.9 \mathrm{~g} / 100 \mathrm{~g}$ dry solid. Milli-Q water (resistivity $18.2 \mathrm{M} \Omega \mathrm{cm}$ at $25^{\circ} \mathrm{C}$; Merck Millipore, Billerica, MA, USA) was used in all experiments. The fluorescent dye Alexa Fluor ${ }^{\circledR}$ 633 succinimidyl ester (Alexa 633, MW $\approx 1200 \mathrm{Da}$ ) was purchased from Life Technologies (Carlsbad, CA, USA); pepsin from porcine gastric mucosa (lyophilized powder, 3,200-4,500 units/mg protein, MW $=34.6 \mathrm{kDa}$ ) and all other chemicals used were purchased from Sigma Aldrich (St. Louis, MO, USA).

EGFP (MW $=26.9 \mathrm{kDa}$ ) was produced in-house at Wageningen University, via the method described by (Nolles et al. 2015).

\subsubsection{Preparation of whey protein isolate gels and simulated gas- tric fluid}

WPI was dissolved in water $(15 \mathrm{wt} \%$ or $20 \mathrm{wt} \%)$ and stirred at room temperature for at least $2 \mathrm{~h}$. The solutions were centrifuged at 1000 $\mathrm{rpm}(\sim 200 \mathrm{G}$ relative centrifuge force) for $10 \mathrm{~min}$ to remove large aggregates and air bubbles.

FCS was performed on WPI gels that were prepared as follows: $200 \mu \mathrm{s}$ of the WPI solution was pipetted into each well of an eight-well Nunc $^{\mathrm{TM}}$ Lab-Tek ${ }^{\mathrm{TM}}$ Chambered Coverglass (Thermo Fisher Scientific, Waltham, MA, USA). The system was sealed and heated at $90{ }^{\circ} \mathrm{C}$ for 
$30 \mathrm{~min}$ in a hot-air oven. The WPI gel was then cooled to room temperature and stored at $4{ }^{\circ} \mathrm{C}$. The thickness of the gel layer was 1-2 mm. Further FCS experiments were performed within 2-3 days.

WPI gels for digestion experiments were prepared in Teflon tubes incubated in a $90^{\circ} \mathrm{C}$ water bath for $30 \mathrm{~min}$, as described previously (Q. Luo, Boom, and Janssen 2015). To analyse the texture of the WPI gels, cylindrical samples (diameter $2 \mathrm{~cm}$ and height $2 \mathrm{~cm}$ ) were compressed between two flat plates using a Instron texture analyser 5564 (Instron, Norwood, MA, USA) with test speed of $5 \mathrm{~mm} / \mathrm{min}$. The Young's moduli for WPI $15 \%$ and $20 \%$ were $(18 \pm 6) \mathrm{kPa}$ and $(270 \pm 80) \mathrm{kPa}$ respectively (mean \pm standard deviation of four experiments), calculated from the slope of the stress-strain curve in linear region.

The simulated gastric fluid (SGF) for digestion experiments comprised of pepsin $\left(1 \mathrm{~g} \mathrm{~L}^{-1}\right)$, mucin $\left(1.5 \mathrm{~g} \mathrm{~L}^{-1}\right)$ and $\mathrm{NaCl}\left(8.775 \mathrm{~g} \mathrm{~L}^{-1}\right)$ and was adjusted to $\mathrm{pH} 2.0$, also as prepared previously (Q. Luo, Boom, and Janssen 2015).

\subsubsection{Pepsin labeling}

Ten milligrams of pepsin was dissolved in $1 \mathrm{~mL} 2$-(N-morpholino) ethanesulfonic acid buffer (MES buffer, $10 \mathrm{mmol} \mathrm{L}^{-1}, \mathrm{pH}$ 6.5). The fluorescent dye Alexa 633 was dissolved in dimethyl sulfoxide (DMSO) at $10 \mathrm{mg} \mathrm{mL}^{-1}$. A total amount of $100 \mu \mathrm{L}$ Alexa 633 solution was slowly added in small quantities to the pepsin solution while mixing vigorously. The mixture was incubated at room temperature for $1 \mathrm{~h}$. After incubation, the conjugate was purified by a $5 \mathrm{~mL}$ HiTrap ${ }^{\mathrm{TM}}$ desalting column packed with Sephadex ${ }^{\mathrm{TM}}$ G-25 Superfine medium (GE Healthcare Life Sciences, Little Chalfont, UK). The column was operated with a $2 \mathrm{~mL}$ syringe and the purification process was repeated twice. The purity was verified on an ÄKTA system (GE Healthcare Life Sciences) with dual-wavelength detector; it showed a single peak at the same elution volume at $621 \mathrm{~nm}$ and $280 \mathrm{~nm}$. The conjugate was finally preserved in buffer containing $20 \%$ glycerol at $-25^{\circ} \mathrm{C}$. The final concentration of pepsin was approximately $4 \mathrm{mg} \mathrm{mL}^{-1}$ due to the dilution 
from the purification step and glycerol.

\subsubsection{Fluorescence correlation spectroscopy}

Five $\mu \mathrm{L}$ of purified Pepsin-Alexa 633 conjugate (later referred to as PepA633) solution or EGFP was pipetted onto each well of an eightwell plate containing WPI gel. The samples were kept at $4{ }^{\circ} \mathrm{C}$ for approximately $20 \mathrm{~h}$ before measuring. This duration allowed adequate fluorescent molecules to migrate from the surface of the gel toward the glass bottom and be measured. FCS was performed on a Leica TCS SP5X system (Leica Microsystem, Wetzlar, Germany) equipped with a $63 \times 1.20$ NA water immersion objective and a supercontinuum white light laser, which emits a continuous spectrum from 470 to 670 nm. Alexa Fluor 633 was excited by selecting the $621 \mathrm{~nm}$ laser line at a pulsed frequency of $80 \mathrm{MHz}$. Fluorescence was recorded through a size-adjustable pinhole set at $90 \mu \mathrm{m}$, and filtered using a $630 \mathrm{~nm}$ $690 \mathrm{~nm}$ spectral filter. EGFP was excited at wavelength $488 \mathrm{~nm}$ at the same pulsed frequency. The pinhole was now $75 \mu \mathrm{m}$ and the spectral filter was set at $495 \mathrm{~nm}-525 \mathrm{~nm}$. Fluorescence was recorded via the internal hybrid detector, which was coupled to a PicoHarp 300 TCSPC module (PicoQuant GmbH, Berlin, Germany). For each sample, 30s measurements were repeated 10 times. All individual experiments were performed more than three times at $20^{\circ} \mathrm{C}$ and neutral $\mathrm{pH}$, due to the $\mathrm{pH}$ dependence of the fluorophores. The principles of FCS have been described previously (Lakowicz 2006; Nolles et al. 2015). Briefly, the obtained fluorescence intensity fluctuation from a confocal volume can be described by an autocorrelation function:

$$
G(t)=\frac{\langle I(t) \times I(t+\tau)\rangle}{\langle I\rangle^{2}}
$$

where $I(t)$ and $I(t+\tau)$ are the fluorescence intensities at timet and $t+\tau$; $I$ is the average fluorescence intensity. The fluctuations in intensity are caused by diffusion, and in some cases they are additionally caused by triplet dynamics of the fluorophore. The equation used to fit the translational diffusion data and includes triplet state is as follows: 


$$
\begin{aligned}
G(\tau)=1+\frac{1}{\langle N\rangle}(1+ & \left.\frac{F_{\text {trip }}}{1-F_{\text {trip }}} \cdot e^{-t / T_{\text {trip }}}\right) \\
& \cdot \sum_{i=1}^{n} \frac{F_{i}}{\left(1+\left(t / \tau_{\text {dif }, i}\right)\right) \cdot \sqrt{1+\left(\omega_{x y} / \omega_{z}^{2} \cdot\left(t / \tau_{\text {dif }, i}\right)\right.}}
\end{aligned}
$$

where $\langle\mathrm{N}\rangle$ is the average number of fluorescent particles $\mathrm{N}$ in the spot. The exponential term describes the triplet state behavior, in which Ftrip is the fraction of molecules in the triplet state and Ttrip (ms) is the average time a molecule resides in the triplet state. The last part of the equation describes the diffusion behavior of the molecules, where $\mathrm{n}$ is the number of species, $F_{i}$ is the fraction of species $\mathrm{i}, \tau_{d i f, i}$ (ms) is the diffusion time of species $i$ and $\omega x y(n m)$ and $\omega z(n m)$ are the equatorial and axial radii of the detection volume, respectively. The diffusion constant Di of species i correlates the observed diffusion time $\tau_{d i f, i}$, according to the following equation:

$$
D_{i}=\frac{\omega_{x y}^{2}}{4 \cdot \tau_{d i f, i}}
$$

The value of $\omega_{x y}$ can be obtained by calibration with a solution of a fluorophore with a known diffusion constant. Alexa $633(\mathrm{D}=$ $3.0 \times 10^{-10} \mathrm{~m}^{2} \mathrm{~s}^{-1}$ in water at $20^{\circ} \mathrm{C}$; data from PicoQuant) was used to calibrate the confocal volume of the setup for $621 \mathrm{~nm}$ excitation using a $90 \mathrm{~nm}$ pinhole; a diffusion time of $42 \mu$ s and a structural parameter $\left(\omega_{z} / \omega_{x y}\right)$ between 5 and 8 were obtained, resulting in a confocal volume of approximately $0.4 \mathrm{fL}$. Rhodamine $110\left(\mathrm{D}=4.3 \times 10^{-10} \mathrm{~m}^{2} \mathrm{~s}^{-1}\right.$ in water at $20^{\circ} \mathrm{C}$ ) was used to calibrate the confocal volume of the setup for $488 \mathrm{~nm}$ excitation using a $75 \mu \mathrm{m}$ pinhole; a diffusion time of $19 \mu$ s and a structural parameter between 6 and 8 were obtained, resulting in a confocal volume of approximately $0.2 \mathrm{fL}$.

FFS data processor version 2.3 (Scientific Software Technologies Software Centre, Minsk, Belarus) was used to fit the data to a diffusion model including triplet state. The parameter fitting was based on the 
Marquardt-Levenberg nonlinear method of least squares. The confidence intervals of the recovered parameters were calculated by the exhaustive search method. Those procedures were all performed within the software package, more details have been described by Skakun et al. Skakun, Digris, and Apanasovich (2014).

\subsubsection{Gel composition analysis by size-exclusion chromatography}

Digestion of WPI gels was performed inside the Teflon tubes (inner diameter $2 \mathrm{~cm}$, length $10 \mathrm{~cm}$ ) to impose one-dimensional diffusion (assuming the radial variations are negligible) and digestion: a small upper part of the prepared gel was removed and $2 \mathrm{~mL}$ SGF was added on top of the remaining gel. The gels were then digested in a $37^{\circ} \mathrm{C}$ water bath for $6 \mathrm{~h}$. Afterwards, the SGF was removed and pepsin in SGF was inactivated in a pre-heated Eppendorf Thermomixer Comfort (Eppendorf AG, Hamburg, Germany) at $90{ }^{\circ} \mathrm{C}$, shaking at 1400 $\mathrm{rpm}$ for $5 \mathrm{~min}$. The WPI gels were cut perpendicularly to the axis of the tube ( $2 \mathrm{~mm}$ thick slices). In some experiments, the slices were crushed and soaked overnight in water $(0.5 \mathrm{wt} \%$ dry matter of gel in water including pepstatin $\left(30 \mu \mathrm{mol} \mathrm{L}^{-1}\right)$ to inhibit pepsin activity) for analyzing the water-soluble content inside the gel; others were immediately frozen and lyophilized for analyzing the gel composition.

The lyophilized gel slices were ground with a mortar and dissolved overnight in a solvent consisting of $8 \mathrm{~mol} / \mathrm{L}$ urea and $0.03 \mathrm{~mol} / \mathrm{L}$ dithiothreitol (DTT) ( $0.5 \mathrm{wt} \%$ gel dry matter in solvent). The dissolved gels were then analyzed by size-exclusion chromatography with a combination of a TSKgel G2000SWxl and TSKgel G3000SWxl column (Tosoh Bioscience LLC, King of Prussia, PA, USA), using a method as described previously (Q. Luo, Boom, and Janssen 2015) except that the standard proteins were also dissolved in the same urea and DTT solution. The gel composition analysis was performed in duplicate. The water-soluble content was also analyzed using size-exclusion chromatography. 


\subsubsection{Scanning electron microscopy}

WPI gels were cut into $7 \mathrm{~mm} \times 5 \mathrm{~mm}$ diameter cylindrical samples and digested in SGF for $1 \mathrm{~h}$ in a static soaking system (Q. Luo, Boom, and Janssen 2015). The samples were fixated with $3 \%(\mathrm{v} / \mathrm{v})$ glutaraldehyde immediately for at least $2 \mathrm{~h}$ and subsequently rinsed with Milli-Q water $(3 \times 10 \mathrm{~min})$. The samples were then immersed in $40 \mathrm{mmol} \mathrm{L}^{-1}$ osmium tetroxide for $2 \mathrm{~h}-4 \mathrm{~h}$, rinsed with Milli-Q water $(3 \times 10 \mathrm{~min})$ and dehydrated in an ethanol-water gradient series (10\%, 30\%, 50\%, 70\%, $90 \%, 100 \%$ volume fraction for $15 \mathrm{~min}$ each). Afterward, the samples were dried in a critical point dryer (CPD 030, Bal-Tec AG, Balzers, Liechtenstein) with supercritical $\mathrm{CO}_{2}$. The dried samples were glued on stubs using conductive carbon glue and coated with $12 \mathrm{~nm}$ tungsten by a Leica EM MED020 sputter coater (Leica Microsystems, Wetzlar, Germany). The microstructures of samples were observed using a Magellan 400 field emission scanning electron microscope (FEI, Hillsboro, OR, USA) at room temperature with $2 \mathrm{kV}$ voltage.

\subsection{Results and discussion}

\subsubsection{Diffusivity of enhanced green fluorescent protein and pepsin}

The diffusion coefficients of fluorescently labeled pepsin as well as EGFP were determined using FCS. The autocorrelation curves obtained for EGFP in water and WPI gels are reported in Fig. 3.1A. The typical autocorrelation curves were fitted with a one-component model resulting in an optimal fit indicated by the straightness of the weighted residuals and low chi square values.

The autocorrelation curves for labeled pepsin in water and WPI gels are displayed in Fig. 3.1B. Data analysis [eq. (3.2)] revealed different species with distinct mobility. The pepsin conjugate (PepA633) curve in water (red circles) shows a two-component behavior $[\mathrm{n}=2 \mathrm{in}$ eq. (3.2)]. The faster component has similar diffusion time as free Alexa 

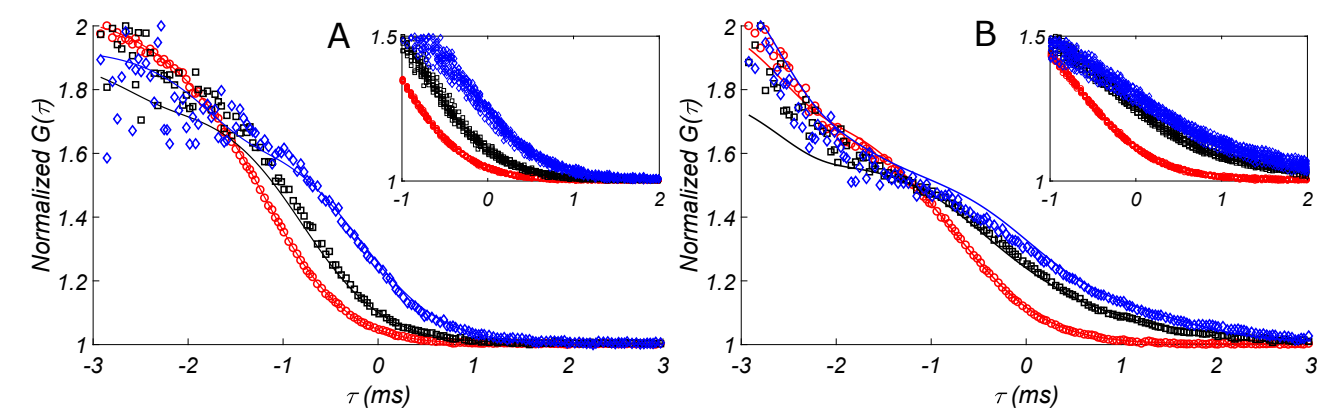

Figure 3.1: Examples of FCS autocorrelation curves. We show one measurement each for EGFP (A) and Pepsin (B) in water (red circle), in whey protein isolate (WPI) gel of $15 \mathrm{wt} \%$ (black square) and of $20 \mathrm{wt} \%$ (blue diamond). The corresponding lines are the fitted curves of diffusion models based on 10 measurements in one experiment. Those experiments of 10 measurements are shown in the insets.

633, which suggests the presence of free Alexa 633 molecules: we hypothesized that Pepsin-Alexa 633 conjugation is not completely stable and part of the Alexa 633 is released slowly from the conjugate over time, although the conjugate was quite pure after purification and was stored in $20 \%$ glycerol at $-25^{\circ} \mathrm{C}$. Therefore, we set the diffusion time of the faster component as equal to that of free Alexa 633 and regarded the other component as the PepA633 conjugate.

In contrast, the curves of the PepA633 conjugate in both types of the WPI gels have higher variance (see the black squares and blue diamonds in the inset of Fig. 3.1B) than those for EGFP in WPI gels and PepA633 in water. A three-component model was needed to describe the autocorrelation curve $[n=3$ in eq. (3.2)]. Among the three components yielded, the diffusion coefficient of the fastest component is in the range of free Alexa 633 with an amplitude of approximately $40 \%$. The amplitude of the second component is around $50 \%$, and its diffusion time was of the same order of magnitude as the diffusivity of PepA633 in water. The third component is around $10 \%$, with a diffusion time of $80 \mathrm{~ms}$ regardless of the percentage of WPI gel type. This diffusion time corresponds to an extremely small diffusion coefficient of $2 \times 10^{-13} \mathrm{~m}^{2} \mathrm{~s}^{-1}$. If we exclude the fraction of free Alexa 633, this 
slow diffusion represents $17 \%$ of the total amplitude.

The slowest mode of diffusion may have several causes:

1. The experiments were performed under neutral $\mathrm{pH}$, where PepA633, EGFP and the whey protein gel network are all negatively charged. Both electrostatic attraction and repulsion can hinder diffusion of charged particles (Stylianopoulos et al. 2010; Thorne et al. 2008). However, since EGFP did not show the slow diffusion mode, this cannot explain why the slow diffusion mode was found only with the labeled pepsin.

2. Aggregation of fluorescent conjugates may also cause a slower diffusion mode, but there was no evidence for slow diffusion mode of PepA633 in water. In addition, a diffusion coefficient that is $100 \mathrm{x}$ lower would require massive aggregates of 106 molecules (assuming Stokes-Einstein's equation to be valid inside the WPI matrix), which would have been visible during the experiments.

3. A bimodal pore size distribution could explain a fast and a slow diffusion mode; however, in this case, one would expect that it would be seen with both proteins, EFGP and the PepA633 conjugate.

4. In FCS studies, detecting extra species with slow diffusion could indicate probe-network interaction (Wöll 2013). The slow diffusion mode occurs only with the conjugate, and the most obvious difference between the two proteins is that pepsin naturally binds to proteins. Our hypothesis, therefore, is that the slow conjugate diffusion mode is related to the pepsin that forms a temporary complex with the WPI matrix. The fact that the fraction of conjugate in the slow mode is the same in both gels supports this hypothesis.

The diffusion coefficients are reported in Fig.3.2; we regard the second component as the PepA633 diffusing in WPI gels. The EGFP diffusion in water is $1.2 \times 10^{-10} \mathrm{~m}^{2} \mathrm{~s}^{-1}$, which is in agreement with other studies (Nolles et al., 2015). The diffusion coefficient of PepA633 in 


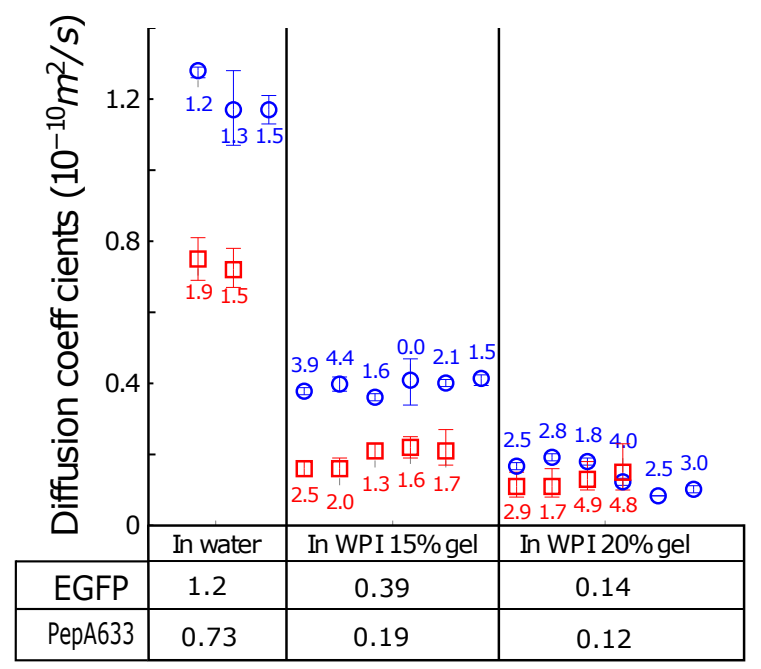

Figure 3.2: Diffusion coefficients of Enhanced Green Fluorescent Protein (EGFP, blue circle) and Pepsin-Alexa 633 conjugates (PepA633, red square) in water and in Whey Protein Isolate (WPI) gel $15 \mathrm{wt} \%$ and $20 \mathrm{wt} \%$. Each data point is calculated from the fitted parameter of 10 measurements in one experiments; the number next to it is the $\chi^{2}$ value from the nonlinear least square fitting process; error bars are its $95 \%$ confidence intervals. The values in the table below are the mean values of the correspondent repeated experiments. 
water is $7.3 \times 10^{-11} \mathrm{~m}^{2} \mathrm{~s}^{-1}$, which is slightly lower than the pepsin diffusion coefficient in water as reported previously $\left(8.7 \times 10^{-11} \mathrm{~m}^{2} \mathrm{~s}^{-1}\right.$; (Tyn and Gusek 1990)). The larger diffusion coefficient of EGFP in water compared with that of PepA633 may stem from its lower molecular mass and thus smaller hydrodynamic radius (Erickson (2009) demonstrated the correlation between molecular weight and hydrodynamic radius of proteins). In 15\% WPI gel, the diffusion coefficients of EGFP and PepA633 are both smaller than in water, while the EGFP diffusion remains faster than that of PepA633. In 20\% WPI gel, the differences between EGFP and PepA633 are negligible. The hindered diffusion of solute in hydrogels has been explained using various theories. For instance, the free volume theory suggested that hydrogels reduce free volume that allows solute to diffuse; the hydrodynamic theory proposed that hydrogels enhance the frictional drag on the solute (Amsden 1998). Thus, as shown in our experiments, protein gels with higher protein fraction have greater hindrance on the PepA633 and EGFP diffusion. The diffusion coefficients can be used to estimate the enzyme concentration gradient inside protein gels during digestion, using Fick' s second law [eq. 3.4] and its integration for onedimensional diffusion [eq. 3.5] (Walstra 2002):

$$
\begin{gathered}
\frac{\partial C}{\partial t}=D \frac{\partial^{2} C}{\partial x^{2}} \\
C=C_{0}\left(1-\frac{2}{\sqrt{\pi}} \int_{0}^{\frac{x}{2 \sqrt{D t}}} e^{-t^{2}} d t\right)
\end{gathered}
$$

where $C$ is the concentration dependent on the position (x) and time (t), $C_{0}$ is the constant concentration at the boundary; $\mathrm{D}$ is the diffusion coefficient. Fig. 3.3 shows the relative pepsin concentration $\left(C / C_{0}\right)$ along the diffusion distance $(\mathrm{x}=0 \mathrm{~mm}-2 \mathrm{~mm})$ in one dimension after a certain period of time ( $1 \mathrm{~h}$ or $6 \mathrm{~h}$ ), assuming that the bulk concentration of pepsin and diffusion coefficients are constant regardless of time and location. One can either only consider the fast mode of pepsin diffusion or include the slow mode diffusion that $17 \%$ of the pepsin 
exhibits, as indicated above. The dashed lines in Fig. 3.3 excluded the slow mode diffusion, and the solid lines included the slow mode diffusion.

Within $6 \mathrm{~h}$, which is in the range of gastric emptying time of solid meals (Bornhorst, Chang, Rutherfurd, Moughan, and R. Singh 2013; Collins et al. 1991), the pepsin concentration reaches a significant level only in the first $2 \mathrm{~mm}$ of the gels. Thus, the enzymatic hydrolysis of gel matrix is constrained within a thin layer. This may cause the limited digestion of protein gel structure compared with protein in solution that was found earlier (Q. Luo, Boom, and Janssen 2015). However, the differences in the pepsin concentration between $15 \%$ and $20 \% \mathrm{WPI}$ gels are much smaller than the differences in the degrees of hydrolysis obtained in our previous research, where WPI 15\% gel underwent a much higher degree of hydrolysis than WPI 20\% gel during simulated gastric digestion (Q. Luo, Boom, and Janssen 2015). Therefore, the diffusional constraint might not be the only explanation for the hindered digestion of protein in gel matrices. The FCS experiments were performed at neutral $\mathrm{pH}$, where pepsin has little activity; while in realistic digestion, one should consider that the action of pepsin may change the gel structure and consequently change the pepsin diffusivity.

\subsubsection{Gel composition analysis by size-exclusion chromatogra- phy}

To validate and explore the effect of pepsin diffusion in protein gel digestion, we dissolved the gel slices with urea and DTT after digestion, and analyzed the gel composition using size-exclusion chromatography. The resulting chromatograms for WPI gels of $15 \mathrm{wt} \%$ and 20 $w t \%$ are shown in Fig. 3.4. The compositions of the second and onward slices were identical to that of undigested gels for both gels (only the second slices were shown), while the first slice was distinctively different. This shows that indeed the pepsin did not affect the second slices. The chromatogram of the first slice of the WPI gel showed several peaks after 10 min of retention time, which indicates the pres- 

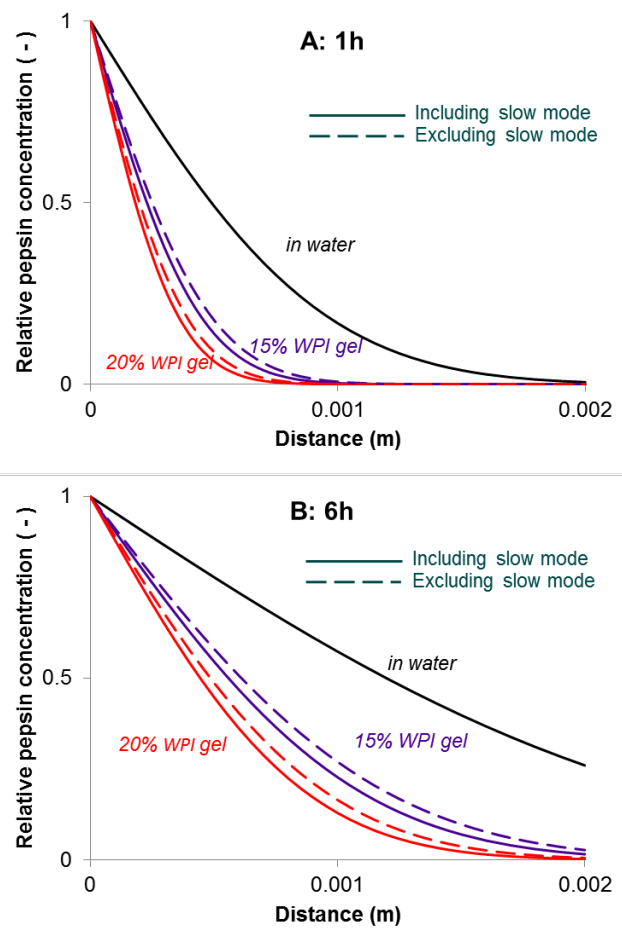

Figure 3.3: Size-exclusion chromatograms of composition analysis of whey protein isolate gels $15 \mathrm{wt} \%$ (A) and $20 \mathrm{wt} \%$ (B) after $6 \mathrm{~h}$ digestion and the correspondent simulated gastric fluid (SGF). Each gel slice has a thickness of $2 \mathrm{~mm}$.
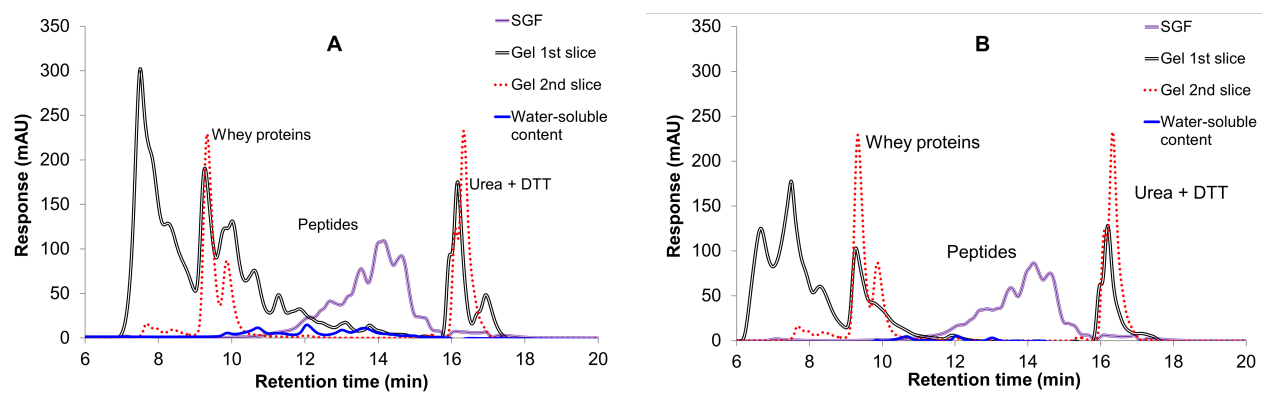

Figure 3.4: Size-exclusion chromatograms of composition analysis of whey protein isolate gels $15 \mathrm{wt} \%$ (A) and $20 \mathrm{wt} \%$ (B) after $6 \mathrm{~h}$ digestion and the correspondent simulated gastric fluid (SGF). Each gel slice has a thickness of $2 \mathrm{~mm}$. 
ence of hydrolytic products. Therefore, hydrolysis had occurred in and only within the first $2 \mathrm{~mm}$ of the gel, which is in accordance with the estimation based on enzyme diffusion. Moreover, the hydrolysis fragments in the first gel slice were larger than the small peptides in the SGF, based on their distributions in retention time. The 20\% WPI gel (Fig. 3.4B) showed the same trend as the 15\% WPI gel, but with lower amounts of peptides in the gel slice and in the SGF.

We hypothesized previously that the different peptide distributions obtained during the digestion of a whey protein solution and of a gel (Q. Luo, Boom, and Janssen 2015) may be caused for two reasons: the hydrolysis fragments may either be still attached to the WPI network, or they may be constrained in their egression. The water-soluble content inside the WPI gels' first slices showed similar amount of small peptides (retention time $>12 \mathrm{~min}$ ) but a lower amount of larger peptides (retention time $<12 \mathrm{~min}$ ), compared with that of the dissolved first slices of gels (Fig. 3.4). Therefore, those larger peptides may be still attached to the WPI gel network and can only be dissolved with urea and DTT, which supports the first hypothesis.

Large peaks at 7.5 min retention time were observed in the first slices that were digested either with SGF or with $\mathrm{pH} 2$ acidic water (data not shown). We presume that is the stable self-assembly of whey protein formed under acidic condition, since it has been reported previously that $\beta$-lactoglobulin at $\mathrm{pH} 2$ can form irreversible fibrillar protein aggregates (Akkermans et al. 2008).

\subsubsection{Microstructure of WPI gels}

Scanning electron microscopy was employed to observe the effect of pepsin diffusion on the microstructure of WPI gels. The surfaces of original WPI $15 \mathrm{wt} \%$ and $20 \mathrm{wt} \%$ gels, shown in Fig. 3.5, are finestranded gels with rather homogeneous microstructure and a fine network. The network of the $20 \mathrm{wt} \%$ gel has smaller pore size than the $15 \%$ gel network, in agreement with the lower diffusion rates of both EGFP and PepA633 in the $20 \%$ gel. We found that the diffusivity of 


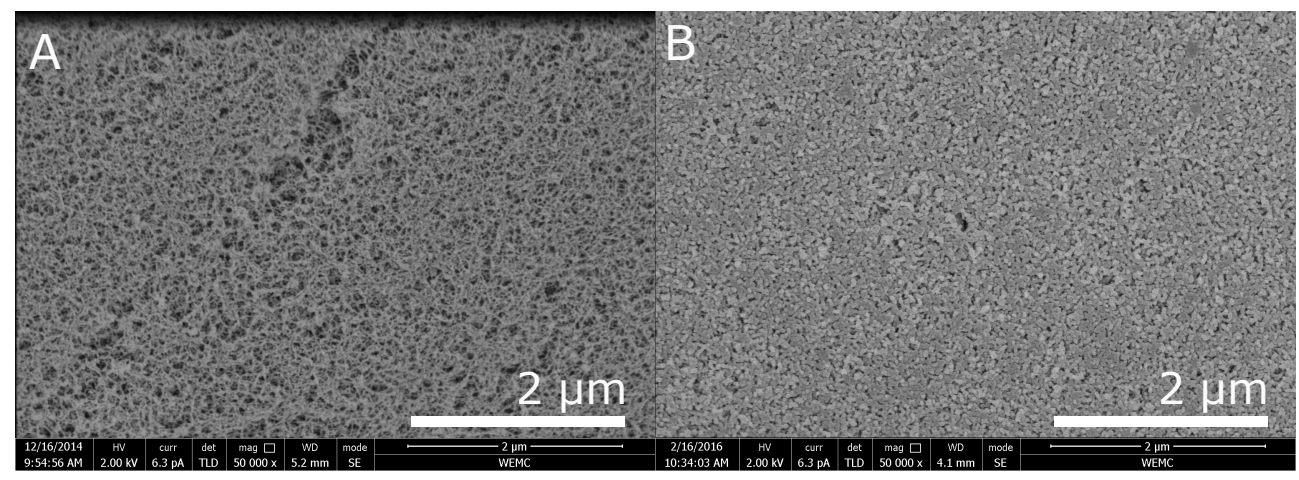

Figure 3.5: Scanning electron micrograph of the original surface of whey protein isolate gels $15 \mathrm{wt} \%$ (A) and $20 \mathrm{wt} \%$ (B).

PepA633 was reduced by about $70 \%$ in $15 \mathrm{wt} \%$ gel and $80 \%$ in 20 wt $\%$ gel compared with its diffusivity in water (Fig. 3.2). Colsenet et al. (2006a) reported on the diffusivity of poly(ethylene glycol)s in whey protein gels; they found a reduction of $70 \%$ for the $82 \mathrm{kDa}$ poly(ethylene glycol) in a $19.35 \mathrm{wt} \% \mathrm{WPI}$ gel (heated at $70^{\circ} \mathrm{C}$ for 30 min, $\mathrm{NaCl} 0.1 \mathrm{mmol} \mathrm{L}^{-1}$ ) compared with $D_{0}$ in water, which is in the same order of magnitude for both EGFP and pepsin in $20 \mathrm{wt} \% \mathrm{WPI}$ gel. This small discrepancy in diffusivity reduction may stem from the different gel microstructures caused by the differences in heat treatment and ionic strength: a higher ionic strength during gel formation leads to a particulate gel structure and a larger pore sizes (Doi 1993). Moreover, poly(ethylene glycol)s are linear, flexible molecules that can adjust their shape according to the network (Petit, Zhu, and Macdonald 1996), while EGFP and PepA633, which are globular, rigid and charged proteins, thus behave different than poly(ethylene gly$\mathrm{col}) \mathrm{s}$.

After 1 h of digestion, both the 15\% and 20\% WPI gel surfaces changed compared with native samples and some heterogeneity appeared (Fig. 3.6): some areas appeared to be smoother than others; the smooth areas remained rather homogeneous, while the structure became more open than the original microstructure. We suppose that the pepsin hydrolysis weakens the gel microstructure. The rougher areas resemble 'fragments' with more random formation, which may be ag- 


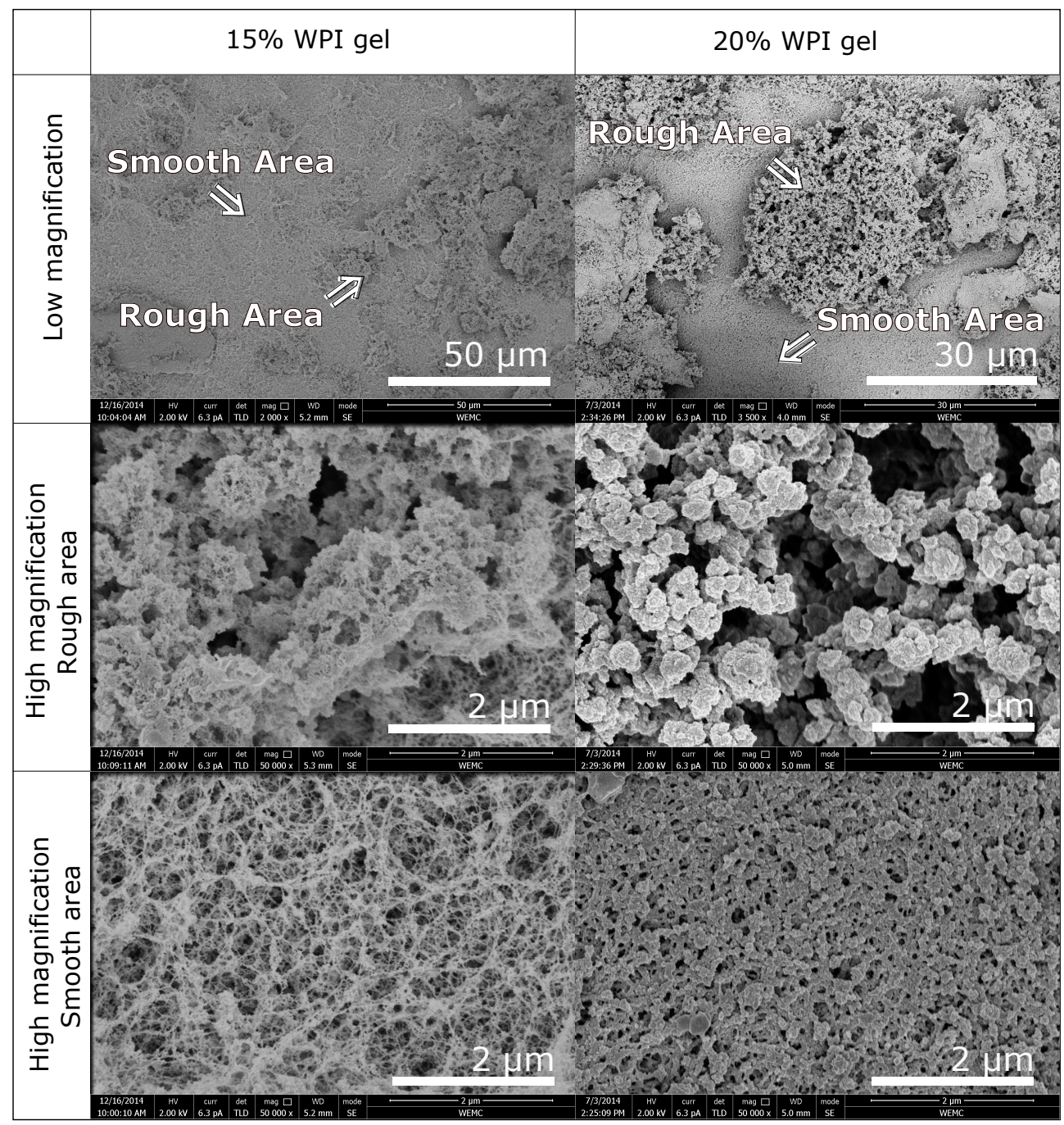

Figure 3.6: Scanning electron micrograph of whey protein isolate (WPI) gel (15 wt $\%$ and $20 \mathrm{wt} \%$ ) surface after $1 \mathrm{~h}$ static soaking in simulated gastric fluid. Low magnification images show the overview and high magnification images show the details of rough area and smooth area. 
gregates induced by hydrolysis and the acidity. We remind the reader that stable aggregates were also observed in the size-exclusion chromatograms (Fig. 3.4).

The loosened microstructure in the smooth area may lead to faster pepsin diffusion.. Thus, the pepsin concentration in realistic gastric digestion may be slightly higher than our estimation in Chapter Section 3.1 where we assumed the diffusion coefficients are constant regardless of time and location. Regarding the different digestion between $15 \%$ and $20 \%$ WPI gels, the diffusional constraint might not be the only hindrance; with the microstructure observation we hypothesize that the different rate of structure loosening may be another cause. The summed effect of different diffusion limitations, hydrolysis rates and differences in microstructure and mechanical strength may have caused the difference in disintegration and digestion of two WPI gels.

\subsection{Conclusion}

We measured the diffusivity of pepsin in whey protein gels by FCS and found significantly slower pepsin diffusion in $15 \mathrm{wt} \%$ and $20 \mathrm{wt} \% \mathrm{WPI}$ gels compared with pepsin diffusion in water, due to steric hindrance in the gel microstructure. The diffusivity of EGFP in the respective protein gels was similar to that of pepsin, but did not show a characteristic slow diffusion mode that was observed for pepsin. This slow mode, for about $17 \%$ of the pepsin, is thought to be the pepsin that is temporarily bound to the WPI protein matrix.

Pepsin hydrolysis in the gel matrix is constrained to a thin layer at the surface for timescales that are similar to human gastric digestion. Since pepsin has limited penetration depth, digestion processes are constrained largely to the surface area of the gel particles and on the surface erosion rate.

Analysis of hydrolysis products inside the gels and in SGF indicated that also the reaction products cannot diffuse freely out of the gel but 
are significantly retained inside the gel structure.

By combining diffusivity study, gel composition analysis and microstructure observation, we can conclude that the mode of WPI gel digestion is determined by the summed effect of diffusion limitation, hydrolysis rate and microstructure transformation. This summed effect could also have caused the distinctive digestion rate between WPI $15 \mathrm{wt} \%$ and $20 \mathrm{wt} \%$ gels.

We demonstrated the digestion process of WPI gels from a mechanistic view at the microscale level. This knowledge may be used further to predict the digestion of solid food in general, from protein-based food to more complex food structures.

\section{References}

Akkermans, C., A. J. van der Goot, P. Venema, E. van der Linden, and R. M. Boom (Oct. 2008). "Formation of Fibrillar Whey Protein Aggregates: Influence of Heat and Shear Treatment, and Resulting Rheology." In: Food Hydrocolloids 22.7, pp. 1315-1325. Dor: 10. 1016/ j . foodhyd.2007.07.001.

Amsden, B. (Nov. 1, 1998). "Solute Diffusion within Hydrogels. Mechanisms and Models." In: Macromolecules 31.23, pp. 8382-8395. Dor: 10.1021/ma980765f.

Bornhorst, G. M., L. Q. Chang, S. M. Rutherfurd, P. J. Moughan, and R. Singh (Mar. 2013). "Gastric Emptying Rate and Chyme Characteristics for Cooked Brown and White Rice Meals in Vivo." In: Journal of the Science of Food and Agriculture. DoI: 10.1002/ jsfa. 6160.

Bornhorst, G. M. and R. P. Singh (Feb. 28, 2014). "Gastric Digestion In Vivo and In Vitro: How the Structural Aspects of Food Influence the Digestion Process." In: Annual Review of Food Science and Technology 5.1, pp. 111-132. DoI: 10.1146/annurev-food-030713-092346.

Collins, P. J., L. A. Houghton, N. W. Read, M. Horowitz, B. E. Chatterton, R. Heddle, and J. Dent (Jan. 6, 1991). "Role of the Proximal and 
Distal Stomach in Mixed Solid and Liquid Meal Emptying." In: Gut 32.6, pp. 615-619. DoI: 10.1136/gut.32.6.615.

Colsenet, R., O. Söderman, and F. Mariette (2006a). "Effect of Casein Concentration in Suspensions and Gels on Poly (Ethylene Glycol) s NMR Self-Diffusion Measurements." In: Macromolecules 38, pp. 9171-9179.

Colsenet, R., O. Söderman, and F. Mariette (Feb. 1, 2006b). "Pulsed Field Gradient NMR Study of Poly(Ethylene Glycol) Diffusion in Whey Protein Solutions and Gels." In: Macromolecules 39.3, pp. 1053-1059. Dor: 10.1021/ma0519922.

Croguennoc, P., T. Nicolai, M. E. Kuil, and J. G. Hollander (June 1, 2001). "Self-Diffusion of Native Proteins and Dextran in HeatSet Globular Protein Gels." In: The Journal of Physical Chemistry B 105.24, pp. 5782-5788. Dor: 10.1021/ jp0043726.

Doi, E. (Jan. 1993). “Gels and Gelling of Globular Proteins.” In: Trends in Food Science E Technology 4.1, pp. 1-5. Dor: 10 . 1016 / S0924 2244 ( 05 ) 80003-2.

Erickson, H. P. (May 15, 2009). "Size and Shape of Protein Molecules at the Nanometer Level Determined by Sedimentation, Gel Filtration, and Electron Microscopy." In: Biological Procedures Online 11, pp. 32-51. Dor: 10. 1007/s 12575-009-9008-x. pmid: 19495910.

Fersht, A. (1985). "Structures and Mechanisms of Selected Enzymes." In: Enzyme Structure and Mechanism. 2nd. New York: W. H. Freeman \& Co, pp. 389-452.

Guo, Q., A. Ye, M. Lad, M. Ferrua, D. Dalgleish, and H. Singh (Jan. 6, 2015). "Disintegration Kinetics of Food Gels during Gastric Digestion and Its Role on Gastric Emptying: An in Vitro Analysis." In: Food E Function 6, pp. 756-764. Dor: 10.1039/C4F000700J.

Inouye, K. and J. S. Fruton (1967). "Studies on the Specificity of Pepsin*." In: Biochemistry 6.6, pp. 1765-1777.

Kwaaitaal, M., M. Schor, M. A. Hink, A. J. Visser, and S. C. de Vries (Jan. 1, 2011). "Fluorescence Correlation Spectroscopy and Fluorescence Recovery After Photobleaching to Study Receptor Kinase Mobility In Planta." In: Plant Kinases. Ed. by N. Dissmeyer and A. 
Schnittger. Methods in Molecular Biology 779. New York: Humana Press, pp. 225-242. DoI: 10 .1007/978-1-61779-264-9_13.

Lakowicz, J. R. (2006). "Fluorescence Correlation Spectroscopy." In: Principles of Fluorescence Spectroscopy. New York: Springer US, pp. 797-840.

Luo, Q., R. M. Boom, and A. E. M. Janssen (Sept. 2015). "Digestion of Protein and Protein Gels in Simulated Gastric Environment." In: LWT - Food Science and Technology 63.1, pp. 161-168. DoI: 10.1016/ j. Iwt.2015.03.087.

Nolles, A., A. H. Westphal, J. A. de Hoop, R. G. Fokkink, J. M. Kleijn, W. J. H. van Berkel, and J. W. Borst (May 11, 2015). "Encapsulation of GFP in Complex Coacervate Core Micelles." In: Biomacromolecules 16.5, pp. 1542-1549. DoI: 10. 1021/acs . biomac. 5b00092.

Nyemb-Diop, K., D. Causeur, J. Jardin, V. Briard-Bion, C. GuérinDubiard, S. M. Rutherfurd, D. Dupont, and F. Nau (2016). "Investigating the Impact of Egg White Gel Structure on Peptide Kinetics Profile during in Vitro Digestion." In: Food Research International 88, pp. 302-309. DoI: 10.1016/ j . foodres.2016.01.004.

Petit, J.-M., X. X. Zhu, and P. M. Macdonald (Jan. 1996). "Solute Probe Diffusion in Aqueous Solutions of Poly(Vinyl Alcohol) As Studied by Pulsed-Gradient Spin-Echo NMR Spectroscopy." In: Macromolecules 29.1, pp. 70-76. DoI: $10.1021 /$ ma9510597.

Piper, D. and B. H. Fenton (1965). "pH Stability and Activity Curves of Pepsin with Special Reference to Their Clinical Importance." In: Gut 6.5, pp. 506-508.

Royant, A. and M. Noirclerc-Savoye (May 2011). "Stabilizing Role of Glutamic Acid 222 in the Structure of Enhanced Green Fluorescent Protein." In: Journal of Structural Biology 174.2, pp. 385-390. Dor: 10.1016/ j . jsb.2011.02.004.

Singh, H., A. Ye, and M. J. Ferrua (June 2015). "Aspects of Food Structures in the Digestive Tract." In: Current Opinion in Food Science. Sensory Sciences and Consumer Perception • Food Physics and Material Science 3, pp. 85-93. Dor: 10.1016/ j . cofs.2015.06.007.

Skakun, V., A. Digris, and V. Apanasovich (Jan. 1, 2014). "Global Analysis of Autocorrelation Functions and Photon Counting Distri- 
butions in Fluorescence Fluctuation Spectroscopy." In: Fluorescence Spectroscopy and Microscopy. Ed. by Y. Engelborghs and A. J. W. G. Visser. Methods in Molecular Biology 1076. New York: Humana Press, pp. 719-741.

Stylianopoulos, T., M.-Z. Poh, N. Insin, M. G. Bawendi, D. Fukumura, L. L. Munn, and R. K. Jain (Sept. 8, 2010). “Diffusion of Particles in the Extracellular Matrix: The Effect of Repulsive Electrostatic Interactions." In: Biophysical Journal 99.5, pp. 1342-1349. Dor: 10.1016 / j .bp j .2010.06.016.

Thorne, R. G., A. Lakkaraju, E. Rodriguez-Boulan, and C. Nicholson (June 17, 2008). "In Vivo Diffusion of Lactoferrin in Brain Extracellular Space Is Regulated by Interactions with Heparan Sulfate." In: Proceedings of the National Academy of Sciences 105.24, pp. 84168421. Dor: $10.1073 /$ pnas.0711345105. pmid: 18541909.

Tyn, M. T. and T. W. Gusek (1990). "Prediction of Diffusion Coefficients of Proteins." In: Biotechnology and Bioengineering 35.4, pp. 327-338. DoI: 10.1002/bit. 260350402.

Videcoq, P., K. Steenkeste, E. Bonnin, and C. Garnier (May 1, 2013). "A Multi-Scale Study of Enzyme Diffusion in Macromolecular Solutions and Physical Gels of Pectin Polysaccharides." In: Soft Matter 9.20, pp. 5110-5118. Dor: 10.1039/C3SM00058C.

Walstra, P. (Oct. 8, 2002). Physical Chemistry of Foods. Boca Raton, Florida: CRC Press. 749 pp.

Whitney, E. N., C. B. Cataldo, and R. R. Sharon (1998). Understanding Normal and Clinical Nutrition. 5th ed. Wadsworth Publishing Company, Inc.

Wöll, D. (Dec. 3, 2013). "Fluorescence Correlation Spectroscopy in Polymer Science.” In: RSC Advances 4.5, pp. 2447-2465. DoI: 10 . 1039/C3RA44909B. 


\section{Chapter 4}

\section{Analysis and modeling of enhanced green fluorescent protein diffusivity in whey protein gels}

This chapter is based on:

Q. Luo, E. Sewalt, J. W. Borst, A. H. Westphal, R. M. Boom, A. E.M. Janssen. "Analysis and modeling of enhanced green fluorescent protein diffusivity in whey protein gels." Submitted for publication. 


\section{Abstract}

During gastric digestion, hydrolysis of proteins by pepsin contributes largely to the breakdown of protein-rich food. The effect of pepsin is limited by its diffusivity, which is co-determined by the structure of the food that is digested. We used enhanced green fluorescent protein (EGFP) as probe to study the diffusivity of pepsin in whey protein isolate gels, by fluorescence correlation spectroscopy (FCS). Two gels made with different ionic strength showed elastic moduli but do not show differences in protein diffusivity. Some models for diffusion in hydrogels yield good description, and offer the possibility to predict enzyme diffusion in diverse food matrices. However, to yield more accurate predictions, electrostatic and enzyme-substrate interaction also need to be considered. 


\subsection{Introduction}

The digestion kinetics of food are dependent on the structure of the food that is digested. Food structure influences the oral processing, the gastric disintegration rate, and the consequent gastric emptying towards the duodenum (H. Singh, A. Ye, and M. J. Ferrua 2015). Hydrolysis of proteins by pepsin contributes largely to the breakdown of protein-rich food in the stomach. The hydrolysis by pepsin is limited by diffusion into the solid food matrix. The hydrolysis kinetics of egg white protein gels and whey protein gels differed strongly from that of the same proteins in solution, which is likely due to the diffusion limitation in gels for both the pepsin and the hydrolysates (Q. Luo, Boom, and Janssen 2015). Compared to acid-induced dairy gels, a rennetinduced casein gel consists of compact protein aggregates in the acidic gastric environment, and the rennet gel had much slower proteolysis kinetics than that of acid induced gels (Floury et al. 2018). Thus, a quantitative investigation of pepsin diffusion in food structures may contribute to the understanding of food breakdown and digestion kinetics.

We previously measured the diffusivity of pepsin in whey protein isolate (WPI) gels by fluorescence correlation spectroscopy (FCS). We found that the pepsin does not penetrate deep into the gel but remains in a thin layer below the surface of the gel. A second finding was that the diffusivity of pepsin depends strongly on the concentration of the protein gels (Q. Luo, Borst, et al. 2017). Fluorescence Correlation Spectroscopy (FCS) was used for its non-invasiveness and suitability to be used within protein gels. In FCS, a confocal laser microscope is coupled with a photon detector to measure fluorescence intensity fluctuations in a small focal volume. If these fluctuations originate primarily from the diffusion of the fluorophores through the focal volume, autocorrelation analysis can quantify the diffusion rate of the fluorophore.

Whey protein gels were used before as model for protein-based solid foods (Q. Luo, Borst, et al. 2017). Whey protein gelation is generally 
a two-step process. After heat denaturation, protein oligomers form primary aggregates with different shapes and sizes depending on the $\mathrm{pH}$ and the salt concentration. These primary aggregates then form large self-similar aggregates that precipitate or gel above a critical concentration (Aymard et al. 1996; Nicolai, Britten, and Schmitt 2011).At neutral $\mathrm{pH}$, the primary aggregates consist of short, curved strands with a length of about $50 \mathrm{~nm}$ and a diameter of about $10 \mathrm{~nm}$, independent from ionic strength. At low ionic strength, the large aggregates mainly form via head-to-tail association of the primary aggregates, while at higher ionic strengths the structure is more densely branched (Nicolai, Britten, and Schmitt 2011; Pouzot et al. 2005).

We here aim to find an appropriate model to describe diffusion in protein gel matrices, for predicting pepsin diffusion in food during gastric digestion. We also explore the correlation between a macroscopic parameter such as the elastic modulus and the diffusivity of a protein in the gel. Two types of whey protein gel matrices were constructed by altering the ionic strength but the same protein concentration, so that we can compare the diffusion in the gels at the same volume fraction but at different gel strengths. Enhanced Green Fluorescent Protein (EGFP) was used as the pepsin analogue since it has a similar size (EGFP MW $=26.9 \mathrm{kDa}$, pepsin $\mathrm{MW}=34.6 \mathrm{kDa}$ ) and similar diffusivity to pepsin (Q. Luo, Borst, et al. 2017). EGFP is auto-fluorescent, thus it can avoid the interference of a free dye that could be released through conjugate dissociation. Quantification of enzyme diffusion in food products will not only improve the understanding of digestion, but may also elucidate the bioaccessibility of proteins and other nutrients. Moreover, the activity of pepsin inside a protein gel network can change the structure of the network which may lead to a change of diffusivity (Q. Luo, Borst, et al. 2017). Models that account for such a change of structure during diffusion can offer better description. 


\subsection{Theory}

Many models for solute diffusion in hydrogels are based on the hydrodynamic theory or the obstruction theory (Amsden 1998; Masaro and Zhu 1999). The hydrodynamic theory is based on the Stokes-Einstein equation for solute diffusivity. The solute is assumed to be a hard sphere which moves with constant velocity through a continuous solvent, experiencing friction. Polymer chains present in the medium reduce the local velocity of the fluid, and hence increase the friction of a solute with its surroundings. In the obstruction theory, which is connected to the free volume theory the polymer chain network obstructs specific sites that were otherwise available for the solute, and therefore reduces the available paths for diffusion. The chains themselves are considered immobile and impenetrable for the solute. The models have been thoroughly discussed in the two reviews of Amsden (1998) and of Masaro and Zhu (1999). We selected some models based on their feasibility for our system of interest. One of the models is based on the hydrodynamic theory, some models on the obstruction theory and some models combine the theories. These models are briefly discussed hereafter, the meaning of each symbol is listed in Table 4.1.

Cukier' s model (1984) is based on the hydrodynamic theory, and that assumes the friction of the solute with the medium is the main cause of reduced diffusion rate:

$$
\frac{D}{D_{0}}=\exp \left(-k_{c} r_{s} \phi^{v}\right)
$$

Ogston's model, based on obstruction-scaling theory, assumed solute diffusion is a succession of directionally random unit steps (Ogston, Preston, and Wells 1973). The polymers are considered to be long, straight fibers of small width, while the solute is considered as a hard sphere. The unit step was defined as the root-mean-square average diameter of the spherical solute molecules within the fiber network. 
Table 4.1: List of symbols

\begin{tabular}{|c|c|}
\hline Symbol & Description \\
\hline $\mathrm{D}$ & Diffusion coefficient \\
\hline $\mathrm{D}_{0}$ & Diffusion coefficient at infinite dilution \\
\hline$r_{s}$ & $\begin{array}{l}\text { Radius of the solute, calculated using the Stokes- } \\
\text { Einstein equation: } r_{s}=\frac{k_{B} T}{6 \pi \eta D} \text {. Where } k_{B} \text { is the Boltz- } \\
\text { mann' s constant, } T \text { is temperature and } \eta \text { is the water } \\
\text { viscosity. }\end{array}$ \\
\hline$r_{f}$ & Radius of the polymer fibre \\
\hline$\varphi$ & Polymer volume fraction \\
\hline$\alpha$ & $\alpha=\phi\left(\frac{r_{s}+r_{f}}{r_{f}}\right)^{2}$ \\
\hline $\mathrm{k}_{\mathrm{c}}$ & $\begin{array}{l}\text { interaction parameter for a given polymer-solvent sys- } \\
\text { tem }\end{array}$ \\
\hline $\mathrm{v}$ & screening parameter \\
\hline $\mathrm{k}_{1}$ & $\begin{array}{l}\text { constant for a given polymer-solvent system, depen- } \\
\text { dent on the length of a monomer unit and the stiffness } \\
\text { of the polymer chain }\end{array}$ \\
\hline $\mathrm{k}$ & $\begin{array}{l}\text { Hydraulic permeability, estimated using a correlation } \\
\text { derived by Jackson and James (1986): } k=0.31 r_{f}^{2} \phi^{-1.17}\end{array}$ \\
\hline f & $f=\left(1+r_{s} / r_{f}\right)^{2} \phi$ \\
\hline$\lambda$ & $\lambda=r_{f} / r_{s}$ \\
\hline $\mathrm{a}$ & $a=3.727-2.460 \lambda+0.822 \lambda^{2}$ \\
\hline $\mathrm{b}$ & $b=0.358+0.366 \lambda-0.0939 \lambda^{2}$ \\
\hline
\end{tabular}




$$
\frac{D}{D_{0}}=\exp \left[-\frac{r_{s}+r_{f}}{r_{f}} \sqrt{\phi}\right]
$$

Johansson' s model, also based on obstruction-scaling theory, views the gel as a collection of cylindrical cells of a given radius (Johansson and Elvingson 1991). Each cell contains an infinitely long polymer rod and is filled with solvent.

$$
\frac{D}{D_{0}}=\exp \left[-0.84 \alpha^{1.09}\right]
$$

Tsai and Strieder' s obstruction-scaling model (Tsai and Strieder 1985) assumed a random network of overlapping fibres:

$$
\frac{D}{D_{0}}=\left(1+\frac{2}{3} \alpha\right)^{-1}
$$

E. M. Johnson et al. (1996) combined the obstruction model of Johansson with the hydrodynamic term of R. J. Phillips, Deen, and Brady (1989). The model includes the hydraulic permeability of the medium, which is considered to be a network of straight, rigid fibers with random, three-dimensional orientation.

$$
\frac{D}{D_{0}}=\frac{\exp \left(-0.84 \alpha^{1.09}\right)}{1+\left(\frac{r_{s}^{2}}{k}\right)^{1 / 2}+\frac{1}{3} \frac{r_{s}^{2}}{k}}
$$

Clague and R. J. Phillips (1996) combined Tsai and Strieder's obstruction model (Eq. 4.4) with a hydrodynamic term. The hydrodynamic effects are calculated by taking the solute as a sphere made up of point singularities, and the polymer fibers are accounted for using a numerical version of the slender-body theory.

$$
\frac{D}{D_{0}}=\left(1+\frac{2}{3} \alpha\right)^{-1} \exp \left(-\pi \phi^{0.174 \ln \left(59.6 \frac{r_{f}}{r_{s}}\right)}\right)
$$


Later, Phillips also combined Johansson's obstruction model (Eq. 4.3) with the hydrodynamic term of Clague and Phillips (Eq. 4.6), resulting in a model suitable for hindered diffusion of proteins and micelles in hydrogels (R. J. Phillips 2000):

$$
\frac{D}{D_{0}}=e^{-0.84 f^{1.09}} e^{-a \phi^{b}}
$$

These diffusion models are based on specific theories, while protein gels have more complex structure than the polymer gels. Therefore, a screening of these models is required to find out the suitable models for describing the enzyme diffusion in protein gels. Models that have better prediction could suggest the suitable theory for protein diffusion inside a protein network.

\subsection{Material and methods}

\subsubsection{Materials}

Whey Protein Isolate (WPI) (Bipro, lot no. JE 034-7-440-6) was purchased from Davisco Food International, Inc. (Le Sueur, USA). This batch of WPI was reported to have a protein content of $97.9 \mathrm{~g} / 100 \mathrm{~g}$ dry solid. Milli-Q water (resistivity $18.2 \mathrm{M} \Omega \mathrm{cm}$ at $25^{\circ} \mathrm{C}$, Merck Millipore, Billerica, USA) was used in all experiments. All other chemicals used were purchased from Sigma Aldrich (St. Louis, USA).

Enhanced green fluorescent protein (EGFP) was produced in-house at Wageningen University \& Research, following the method described by Nolles et al. (2015). 


\subsubsection{Methods}

\section{Gel preparation}

Whey protein isolate was dissolved in water or in $0.05 \mathrm{~mol} / \mathrm{L}$ sodium chloride solution, the gels made from these solutions are denoted as 'WPI gels' and 'WPI-NaCl gels' respectively. The protein weight fractions of the solutions are shown in Table 4.2, the volume fraction was calculated based on the voluminosity of heat-induced whey protein aggregates $\left(2.3 \mathrm{~mL} \mathrm{~g}^{-1}\right.$, Grácia-Juliá et al. (2008), the minimum concentration was chosen based on their critical gelation concentration based on preliminary experiments and literature (Ako et al. 2009). The solutions were stirred at room temperature for at least $2 \mathrm{~h}$. Afterward, they were centrifuged at $1000 \mathrm{rpm}(\sim 200 \mathrm{~g}$ relative centrifugal force) for $10 \mathrm{~min}$ to remove any large aggregates and air bubbles. Then they were degassed using $17.50 \mu \mathrm{m}$ ultrasonic displacement for $3 \mathrm{~min}$, followed by another centrifugation step (1000 rpm, $10 \mathrm{~min})$. The $\mathrm{pH}$ of the WPI solutions was measured to be $\mathrm{pH} 7$.

For fluorescence correlation spectroscopy (FCS) the gels were prepared by pipetting $200 \mu \mathrm{L}$ of protein solution into each well of a $\mu$-Slide 8 well chambered glass slide (ibidi, Martinsried, Germany). The system was sealed and heated for 30 minutes $90^{\circ} \mathrm{C}$ in a hot-air oven. The system was cooled to room temperature and stored at $4{ }^{\circ} \mathrm{C}$. The thickness of the gel layer was 1-2 mm. FCS measurements were performed within 2-3 days.

For texture analysis, the gels were prepared by pouring the protein solution into Teflon tubes of $2 \mathrm{~cm}$ diameter. The Teflon tubes were then heated at $90{ }^{\circ} \mathrm{C}$ in a water bath while rotating at $30 \mathrm{rpm}$ for 30 minutes. Afterward, the tubes were immediately cooled in ice water and stored at $4{ }^{\circ} \mathrm{C}$. Texture analysis was performed within 2-4 days. All measurements were performed at $20^{\circ} \mathrm{C}$. 
Table 4.2: The weight and volume fraction of WPI gels and WPI-NaCl gels used. WPI-NaCl gels were prepared with $0.05 \mathrm{M} \mathrm{NaCl}$.

\begin{tabular}{lllllll}
\hline WPI gel (wt\%) & 10 & 13.3 & 15 & 16.7 & 18.3 & 20 \\
Volume fraction (-) & 0.074 & 0.098 & 0.111 & 0.124 & 0.135 & 0.148 \\
\hline WPI-NaCl gel (wt\%) & 5 & 10 & 12.5 & 15 & 19.2 & 20 \\
Volume fraction (-) & 0.037 & 0.074 & 0.091 & 0.111 & 0.142 & 0.148 \\
\hline
\end{tabular}

Fluorescence correlation spectroscopy

Twenty $\mu \mathrm{L}$ of $3.2 \mu \mathrm{mol} \mathrm{L}{ }^{-1}$ EGFP solution was pipetted onto the wells of the eight-well plate containing WPI gels. The samples were stored at $4{ }^{\circ} \mathrm{C}$ for approximately $20 \mathrm{~h}$ before they were measured, to allow the EGFP to disperse homogeneously throughout the system.

The principles and practice of FCS have been explained in the previous paper of the authors (Q. Luo, Borst, et al. 2017), only the experimental details are described here. FCS was performed on a confocal microscope (Leica TCS SP8, Leica, Microsystem, Wetzlar, Germany). The microscope was equipped with a $63 \times 1.20$ NA water immersion objective and a supercontinuum white light laser, which emits a continuous spectrum from 470 to $670 \mathrm{~nm}$. EGFP was excited at wavelength $488 \mathrm{~nm}$ at a pulsed frequency of $80 \mathrm{MHz}$. The fluorescence intensity was recorded through a $70 \mu \mathrm{m}$ pinhole using a $495 \mathrm{~nm}-525 \mathrm{~nm}$ spectral filter. The fluorescence was recorded via the internal hybrid detector, which was coupled to a PicoHarp 300 TCSPC module (PicoQuant GmbH, Berlin, Germany). Every gel was measured 10 times for 30 seconds each. Experiments were repeated 3 times at $20^{\circ} \mathrm{C}$ and neutral $\mathrm{pH}$, due to the $\mathrm{pH}$-dependency of the used fluorophore. The focal position of the gel in the well was chosen such that the number of fluorescent molecules in the confocal volume at any given time was lower than 10. A blank gel without EGFP was measured to check for noise from the gel. Rhodamine $110\left(\mathrm{D}=4.3 \times 10^{-10} \mathrm{~m}^{2} \mathrm{~s}^{-1}\right)$ was used to calibrate the setup. At each calibration, diffusion times between $20 \mu$ s and $25 \mu$ s and a structural parameter between 5.2 and 6.6 were obtained, 
resulting in confocal volumes of approximately $4.2 \mathrm{fL}-9.48 \mathrm{fL}$.

Fluorescence Fluctuation Spectroscopy software (FFS data processor version 2.3 from Scientific Software Technologies Software Centre, Belarus) was used to fit the fluctuation data to a diffusion model that includes the triplet state of the fluorophore. Ten measurements of one sample were fitted by a global analysis based on the MarquardtLevenberg nonlinear least-squares method. The goodness of fit was confirmed by the straightness of the weighted residuals and low chisquare values. The confidence intervals of the recovered parameters were calculated by the exhaustive search method. Those procedures were all performed within the software, more details have been described by Skakun, Digris, and Apanasovich (2014).

\section{Texture analysis}

To determine the tensile elastic modulus of the protein gels, a texture analyzer (type 5564, Instron, MA, USA) was used. Cylindrical gel samples (diameter $20 \mathrm{~mm}$ and height $20 \mathrm{~mm}$ ) were compressed to $25 \%$ of their original height at a rate of $30 \mathrm{~mm} / \mathrm{min}$ using a $2000 \mathrm{~N}$ load cell. The compressional extension and load were logged during the experiment to determine the elastic modulus:

$$
E=\frac{\text { Stress }}{\text { Strain }}=\frac{F / A_{0}}{d L / L_{0}}
$$

Where $F$ is the load, $A_{0}$ is the initial area of the surface where the force of compression is applied, $d L$ is the extension and $L_{0}$ is the initial height of the sample. The experiments were repeated at least three times per sample composition.

We calculated the crosslinking density $M_{c}$, defined as the molecular weight of the polymeric units between the crosslinks, based on the elastic contribution of the Flory-Rehner model (van der Sman 2012): 


$$
M_{c}=\frac{\rho_{s} R T}{E}
$$

Where $\mathrm{E}$ is the elastic modulus, $\mathrm{R}$ is the gas constant, $\mathrm{T}$ is the temperature, the density of the polymer $\rho_{s}$ is $1421 \mathrm{~kg} \mathrm{~m}^{-3}$ (Papiz et al. 1986).

\section{Modeling}

The models for diffusion in hydrogels were fitted to the measured diffusion coefficients using Matlab R2015b (MathWorks, Natick, USA). Model fitting was done using the nonlinear fitting function lsqcurvefit that solves fitting problems using a least-squares approach. The algorithm used was the trust-region-reflective method. The accuracy of the resulting fit was analyzed by determining the coefficient of determination of the fit using the resnorm option of lsqcurvefit. The function nlparci was used to extract the $95 \%$ CI of the parameters out of the Jacobian matrix.

\subsection{Results and discussion}

\subsubsection{Texture analysis}

Manual inspection and texture analysis showed that higher protein mass fractions result in gels with a larger elastic modulus. The elastic moduli of the protein gels are reported in Figure 4.1. The WPI gels of $10 \mathrm{wt} \%$ and $11.7 \mathrm{wt} \%$ and the $5 \mathrm{wt} \% \mathrm{WPI}-\mathrm{NaCl}$ gel behaved like viscous semi-fluids, thus were unfit for elasticity measurements.

The elastic modulus increases strongly as the protein weight fraction approaches $20 \mathrm{wt} \%$ with consistently higher elastic moduli for the WPI-NaCl gels than WPI gels. The crosslinking density, found with the Flory-Rehner equation, is inversely proportional to the elastic modulus (Eq. 4.9) and is shown in Fig. 4.1B. It shows that the 

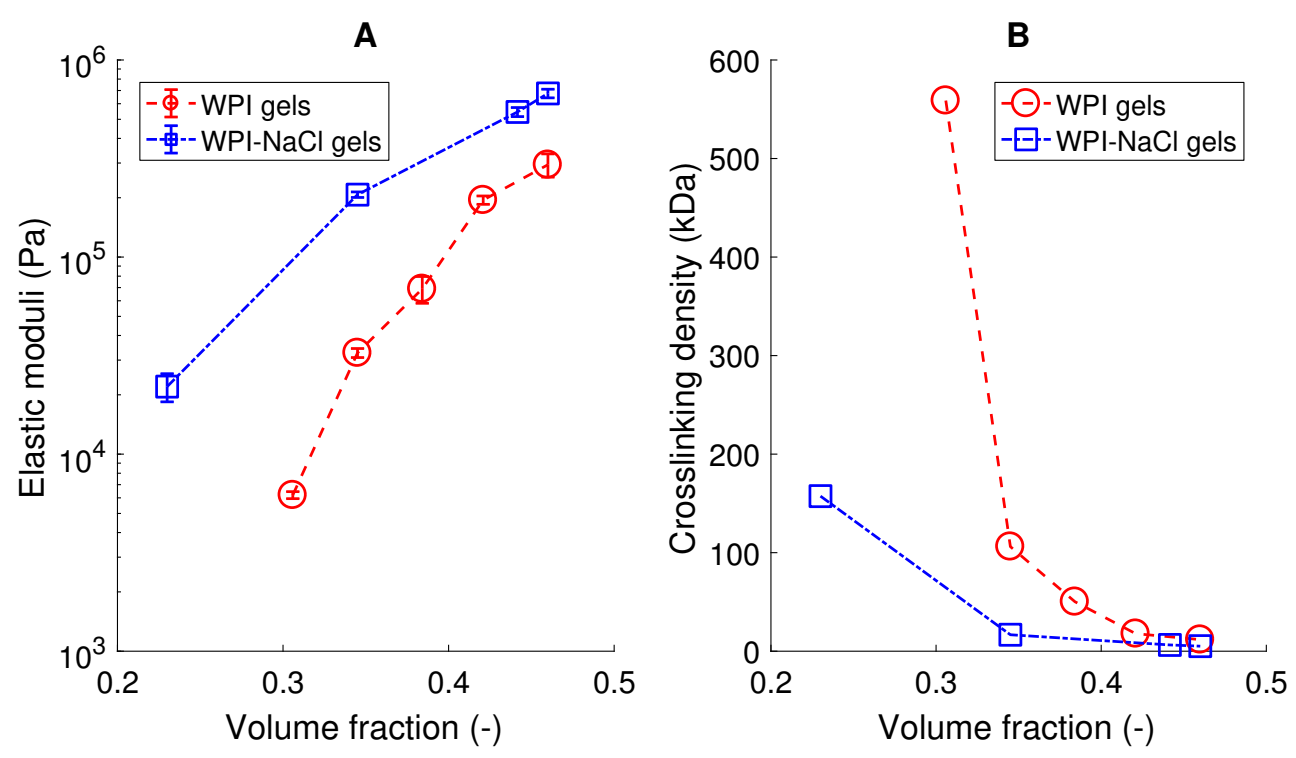

Figure 4.1: The elastic moduli (A) and crosslinking density (B) of WPI gels (red circles) and WPI-NaCl gels (blue squares). Each data point is the average of 3 experiments, error bars are the standard deviations. The crosslinking density is calculated based on the elastic contribution of the Flory-Rehner model (Eq. 4.9). The dashed lines are guides for the eye.

WPI-NaCl gels are more densely cross-linked, which agrees with the observation that the protein aggregates at higher ionic strengths are more strongly branched (Nicolai, Britten, and Schmitt 2011).

One would expect the rate of diffusion to decrease as the polymers become more densely cross-linked, since the one might expect the steric hindrance of a solute molecule in a more tightly crosslinked polymer network to be larger. This can be evaluated with direct diffusivity measurements.

\subsubsection{Diffusivity experiments}

Report on diffusivity data

The diffusivity of EGFP in WPI and WPI-NaCl gels was assessed using fluorescence correlation spectroscopy. The autocorrelation curves 
obtained via FCS were fitted with a one-component model resulting in a good fit, yielding a diffusion coefficient of EGFP in water of $1.3 \times 10^{-10} \mathrm{~m}^{2} \mathrm{~s}^{-1}$. The diffusivity reduction $\left(\mathrm{D} / \mathrm{D}_{0}\right)$ of EGFP in both the WPI and WPI-NaCl gels were calculated and reported in Figure 4.2. As expected, the diffusivity in both types of gels decreases as the WPI concentration increases. While the two types of gels had distinctive trends in the change of their elastic moduli (Figure 4.1A), they do not show any differences in their reduction in diffusivity. Therefore, although both elasticity and diffusivity are related to the gel microstructure, these two properties are not directly correlated. We see that the volume fraction of the protein gel is the main determinant of the diffusivity reduction, and we expect that the elastic modulus will be also be determined by the exact microstructure of the gel.

This does not mean that the gel microstructure has no influence on the diffusion related properties. The diffusion of pepsin into the gel is a necessary first step In the gastric digestion of protein gels. Guo et al found that food gels that have the same protein volume fraction but different strength, do differ in their gastric disintegration kinetics (Guo, A. Ye, Lad, M. Ferrua, et al. 2015). Although the microstructure of the gels (elasticity or fracture strength) may not determine the diffusivity reduction in the gels, it is correlated with other factors that contribute to the ultimate disintegration of the gel.

\section{Model fitting and analysis}

The models discussed in the theory section (eq. 4.1 - 4.7) are examined using the experimental diffusivity data. In the fitting process, the radius of EGFP $r_{\mathrm{s}}(1.65 \mathrm{~nm})$ is calculated from the measured diffusion coefficient in water, using the Stokes-Einstein equation; the radius of the polymer fiber and the other unknown constants are used as fitted parameters. All the fitted parameters are shown in table 4.3.

In Cukier' $\mathrm{s}$ model (Eq. 4.1), the screening parameter $\mathrm{v}$ has been shown to vary in different regimes of concentrations. By definition, in the dilute regime, polymer chains move independently; in the semi- 


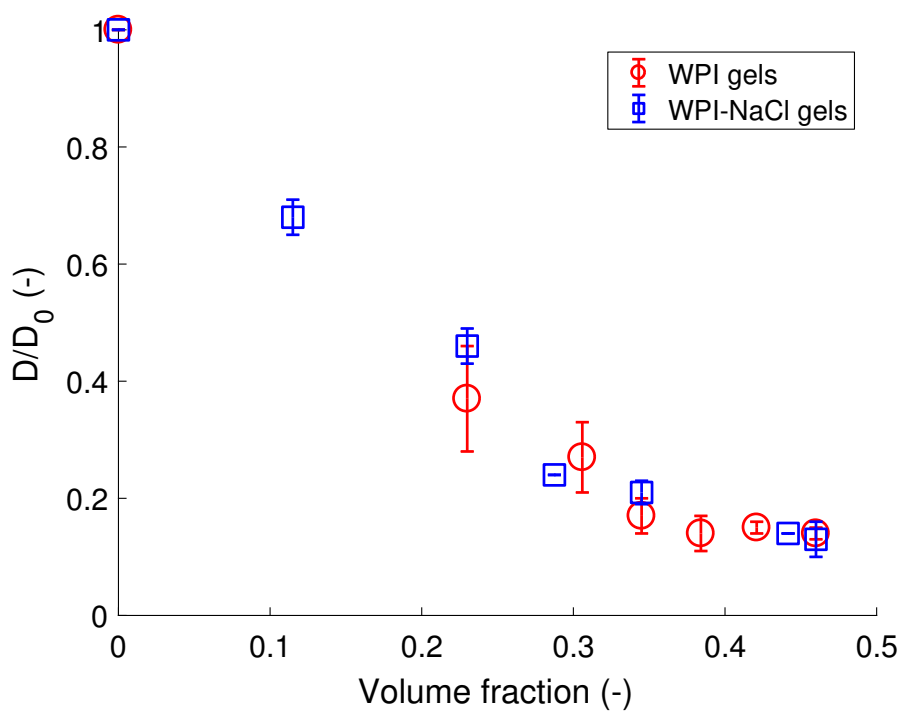

Figure 4.2: Diffusivity reduction $\left(\mathrm{D} / \mathrm{D}_{0}\right)$ of enhanced green fluorescent protein in WPI gels (red circles) and WPI-NaCl gels (blue squares). Each data point is the average of 2 or more experiments, error bars are the standard deviations. The dashed lines are guides for the eye.

dilute regime, polymer chains start to overlap; and in the concentrated regime, diffusion is dominated by polymer friction. Cukier found an exponent of 0.5 for small solutes in semi-dilute polymer solutions and slightly cross-linked gels (Cukier 1984). Freed and Edwards (1974) obtained an exponent of 1 for polymer chains in a dense polymer solution without entanglements. De Gennes found an exponent of 0.75 in a system of long flexible chains in good solvents (De Gennes 1976). Thévenot et al. applied Cukier' s model with the exponent of 0.75 to the diffusion of labeled pepsin in casein rennet gels and found good fitting description (Thévenot et al. 2017). To determine which screening factor should be used in the EGFP-WPI gel system, we evaluated the model with both $\mathrm{v}=0.75$ and $\mathrm{v}=1$ (Later denoted as Cukier 0.75 and Cukier 1). The model predictions are illustrated in Figure 4.3A/B, the fitted parameters and the goodness of fit are listed in table 3.

Overall, the Cukier' s model describes the diffusivity in our system well. In comparison, using an exponent of 1 yields better fit than using 0.75 . Since we studied the whey protein gels above the criti- 
cal gelation concentration, the gels are densely cross-linked which fall in the concentrated regime. The fitted interaction parameter $k_{c}$ differs slightly between WPI gels and WPI-NaCl gels, however, there is a strong overlap between their $95 \%$ confidence intervals.

In the other models, we used $\mathrm{r}_{\mathrm{f}}$ as the fitted parameter. Among them, Johansson's model and Clague-Phillips' model yielded the best fit, with low SSR, high $\mathrm{R}^{2}$. These two models are shown in Figure 4.3 $\mathrm{C} / \mathrm{D}$ as the examples. The typical $\beta$-lactoglobulin primary aggregates radius is $5 \mathrm{~nm}$, observed with cryo-TEM (Pouzot et al. 2005). In Johansson's model, the fitted polymer radii $\mathrm{r}_{\mathrm{f}}$ are $1.29 \mathrm{~nm}$ and $1.39 \mathrm{~nm}$, which are smaller than the protein aggregate radius. Ogston's model and Tsai-Strieder's model also yielded reasonable fit while the fitted polymer radii are small. The diffusivity reduction may be affected by more than the hydrodynamic or obstruction hindrance that is described in the models, and these effects were reflected in the small $r_{f}$ in the fitting. In the Phillips' model, the confidence intervals are very large which indicate that the parameters in this model are unreliable.

We tested whether the different models can predict the diffusivity of pepsin in WPI gels using the parameters yielded from the EGFP. Cukier 1, Johansson's and Clague-Phillips' model are chosen for the prediction. The experimentally determined diffusion coefficients of Alexa633-labelled pepsin from our previous study (Q. Luo, Borst, et al. 2017) were used. In the models, the hydrodynamic radius of the Alexa633-labelled pepsin $(2.9 \mathrm{~nm})$ was used, while for other parameters we used the values that were obtained with EGFP diffusion in WPI gels. The prediction is shown in Table 4.4. Cukier' s model predicted far lower diffusion coefficients for both gel types. This may indicate that interaction parameter $\mathrm{k}_{\mathrm{c}}$ is not only dependent on the polymer-solvent system but also the solute' $\mathrm{s}$ interaction with the polymer, for example, due to different charge or charge distribution over the different proteins. Johansson' s model also underestimated the diffusion coefficients, while Clague' s model predicted values that are about $60 \%$ of the experiment data, providing the closest prediction among the models. The small polymer fiber radii used in the Johansson' $s$ caused the prediction to be very sensitive to the change 

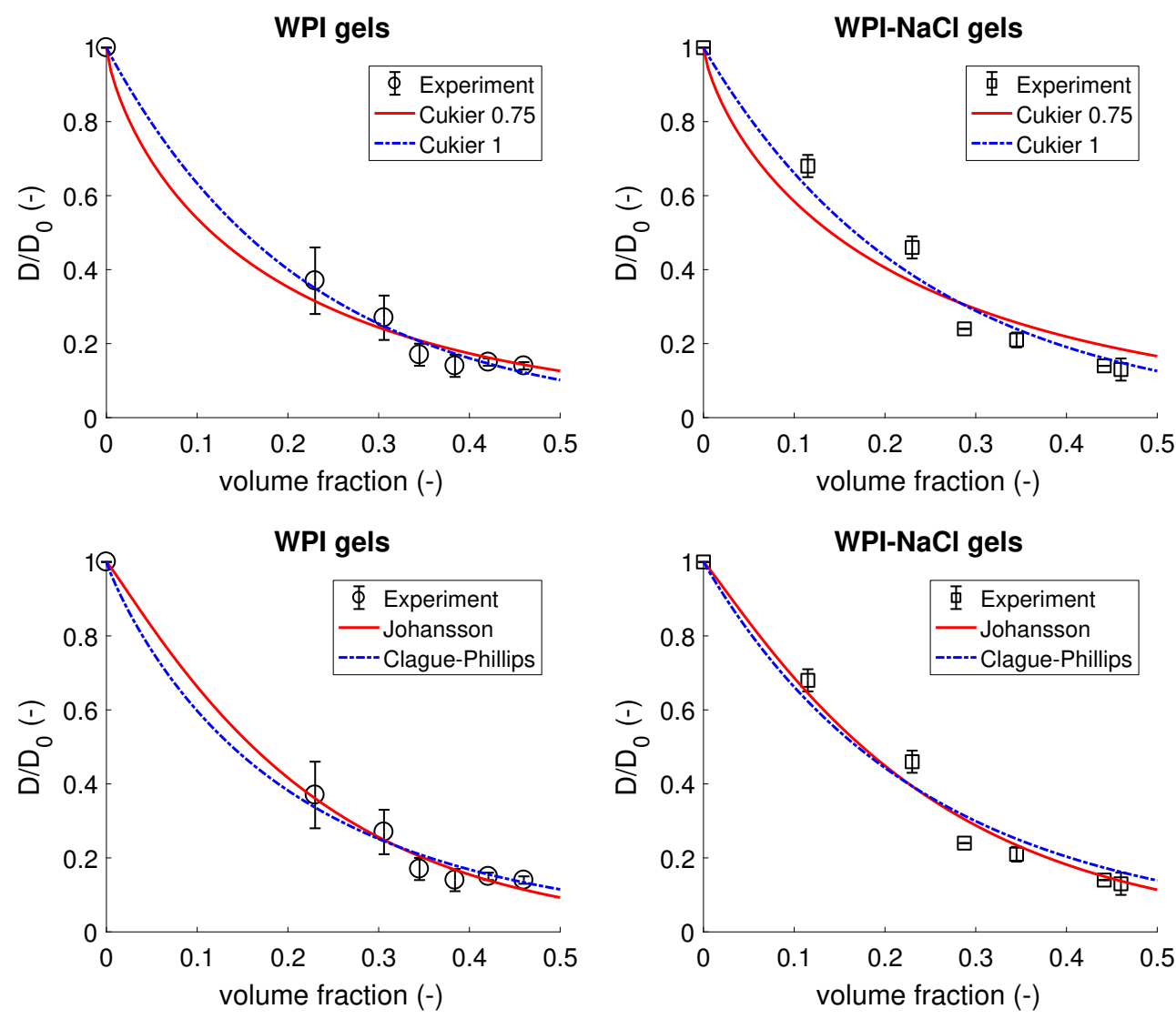

Figure 4.3: Diffusivity reduction $\left(\mathrm{D} / \mathrm{D}_{0}\right)$ of EGFP in WPI gels $(\mathrm{A} / \mathrm{C})$ and WPI-NaCl gels (B/D) and the model predictions. The black circles and squares are the average of 3 or 4 experimental data measured by fluorescence correlation spectroscopy, error bars are their standard deviation. The lines are the model predictions. 
Table 4.3: The fitted parameters of the models. The uncertainty are the $95 \%$ confidence intervals of the fit.

\begin{tabular}{llllll}
\hline \multirow{2}{*}{ Model } & Matrices & $\begin{array}{l}\text { Fitted pa- } \\
\text { rameter }\end{array}$ & Value & $\mathrm{R}^{2}$ & SSR \\
\hline Cukier 0.75 & WPI gel & $\mathrm{k}_{\mathrm{c}}\left(\mathrm{nm}^{-1}\right)$ & $2.11 \pm 0.23$ & 0.987 & 0.008 \\
& WPI-NaCl gel & & $1.83 \pm 0.43$ & 0.950 & 0.038 \\
\hline Cukier 1 & WPI gel & $\mathrm{k}_{\mathrm{c}}\left(\mathrm{nm}^{-1}\right)$ & $2.77 \pm 0.22$ & 0.994 & 0.004 \\
& WPI-NaCl gel & & $2.51 \pm 0.38$ & 0.980 & 0.015 \\
\hline \multirow{2}{*}{ Ogston } & WPI gel & $\mathrm{r}_{\mathrm{f}}(\mathrm{nm})$ & $1.00 \pm 0.25$ & 0.974 & 0.016 \\
& WPI-NaCl gel & & $1.39 \pm 0.84$ & 0.885 & 0.081 \\
\hline \multirow{2}{*}{ Johansson } & WPI gel & $\mathrm{r}_{\mathrm{f}}(\mathrm{nm})$ & $1.29 \pm 0.08$ & 0.994 & 0.003 \\
& WPI-NaCl gel & & $1.39 \pm 0.15$ & 0.985 & 0.011 \\
\hline \multirow{2}{*}{ Tsai } & WPI gel & $\mathrm{r}_{\mathrm{f}}(\mathrm{nm})$ & $0.55 \pm 0.11$ & 0.976 & 0.015 \\
& WPI-NaCl gel & & $0.69 \pm 0.23$ & 0.926 & 0.057 \\
\hline Johnson & WPI gel & $\mathrm{r}_{\mathrm{f}}(\mathrm{nm})$ & $0.05 \pm 0.06$ & 0.921 & 0.046 \\
& WPI-NaCl gel & & $0.24 \pm 0.32$ & 0.757 & 0.179 \\
\hline Clague & WPI gel & $\mathrm{r}_{\mathrm{f}}(\mathrm{nm})$ & $4.73 \pm 1.71$ & 0.992 & 0.005 \\
& WPI-NaCl gel & & $8.23 \pm 5.47$ & 0.979 & 0.017 \\
\hline Phillips & WPI gel & \multirow{2}{*}{$\mathrm{r}_{\mathrm{f}}(\mathrm{nm})$} & $3.02 \pm 11.2$ & 0.990 & 0.007 \\
& WPI-NaCl gel & & $2.99 \pm 18.06$ & 0.952 & 0.048 \\
\hline
\end{tabular}


Table 4.4: Experimental data and model predictions of diffusivity reduction $\left(\mathrm{D} / \mathrm{D}_{0}\right)$ of Alexa 633 labelled pepsin, experimental data is taken from Q. Luo, Borst, et al. (2017).

\begin{tabular}{lllll}
\hline Gel type & $\begin{array}{l}\mathrm{D} / \mathrm{D}_{0}, \quad \text { ex- } \\
\text { perimental }\end{array}$ & Cukier 1 & Clague & Johansson \\
\hline WPI gel 15 wt\% & 0.26 & 0.063 & 0.163 & 0.032 \\
WPI gel 20 wt\% & 0.16 & 0.025 & 0.102 & 0.0091 \\
\hline
\end{tabular}

of the solute radius $r_{s}$. The prediction is too low in all cases, indicating that pepsin is anomalously mobile relative to EGFP in WPI gels, even though the molecular weights are similar, with pepsin slightly larger than EGFP, and EGFP is a very compact molecule compared to other proteins.

The different diffusion behavior of pepsin may be related to a number of effects, as all these models presume to a specific interaction between the diffusant and the matrix.

The first possible interaction is the electrostatic interaction. Kang et al. studied the diffusion of apoferritin (diameter $12.8 \mathrm{~nm}$ ) in bacteriophage $\mathrm{fd}$ (a rod-like virus with contour length of $880 \mathrm{~nm}$ and bare diameter of $6.6 \mathrm{~nm}$ )(Kang et al. 2007). They found that the electrostatic interactions strongly alter the diffusional behavior of apoferritin. Likewise, both EGFP and whey proteins are charged at neutral $\mathrm{pH}$, as well as pepsin. Pepsin, having a very low isoelectric point (IEP), has around 20 negatively charged groups, and will be quite negatively charged at neutral pH. EGFP, in contrast, has a much higher IEP and is only slightly negatively charged at neutral $\mathrm{pH}$. One would expect that pepsin, being more strongly charged, would have less accessible volume in the WPI gel network, especially in more concentrated gels. However, we see that the experimental diffusivities of pepsin are significantly higher than would be expected based on the diffusivity of EGFP in WPI gels.

A second interaction is binding. Pepsin as an enzyme naturally binds to protein, which also negatively affects its diffusivity. We previously 
observed that a part of the pepsin diffuses slower than the expected reduction by the whey protein gel network even at neutral $\mathrm{pH}$ where pepsin is not active (Q. Luo, Borst, et al. 2017). Fadda et al. found anomalously slow diffusion of thermolysin in gelatin gels due to the enzyme-substrate interaction, and the time that the enzyme is trapped on the gel is related to the enzyme kinetics constants. $\mathrm{K}_{\mathrm{m}}$ determines the proportion of enzyme that is trapped in the enzyme substrate, and $\mathrm{k}_{\text {cat }}$ offers an estimate of the elementary trapping time. However, also this aspect would imply a lower diffusion rate for pepsin than for EGFP. One may argue that the hydrolytic action of pepsin may lead to a greater degree of freedom for pepsin to diffuse in a gel matrix; however, our measurements with pepsin were made at neutral $\mathrm{pH}$, and pepsin is not catalytically active at this condition.

At this point, it is not clear why pepsin diffuses faster than EGFP. Further studies will be required to elucidate the exact reason for this.

\subsection{Conclusions}

We investigated the diffusivity of EGFP, as the model for pepsin, in two types of whey protein gels with varied concentrations. The diffusion rates of EGFP decreased dramatically at higher concentrations of whey protein in the gel. Two types of whey protein gels, made with different ionic strength had different elastic moduli at the same protein concentration, but the elastic moduli cannot be directly correlated to the diffusivity reduction.

Cukier' s hydrodynamic model yielded the best description, but the parameter $\mathrm{k}_{\mathrm{c}}$ cannot directly reflect the geometry of the gel matrix; and it varies among different gel matrices. In contrast, Clague' s, Johansson' s and Phillips' models require only basic structural information such as the radius of the polymer fiber $\left(\mathrm{r}_{\mathrm{f}}\right)$ and the radius of the solute $\left(\mathrm{r}_{\mathrm{s}}\right)$.

Surprisingly, the EGFP diffusivity measurements predicted signifi- 
cantly lower diffusivities for pepsin, than was found with pepsin itself. In the translation from EGFP to pepsin, we need to include the different electrostatic interaction and possible enzyme-substrate interaction; however, both effects cannot explain the higher diffusion rates of pepsin relative to those of EGFP.

We conclude that while the hydrodynamic models give good descriptions, they are clearly too simple for a full physical understanding of diffusion of a protein in a protein gel, and that the translation from one diffusant to another may involve several types of interactions.

\section{References}

Ako, K., T. Nicolai, D. Durand, and G. Brotons (2009). "Micro-Phase Separation Explains the Abrupt Structural Change of Denatured Globular Protein Gels on Varying the Ionic Strength or the pH." In: Soft Matter 5.20, pp. 4033-4041. Dor: 10.1039/B906860K.

Amsden, B. (Nov. 1, 1998). "Solute Diffusion within Hydrogels. Mechanisms and Models." In: Macromolecules 31.23, pp. 8382-8395. DoI: 10. 1021/ma980765f.

Aymard, P., J. C. Gimel, T. Nicolai, and D. Durand (1996). "Experimental Evidence for a Two-Step Process in the Aggregation of $\beta$ Lactoglobulin at pH 7." In: Journal de Chimie Physique 93, pp. 987997. Dor: 10.1051/ jcp/1996930987.

Clague, D. S. and R. J. Phillips (July 1996). "Hindered Diffusion of Spherical Macromolecules through Dilute Fibrous Media." In: Physics of Fluids 8.7, pp. 1720-1731. Dor: 10.1063/1.868884.

Cukier, R. I. (Feb. 1, 1984). "Diffusion of Brownian Spheres in Semidilute Polymer Solutions.” In: Macromolecules 17.2, pp. 252-255. DoI: 10.1021/ma00132a023.

De Gennes, P. G. (July 1, 1976). "Dynamics of Entangled Polymer Solutions. I. The Rouse Model.” In: Macromolecules 9.4, pp. 587-593. DoI: $10.1021 / \mathrm{ma} 60052 \mathrm{a} 011$. 
Floury, J., T. Bianchi, J. Thévenot, D. Dupont, F. Jamme, E. Lutton, M. Panouillé, F. Boué, and S. Le Feunteun (Jan. 15, 2018). "Exploring the Breakdown of Dairy Protein Gels during in Vitro Gastric Digestion Using Time-Lapse Synchrotron Deep-UV Fluorescence Microscopy." In: Food Chemistry 239, pp. 898-910. DoI: 10 . 1016 / j . foodchem.2017.07.023.

Freed, K. F. and S. F. Edwards (Nov. 1, 1974). "Polymer Viscosity in Concentrated Solutions." In: The Journal of Chemical Physics 61.9, pp. 3626-3633. Dor: 10.1063/1.1682545.

Grácia-Juliá, A., M. René, M. Cortés-Muñoz, L. Picart, T. LópezPedemonte, D. Chevalier, and E. Dumay (Aug. 1, 2008). "Effect of Dynamic High Pressure on Whey Protein Aggregation: A Comparison with the Effect of Continuous Short-Time Thermal Treatments." In: Food Hydrocolloids 22.6, pp. 1014-1032. DoI: 10 . 1016 / j . foodhyd.2007.05.017.

Guo, Q., A. Ye, M. Lad, M. Ferrua, D. Dalgleish, and H. Singh (Jan. 6, 2015). "Disintegration Kinetics of Food Gels during Gastric Digestion and Its Role on Gastric Emptying: An in Vitro Analysis." In: Food E Function 6, pp. 756-764. Dor: 10.1039/C4F000700J.

Jackson, G. W. and D. F. James (June 1986). "The Permeability of Fibrous Porous Media." In: The Canadian Journal of Chemical Engineering 64.3, pp. 364-374. Dor: 10. 1002 / c j ce.5450640302.

Johansson, L. and C. Elvingson (1991). "Diffusion and Interaction in Gels and Solutions. 3. Theoretical Results on the Obstruction Effect." In: Macromolecules 24, pp. 6024-6029.

Johnson, E. M., D. A. Berk, R. K. Jain, and W. M. Deen (1996). "Hindered Diffusion in Agarose Gels: Test of Effective Medium Model." In: Biophysical journal 70, pp. 1017-1023.

Kang, K., A. Wilk, A. Patkowski, and J. K. Dhont (2007). "Diffusion of Spheres in Isotropic and Nematic Networks of Rods: Electrostatic Interactions and Hydrodynamic Screening." In: The Journal of chemical physics 126.21, p. 214501.

Luo, Q., R. M. Boom, and A. E. M. Janssen (Sept. 2015). "Digestion of Protein and Protein Gels in Simulated Gastric Environment." In: 
LWT - Food Science and Technology 63.1, pp. 161-168. DoI: 10.1016/ j. lwt.2015.03.087.

Luo, Q., J. W. Borst, A. H. Westphal, R. M. Boom, and A. E. M. Janssen (May 2017). "Pepsin Diffusivity in Whey Protein Gels and Its Effect on Gastric Digestion.” In: Food Hydrocolloids 66, pp. 318-325. DoI: 10.1016/ j. foodhyd.2016.11.046.

Masaro, L. and X. X. Zhu (Aug. 1999). "Physical Models of Diffusion for Polymer Solutions, Gels and Solids." In: Progress in Polymer Science 24.5, pp. 731-775. Dor: 10.1016/S0079-6700 (99)00016-7.

Nicolai, T., M. Britten, and C. Schmitt (Dec. 2011). " $\beta$-Lactoglobulin and WPI Aggregates: Formation, Structure and Applications." In: Food Hydrocolloids. 25 years of Advances in Food Hydrocolloid Research 25.8, pp. 1945-1962. DoI: 10 . 1016/ j . foodhyd . 2011. 02 . 006.

Nolles, A., A. H. Westphal, J. A. de Hoop, R. G. Fokkink, J. M. Kleijn, W. J. H. van Berkel, and J. W. Borst (May 11, 2015). "Encapsulation of GFP in Complex Coacervate Core Micelles.” In: Biomacromolecules 16.5, pp. 1542-1549. Dor: 10.1021/acs .biomac.5b00092.

Ogston, A. G., B. N. Preston, and J. D. Wells (1973). "On the Transport of Compact Particles Through Solutions of Chain-Polymers." In: Proceedings of the Royal Society of London. A. Mathematical and Physical Sciences 333, pp. 297-316. Dor: 10.1098/rspa.1973.0064.

Papiz, M., L. Sawyer, E. Eliopoulos, A. North, J. Findlay, R. Sivaprasadarao, T. Jones, M. Newcomer, and P. Kraulis (1986). "The Structure of B-Lactoglobulin and Its Similarity to Plasma RetinolBinding Protein.” In: Nature 324.6095, pp. 383-385.

Phillips, R. J. (Dec. 2000). "A Hydrodynamic Model for Hindered Diffusion of Proteins and Micelles in Hydrogels." In: Biophysical Journal 79.6, pp. 3350-3353. pmid: 11203465.

Phillips, R. J., W. M. Deen, and J. F. Brady (1989). "Hindered Transport of Spherical Macromolecules in Fibrous Membranes and Gels." In: AIChE journal 35.11, pp. 1761-1769.

Pouzot, M., T. Nicolai, R. W. Visschers, and M. Weijers (Mar. 2005). "X-Ray and Light Scattering Study of the Structure of Large Protein 
Aggregates at Neutral pH.” In: Food Hydrocolloids 19.2, pp. 231-238. Dor: $10.1016 /$ j . foodhyd.2004.06.003.

Singh, H., A. Ye, and M. J. Ferrua (June 2015). "Aspects of Food Structures in the Digestive Tract." In: Current Opinion in Food Science. Sensory Sciences and Consumer Perception - Food Physics and Material Science 3, pp. 85-93. Dor: 10.1016/ j . cofs.2015.06.007.

Skakun, V., A. Digris, and V. Apanasovich (Jan. 1, 2014). "Global Analysis of Autocorrelation Functions and Photon Counting Distributions in Fluorescence Fluctuation Spectroscopy." In: Fluorescence Spectroscopy and Microscopy. Ed. by Y. Engelborghs and A. J. W. G. Visser. Methods in Molecular Biology 1076. New York: Humana Press, pp. 719-741.

Thévenot, J., C. Cauty, D. Legland, D. Dupont, and J. Floury (May 15, 2017). "Pepsin Diffusion in Dairy Gels Depends on Casein Concentration and Microstructure." In: Food Chemistry 223, pp. 54-61. DoI: 10. 1016/ j . foodchem.2016.12.014.

Tsai, D. S. and W. Strieder (1985). "Radiation across a Spherical Cavity Having Both Specular and Diffuse Reflectance Components." In: Chemical engineering science 40, pp. 170-173.

Van der Sman, R. G. M. (June 2012). "Thermodynamics of Meat Proteins.” In: Food Hydrocolloids 27.2, pp. 529-535. DoI: 10 . 1016 / j . foodhyd.2011.08.016. 


\section{Chapter 5}

\section{Revisiting the enzymatic kinetics of pepsin using isothermal titration calorimetry}

This chapter is based on:

Q. Luo, D. Chen, R. M. Boom, A. E. M. Janssen. "Revisiting the enzymatic kinetics of pepsin using isothermal titration calorimetry." Submitted for publication. 


\section{Abstract}

Pepsin is the first protease that food proteins encounter in the digestive tract. However, most of the previous studies on the enzymatic kinetics of pepsin were based on the hydrolysis of small synthetic peptides, due to the limitations in methodology and the complexity of protein substrate. To better understand the role of pepsin in protein digestion, we used the isothermal titration calorimetry to study the enzymatic kinetics of pepsin with bovine serum albumin as the substrate. We found that pepsin has a higher catalytic rate at lower $\mathrm{pH}$, while its affinity to substrate is lower. At the same $\mathrm{pH}$, pepsin has lower activity and affinity at higher ionic strengths. We found contrasting kinetic parameters for pepsin-catalyzed hydrolysis of bovine serum albumin and of small synthetic peptides. Time-dependent kinetics also showed that pepsin has lower efficiency towards intermediate peptides during hydrolysis. 


\subsection{Introduction}

The digestion of food proteins in the gastrointestinal tract has been studied both in vivo and in vitro for decades. These studies have investigated the nutritional value (Boirie et al. 1997; Nilsson, Holst, and Björck 2007), digestibility (Hsu et al. 1977; Denis et al. 2016), and allergenicity (Schmidt et al. 1995; Kopper et al. 2004; Polovic et al. 2007) of proteins, however, the reaction kinetics of protein digestion has not been fully quantified to date. The digestion of protein starts in the stomach, where pepsin is the major enzyme present. Therefore, the enzymatic kinetics of pepsin is an important aspect of the digestion process of food proteins that requires better understanding.

Pepsin (EC 3.4.23.1) is an aspartic acid protease. Its zymogen, pepsinogen is secreted by the chief cells on gastric mucosa, and activated in low pH (Kageyama 2014). Pepsin has 330-350 amino acid residues with mainly $\beta$-sheets. The catalytic site of pepsin is located in the middle narrow slit of two lobes; two aspartic acid residues, Asp32 and Asp215, are located at the end of each domain (Dunn 2001). These two aspartic acid residues are connected through a low-barrier hydrogen bond. Findings from recent decades suggested that this lowbarrier hydrogen bond is the key feature in the catalytic mechanism for aspartic proteases, which facilitates the proton transfer during catalysis (Northrop 2001; Dunn 2002).

The specificities of proteinases are often characterized by the cleaved peptide bond (P1-P1'), which consists of two amino acid residues. However, the substrate binding and specificity may also involve the amino acid residues on either side of the cleaved peptide bond (Powers, Harley, and Myers 1977; Foltmann 1981):

$$
\text { Substrate } \quad P_{4}-P_{3}-P_{2}-P_{1} \stackrel{\downarrow}{-} P_{1}^{\prime}-P_{2}^{\prime}-P_{3}^{\prime}-P_{4}^{\prime}
$$

$$
\text { Enzyme } \quad S_{4} \quad S_{3} \quad S_{2} \quad S_{1} \quad S_{1}^{\prime} \quad S_{2}^{\prime} \quad S_{3}^{\prime} \quad S_{4}^{\prime}
$$

where the individual amino acid residues on the substrate are designated P1, P2, P1', etc. and the corresponding subsites of the enzyme are $\mathrm{S} 1, \mathrm{~S} 2, \mathrm{~S} 1$, etc. The arrow indicates the peptide bond cleavage 
between the $\mathrm{P} 1$ and $\mathrm{P} 1$ ' residues.

The specificity of pepsin (i.e. the cleavage probability of peptide bonds by pepsin) is mainly influenced by the amino acid residues at position P1 and P1', while the amino acid residues at other subsites may also play a role. In general, pepsin prefers to cleave after phenylalanine, leucine, and methionine, whereas it rarely cleaves after histidine, lysine, proline, and arginine. Aromatic residues tyrosine, tryptophan, and phenylalanine are favored at position P1'. Proline is strongly disfavored at P2, P2', and P3' position, while histidine, lysine, and arginine are disfavored at the $\mathrm{P} 3$ position. The $\mathrm{P} 4$ and $\mathrm{P} 4$ ' positions have little influence. (Hamuro et al. 2008; Ahn et al. 2013)

The influence of $\mathrm{pH}$ on enzyme activity is generally recognized. Pepsin, as an aspartic protease, has a very low $\mathrm{pH}$ optimum. Kondjoyan, Daudin, and Santé-Lhoutellier (2015) studied the digestibility of myofibrillar proteins and found maximum pepsin activity at $\mathrm{pH}$ around 2. Pletschke, Naudé, and Oelofsen (1995) studied the hydrolysis of hemoglobin by porcine and ostrich pepsin, and also found optimum $\mathrm{pH}$ of 2.0 for pepsin activity.

In contrast to the influence of $\mathrm{pH}$, the effect of ionic strength on enzyme activity is less discussed. Dale and White (1983) showed that increasing the ionic strength clearly decreases the reaction rate of immobilized pancreatic ribonuclease. Butré, Wierenga, and Gruppen (2012) studied the enzymatic hydrolysis of whey protein isolate by alcalase and neutrase, and also found that the presence of $0.5 \mathrm{M} \mathrm{NaCl}$ decreased the rate of hydrolysis.

The enzymatic kinetics can be described by the Michaelis-Menten model (Michaelis and Menten 1913; K. A. Johnson and Goody 2011):

$$
v=\frac{k_{c a t} E S}{K_{m}+S}
$$

where $v$ is the rate of the enzymatic reaction, $E$ is the enzyme concentration, $S$ is the substrate concentration. $K_{m}$ is the Michaelis constant (defined as the substrate concentration where half of the maximum 
reaction rate is reached) that can describe the binding affinity between enzyme and substrate, and $k_{\text {cat }}$ is the catalytic constant, also known as the turnover number. It is the maximum amount of substrate converted to product per enzyme molecule per second. $k_{c a t} / K_{m}$ is defined as the specificity constant that indicates the catalytic proficiency of an enzyme. $k_{\text {cat }}$ and $k_{\text {cat }} / K_{m}$ are now recognized as the two primary steady-state kinetic parameters for enzymes (Miller and Wolfenden 2002).

To obtain the kinetic data of the enzymatic reaction, spectrophotometric methods are commonly used. Since spectrophotometric methods require specific chromophores on either the substrate or product, they are constrained by substrate properties and reaction conditions (temperature and $\mathrm{pH}$ ), and are often laborious. Alternatively, calorimetric methods can be used to measure reaction rate by monitoring the enthalpy change, since the enthalpy change is ubiquitous in most enzymatic reactions.

Isothermal titration calorimetry (ITC) is one of the calorimetric methods that use power compensation to keep reaction condition isothermal. As a chemical reaction takes place in the measurement cell, the thermal power from the controlled heater is adjusted according to the enthalpy change of the reaction (Freyer and Lewis 2008). The monitored thermal power is directly proportional to the reaction rate, which simplifies data analysis. Reaction rates at different substrate concentrations can be obtained in a single experiment by subsequently injecting the substrate (under pseudo-first-order conditions), rather than requiring multiple experiments. Moreover, low amounts of enzyme and substrate are required due to the high sensitivity of ITC (Todd and Gomez 2001).

Pepsin is the first protease that food proteins encounter in the digestive tract, thus the usual substrate for pepsin is mostly intact proteins. However, most previous studies on the enzymatic kinetics of pepsin were based on the hydrolysis of small synthetic peptides. Most studies on pepsin-catalyzed hydrolysis of proteins did not quantify the kinetic parameters. The enzymatic kinetics of pepsin with intact protein is 
most relevant for realistic situations, rather than with short peptides. With information on the kinetics of pepsin in realistic situations, we could better understand the role of pepsin in the digestion process of food proteins. Therefore, we aim to study the enzymatic kinetics of pepsin with bovine serum albumin as a substrate, using the ITC, taking the effect of $\mathrm{pH}$ and ionic strength into consideration. We hypothesize that both the affinity and efficiency of pepsin are influenced by $\mathrm{pH}$ and ionic strength, and the physiological role of pepsin is related to food disintegration.

\subsection{Materials and method}

\subsubsection{Materials}

Pepsin from porcine gastric mucosa (lyophilized powder, 3200 to 4500 units per mg protein, $\mathrm{MW}=34.6 \mathrm{kDa}$ ), bovine serum albumin (purity $\geq 98 \%$ ) from bovine milk, and all other chemicals used were purchased from Sigma Aldrich (St. Louis, MO, USA). All of the water used in the experiments was obtained from a Milli-Q Integral Water Purification System (Merck Millipore, Billerica, MA, USA).

\subsubsection{Sample preparation}

Buffers at different $\mathrm{pH}$ and ionic strength were prepared. $100 \mathrm{mM}$ phosphate buffer at $\mathrm{pH} 2, \mathrm{pH} 2.5, \mathrm{pH} 3$, and $\mathrm{pH} 3.5$ were used. At $\mathrm{pH} 2$, three phosphate buffers were prepared at the ionic strength of $43 \mathrm{mM}$ (that of the buffer without additional salt), $89 \mathrm{mM}$ (equivalent to the total ionic strength of the electrolytes in the simulated gastric fluid according to the international consensus by Minekus et al. (2014)) and $154 \mathrm{mM}$ (physiological salt condition). The ionic strength of buffers at $\mathrm{pH} 2.5$ and $\mathrm{pH} 3$ were $89 \mathrm{mM}$, and $96 \mathrm{mM}$ at $\mathrm{pH} 3.5$, so that the effect of $\mathrm{pH}$ can be compared at similar ionic strength. The ionic strengths were calculated via the buffers' ionic composi- 
tions:

$$
I=\frac{1}{2} \sum_{i=1}^{n} c_{i} z_{i}^{2}
$$

where $c_{i}$ is the molar concentration of ion $i, z_{i}$ is the charge number of that ion, and the sum is taken over all ions in the solution. The ionic strengths were adjusted by adding sodium chloride when necessary. At $\mathrm{pH} 3.5$, the native ionic strength of the $100 \mathrm{mM}$ phosphate buffer is $96 \mathrm{mM}$.

A $10 \mu \mathrm{M}$ stock solution of pepsin was prepared in the buffers, it is stored at $-20^{\circ} \mathrm{C}$ for up to one month and unfrozen before use. Substrate solutions were freshly prepared. Due to the high concentration of the substrate solutions, the $\mathrm{pH}$ was slightly changed from the buffer $\mathrm{pH}$. Thus, we adjusted the $\mathrm{pH}$ to the expected $\mathrm{pH}$ to avoid extra heat effect from a difference in $\mathrm{pH}$. Before all the solution transferred to the instrument, A de-gassing step is performed with an ultrasonic device at $80 \mathrm{kHz}$ for $10 \mathrm{~min}$.

\subsubsection{Isothermal Titration Calorimetry}

The theoretical basis of determining enzymatic rate kinetics using ITC has been described previously (Morin and Freire 1991; Williams and Toone 1993; Todd and Gomez 2001). A summary will be given below: the enthalpy change for the reaction, which is equal to the compensated thermal power $(d Q / d t)$, is directly proportional to the rate of the chemical reaction:

$$
\frac{d Q}{d t}=\Delta H_{a p p} V \frac{d P}{d t}
$$

where $\Delta H_{a p p}$ is the apparent molar enthalpy change for the reaction, $V$ is the volume of the calorimetric cell, and $P$ is the product concentration. $d P / d t$ equals to the reaction rate $v$, therefore Eq. 5.3 can be rearranged to:

$$
v=\frac{1}{V \Delta H_{a p p}} \times \frac{d Q}{d t}
$$


Reaction rates at different substrate concentrations can be obtained by subsequently injecting the substrate into the cell, this method is later referred as the multiple injection method. The subsequent injections are made when the reaction has reached a steady state, while significant reaction of the substrate has not yet occurred. Thus, these determined reaction rates can be regarded as the initial rates to be used in the Michaelis-Menten model (Eq. 5.1). In the multiple injection method, the total volume is changing due to the addition of solution, therefore the dilution of enzyme and substrate is considered during calculations.

The $\Delta H_{\text {app }}$ can be determined by the single injection method, where the reaction proceeds to substrate depletion. Integration of the total enthalpy in the single injection gives the $\Delta H_{a p p}$ :

$$
\Delta H_{\text {app }}=\frac{1}{S_{\text {total }} \times V} \int_{t=0}^{t=\infty} \frac{d Q(t)}{d t} d t
$$

where $S_{\text {total }}$ is the total substrate concentration in the single injection experiments.

In amide hydrolysis, the overall free energy change $\Delta G_{h}$ can be represented by

$$
\Delta G_{h}=\Delta G_{m}+\Delta G_{i}
$$

where $\Delta G_{m}$ is the free energy of hydrolysis of the amide bond to uncharged products and $\Delta G_{i}$ is the free energy of ionization (Martin 1998). $\Delta G_{i}$ may be calculated based on the $\mathrm{pH}$ and the dissociation constant of the corresponding carboxylic acid group and the amino group of the cleaved peptide bond. Based on the hydrolysis of glycyl peptides, Martin (1998) found $\Delta G_{m}$ to be $22.2 \mathrm{~kJ} \mathrm{~mol}^{-1}$ except when a glycine is released from the carboxyl terminus, where $\Delta G_{m}=$ $25.1 \mathrm{~kJ} \mathrm{~mol}^{-1}$. Martin (1998) suggested that these values should also apply to peptide bonds composed of other amino acids. The value of $\Delta G_{m}$ is positive, thus the reverse of hydrolysis (i.e. the synthesis reaction) is favored if ionization is absent. Since $\Delta G_{i}$ is always negative, it can overwhelm the positive $\Delta G_{m}$ and make the overall free energy change $\Delta G_{h}$ negative. The $\Delta G_{h}$ values in Martin's result range 
from $1.7 \mathrm{~kJ}-15.1 \mathrm{~kJ}$ for different cleavages in glycyl peptides of different length, due to different $\Delta G_{i}$ values.

The ITC experiments were conducted with a MicroCal iTC200 calorimeter (MicroCal, LLC., Northampton, MA, USA). This device was connected to a computer with MicroCal iTC200 software to control the device and record data. The sample cell was kept at $37^{\circ} \mathrm{C}$. The reference power was the default value, $10 \mu \mathrm{cal} \mathrm{s}{ }^{-1}(1 \mathrm{cal}=4.184 \mathrm{~J})$. Before every experiment, $200 \mu \mathrm{L}$ of $1 \mu \mathrm{M}$ pepsin solution was loaded to the sample cell, and $300 \mathrm{mM}$ of BSA solution was loaded to the injection syringe. The initial delay before titration was $60 \mathrm{~s}$ and the stirring speed was set to $1000 \mathrm{rpm}$.

Preliminary experiments were performed to determine the parameters of the final experiment, including the concentration of substrate and enzyme, the injection volume, and the injection interval. Blank tests were performed to determine the heat effect other than the reaction heat. In the final experiments, the multiple injection routine was $2 \mu \mathrm{L}$ of substrate solution $\times 19$ injections with an interval of $13 \mathrm{~s}$; in the single injection experiments, $5 \mu \mathrm{L}$ of substrate was injected into the $200 \mu \mathrm{L}$ of $1 \mu \mathrm{M}$ pepsin solution, the duration was $3600 \mathrm{~s}$.

\subsubsection{Determination of peptide bond cleavages}

The real substrates in protein hydrolysis are the peptide bonds. Protein hydrolysis by a single enzyme often cannot reach a theoretical complete conversion at which all peptide bonds would be cleaved, and the degree of hydrolysis varies with different enzymes and conditions. To determine the true reaction enthalpy per peptide bond cleavage, we coupled the ITC single injection method with the OPA method (Nielsen, Petersen, and Dambmann 2001). The OPA method was used to measure the peptide bond cleavage per mole of protein in the same condition and duration as the single injection experiments. A hydrolysis ratio $R_{h}$ is defined:

$$
R_{h}=\frac{P_{\text {amino }}}{S_{\text {protein }}}
$$


where $P_{\text {amino }}$ is the concentration of free amino groups produced in the hydrolysis, measured by the OPA method, $S_{\text {protein }}$ is the protein concentration.

The hydrolyses were performed in $1.5 \mathrm{~mL}$ Eppendorf tubes (Eppendorf, Hamburg, Germany) kept at $37^{\circ} \mathrm{C}$, and the enzyme-substrate ratio was kept the same as that in the ITC single injection experiments. The OPA method was performed as described previously (Q. Luo, Boom, and Janssen 2015), using a DU 720 (Beckman Coulter Inc., Pasadena, USA) spectrophotometer.

\subsubsection{Data analysis}

Matlab R2016b (MathWorks, Natick, USA) was used for data analysis of the ITC results. The function trapz (trapezoidal numerical integration) was used to calculate the peak area in the single injection experiments. Model fitting was done using the nonlinear fitting function lsqcurvefit that solves fitting problems using a nonlinear least-squares approach. The trust-region-reflective algorithm was chosen. The accuracy of fitting was analyzed by determining the coefficient of determination of the fit using the resnorm option of lsqcurvefit. The function nlparci was used to extract the $95 \%$ confidence interval of the parameters out of the Jacobian matrix.

\subsection{Result and discussion}

\subsubsection{Determining the reaction enthalpy}

To determine the true apparent molar enthalpy change for the protein hydrolysis, we used the ITC single injection experiments to measure the total enthalpy. Fig. 5.1A shows an example of the BSA ITC single injection experiment, other single injection data are shown in the supplementary material. In the blank experiment, where BSA was injected into a buffer solution without pepsin, a sharp positive peak 
appeared immediately after injection which returned to the baseline shortly. Generally, this heat effect is due to the dilution of the substrate solution. In the hydrolysis experiment, a smaller positive peak of dilution heat was rapidly overtaken by a large negative peak due to the reaction heat. The negative peak indicates that the protein hydrolysis is overall exothermic. The heat flow generated by the enzyme reaction was equivalent to the decrease in instrumental thermal power $(d Q / d t)$. Although the power supply of reaction experiment does not always return to the same baseline as the blank experiment, minimal change was observed from 1000 s-3600 s. Thus, we consider the reaction as nearly complete at $1000 \mathrm{~s}$, and calculate the apparent enthalpy per mole of protein $\Delta H_{\text {protein }}$ based on the integral between the blank and the hydrolysis curve of the first $1000 \mathrm{~s} \mathrm{(Eq.} \mathrm{5.5).}$

We coupled the single injection methods with the OPA method to determine the true reaction enthalpy per peptide bond cleavage. The values of $\Delta H$ and hydrolysis ratios $R_{h}$ at different conditions are reported in Table 5.1. The hydrolysis ratio $R_{h}$ can be regarded as the 'susceptible peptide bonds in one protein molecule' for a given duration of the reaction. $R_{h}$ can be used to convert $\Delta H_{\text {protein }}$ to the apparent enthalpy per peptide bond cleavage $\Delta H_{b o n d}$, as well as to calculate the substrate concentration $S$ in the Michaelis-Menten equation (Eq. 5.1). The substrate concentration in Eq. 5.1 should not be based on the total number of peptide bonds or the protein concentration, but rather on the peptide bonds that can be cleaved by the protease, which depends on the enzyme specificity. By using the hydrolysis ratio, we can fairly compare the enzymatic kinetics of proteases with different specificity.

The hydrolysis ratios range from 37.9 at $\mathrm{pH} 2$ and ionic strength $89 \mathrm{mM}$, to 59.3 at pH 2 and ionic strength $154 \mathrm{mM}$. Since the hydrolysis can be regarded as nearly completed, the difference in hydrolysis ratios may stem from the variation of pepsin specificity under different conditions. Hamuro et al. (2008) analyzed data from 39 proteins digested with immobilized porcine pepsin at $\mathrm{pHs}$ ranging from 1.3 to 2.5 and summarized the cleavage probability of different amino acid residues. For an estimation, we counted the number of peptide bonds 
Table 5.1: The apparent molar enthalpy for the hydrolysis of BSA by pepsin at different $\mathrm{pH}$ and ionic strengths, in $100 \mathrm{mM}$ phosphate buffers. $\Delta H_{\text {protein }}$ is the apparent enthalpy per mole of protein, and $\Delta H_{\text {bond }}$ is the apparent enthalpy per mole of peptide bond cleavages. The hydrolysis ratio is the mole of peptide bond cleavages per mole of protein in the duration of the single injection experiments (Eq. 5.7), measured by the OPA method. Data are the mean \pm standard deviation of duplicates.

\begin{tabular}{lllll}
\hline $\mathrm{pH}$ & $\begin{array}{l}\text { Ionic } \\
\text { strength } \\
(\mathrm{mM})\end{array}$ & $\begin{array}{l}-\Delta H_{\text {protein }} \\
\left(\mathrm{kJ} \mathrm{mol}^{-1}\right)\end{array}$ & $\begin{array}{l}\text { Hydrolysis } \\
\text { ratio }\end{array}$ & $\begin{array}{l}-\Delta H_{\text {bond }} \\
\left(\mathrm{kJ} \mathrm{mol}^{-1}\right)\end{array}$ \\
\hline 2 & 43 & $215 \pm 16$ & $48.1 \pm 6.8$ & 4.47 \\
2 & 89 & $153 \pm 18$ & $37.9 \pm 6.0$ & 4.04 \\
2 & 154 & $232 \pm 11$ & $59.3 \pm 2.7$ & 3.91 \\
2.5 & 89 & $257 \pm 6$ & $45.8 \pm 1.4$ & 5.61 \\
3 & 89 & $251 \pm 23$ & $46.5 \pm 1.3$ & 5.40 \\
3.5 & 96 & $282 \pm 78$ & $39.5 \pm 2.4$ & 7.14 \\
\hline
\end{tabular}

in BSA that has a cleavage probability $\geq 50 \%$ (based on Hamuro's chart of pepsin specificity by P1-P1' positions). The total count of these favored peptide bonds is 60 , which is roughly in accordance with the hydrolysis ratios we obtained.

Regardless of ionic strength, the $3 \Delta H_{\text {bond }}$ values at $\mathrm{pH} 2$ are very similar, while the values vary at different $\mathrm{pHs}$. This confirms the theory of Martin (1998), that the overall free energy change of peptide bond cleavage is largely determined by the free energy of ionization. One should bear in mind that these calculated $\Delta H_{\text {bond }}$ values are the average of the heat effect in different peptide bond cleavages in BSA. These $\Delta H_{\text {bond }}$ values were further used for determination of the kinetic parameters.

\subsubsection{Fitting kinetic parameters}

An example of an ITC multiple-injection experiment is shown in Fig. 5.1B. The vertical distance between the lowest point after each injec- 


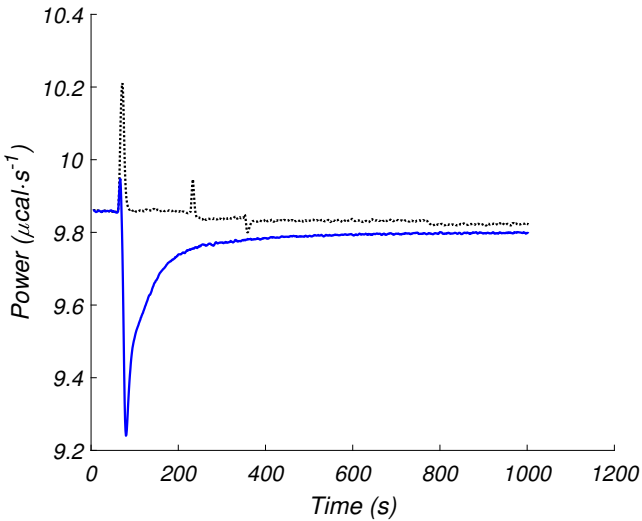

(A) Single injection experiment

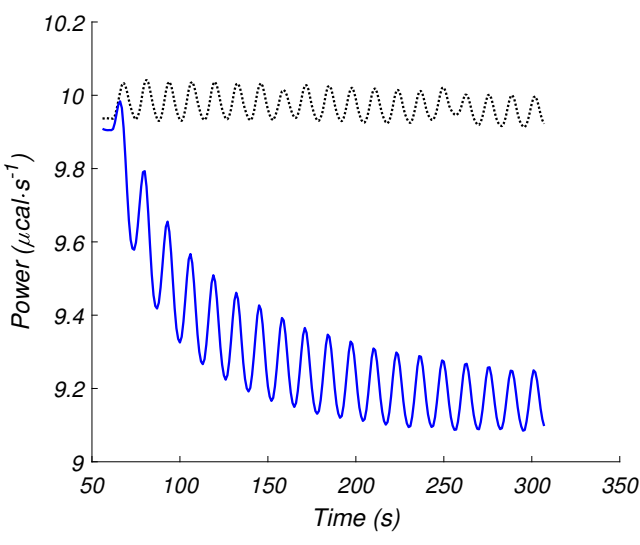

(B) Multiple injection experiment

Figure 5.1: Examples of isothermal tiration calorimetry experiments. The solutions used are $300 \mathrm{mM}$ BSA and $1 \mu \mathrm{M}$ pepsin in $100 \mathrm{mM}$ phosphate buffers. (A): The solid blue line shows one injection of $5 \mu \mathrm{L}$ of BSA into $200 \mu \mathrm{L}$ of pepsin solution. The dotted black line shows the blank where $5 \mu \mathrm{L}$ BSA solution was injected into the buffer solution without enzyme. (B): The solid blue line shows 19 injections of $2 \mu \mathrm{L}$ BSA solution into $200 \mu \mathrm{L}$ pepsin solution; the dotted black line shows the blank where the pepsin is absent, 19 injections of $2 \mu \mathrm{L}$ BSA solution into buffer solution without enzyme. The injection intervals were 13 seconds. 
tion and the blank was regarded as the $d Q / d t$ for calculating the reaction rates (Eq. 5.4). The hydrolysis ratios $R_{h}$ were used to convert the protein concentration to the 'susceptible' peptide bond concentration, which was regarded as the substrate concentration. The reaction rates were corrected for the enzyme concentration $(v / E)$ with consideration of enzyme dilution during titration, then plotted against the corresponding substrate concentration after each injection (Fig. 5.2).

We compared the effect of the ionic strength on the pepsin kinetics at $\mathrm{pH}$ 2. At these conditions, they all showed typical Michaelis-Menten curves. The reaction rate reached the maximum at approximately $4.0 \mathrm{~s}^{-1}$ when the ionic strength was $43 \mathrm{mM}$, but plateaued at $3.0 \mathrm{~s}^{-1}$ and $2.5 \mu \mathrm{M} \mathrm{s}^{-1}$ when the ionic strengths were $89 \mathrm{mM}$ and $154 \mathrm{mM}$ respectively.

When the ionic strength was the same, the reaction rate curves only showed slight differences at $\mathrm{pH} 2, \mathrm{pH} \mathrm{2.5}$, and $\mathrm{pH}$ 3. At $\mathrm{pH} 3.5$, the reaction rate was drastically lower. Interestingly, after reaching the maximum reaction rate at $\mathrm{pH} 3$ and $\mathrm{pH} 3.5$, a decrease of the reaction rate can be observed when the substrate concentration was further increased. We expect that this decrease in reaction rate could be the result of substrate or product inhibition that is more pronounced at higher $\mathrm{pH}$. This inhibition will be discussed later in this paper.

These data were fitted to the Michaelis-Menten equation (Eq. 5.1). The $K_{m}, k_{\text {cat }}$ and $k_{\text {cat }} / K_{m}$ values are reported in Table 5.2a, the model predictions were plotted in Fig. 5.2. To focus on the initial kinetics of pepsin, only the increasing section of the $\mathrm{pH} 3$ and $\mathrm{pH} 3.5$ data was used to fit the model. The kinetic parameters at $\mathrm{pH} 2$ and different ionic strength are in accordance with the analysis of the reaction rate curves: when the ionic strength increases, the $K_{m}$ value slightly increases and the $k_{c a t}$ values decreases, resulting in lower specificity constants $k_{\text {cat }} / K_{m}$. Dale and White (1983) proposed that the charge of the amino acid residues at the active site may influence the enzymatic reaction (which corresponds to how protonation is involved in the catalytic activity (Northrop 2001)). They found a correlation between the logarithm of the immobilized ribonuclease activity and the square root 
of the ionic strength of the reacting solution. Butré, Wierenga, and Gruppen (2012) reported that the enzymatic hydrolysis rate of whey protein isolate by Alcalase was reduced in the presence of $0.5 \mathrm{M} \mathrm{NaCl}$. They proposed that the decreased rate of hydrolysis would be due to increased structural stability of the protein at high ionic strength. Although the exact mechanism is unclear, the effect of ionic strength on enzymatic kinetics should be considered in food digestion research, since the ionic strength of food is diverse.

When the $\mathrm{pH}$ was increased from 2 to 3.5 at similar ionic strengths, we observed a decreasing trend both in $k_{c a t}$ and $K_{m}$. This suggests that pepsin is indeed less efficient at higher $\mathrm{pH}$ due to different protonation of the active site, though the affinity between pepsin and protein substrate may be higher. The difference in affinity may stem from the change in conformation of the pepsin, as well as the protein substrate.

In the pepsin-catalyzed hydrolysis of protein, many different peptide bonds are cleaved spontaneously. The kinetic parameters we observed are the average values of these different cleavages. However, this is still a valuable quantification of pepsin, which offers a better understanding in the function of pepsin in food digestion.

We compared the kinetic parameters for pepsin-catalyzed hydrolysis of BSA to that of small synthetic peptides, that have been extensively investigated and were summarized by Fruton (1970) and Fruton (1976). Some representative data are shown in Table 5.2b. The F-F bond is one of the preferred peptide bonds for pepsin (Hamuro et al. 2008). The kinetic parameters of pepsin with substrate Z-H-F-F-OEt in the $\mathrm{pH}$ range from 1.0 to 5.5 are shown in the first part of the table. The $K_{m}$ values do not show great variation, and they are comparable to the values of BSA as substrate. The $K_{m}$ values were highest at $\mathrm{pH}$ 1.5-2.5 and decreased at higher $\mathrm{pH}$, which agrees with the observation of BSA as substrate. In contrast, the $k_{\text {cat }}$ values are more than 10 times lower compared to that of BSA as substrate. Moreover, the maximum activity was reached at around $\mathrm{pH} 4.5$ which is very different from that of BSA as well as hemoglobin (Pletschke, Naudé, and 
Oelofsen 1995). The kinetic parameters of substrates with the same cleavage site but different length $\left(\mathrm{Z}-(\mathrm{G})_{\mathrm{n}}-\mathrm{F}-\mathrm{F}-\mathrm{OP} 4 \mathrm{P}\right)$ are shown in the second part of the table. The $K_{m}$ values were still similar, but the $k_{\text {cat }}$ values ranged over three orders of magnitude. The $k_{\text {cat }}$ value for Z-G-G-F-F-OP4P is approximately 100 times higher than that of Z-F$\mathrm{F}-\mathrm{OP} 4 \mathrm{P}$, and the values of pepsin with BSA are comparable to that of pepsin with Z-G-G-F-F-OP4P. According to the subsite theory (Powers, Harley, and Myers 1977), the binding of amino acid residues to the subsites may largely affect the pepsin efficiency in bond cleavage. The conformation of pepsin may change when binding to some naturally occurring substrates such as casein, and increase the cleavage efficiency (Foltmann et al. 1981). The short peptides may indicate the bond cleavage preference of pepsin, but they cannot indicate the true kinetics of pepsin with natural occurring substrates. The catalytic efficiency of pepsin is determined by the combination of peptide bond, subsites, and substrate conformation.

\subsubsection{Using single injection data to study time dependent pepsin kinetics}

The single injection experiment contains more information than solely $\Delta H_{a p p}$ : since every record of power compensation indicates the reaction rate at that moment. At any given time, the number of cleaved peptide bonds $\mathrm{P}(\mathrm{t})$ and remaining substrate concentration $\mathrm{S}(\mathrm{t})$ can be determined from the integral amount of heat evolved from the reaction (Todd and Gomez 2001):

$$
\begin{gathered}
P(t)=\frac{\int_{t=0}^{t} Q(t)}{\Delta H_{\text {bond }} \cdot V} \\
S(t)=S_{\text {Total }}-P(t)
\end{gathered}
$$

The degree of hydrolysis can be calculated based on the product concentration:

$$
D H=\frac{P(t)}{N_{p} \times S_{\text {protein }}} \times 100 \%
$$


Table 5.2: Kinetic parameters for pepsin-catalyzed hydrolysis of BSA and synthetic peptides.

(a) BSA as substrate, at different $\mathrm{pH}$ and ionic strength. The uncertainties are the $95 \%$ confidence intervals of the fitted parameters.

\begin{tabular}{llllll}
\hline $\mathrm{pH}$ & $\begin{array}{l}\text { Ionic } \\
\text { strength } \\
(\mathrm{mM})\end{array}$ & $K_{m}(\mathrm{mM})$ & $k_{\text {cat }}\left(\mathrm{s}^{-1}\right)$ & $\begin{array}{l}k_{\text {cat }} / K_{m} \\
\left(\mathrm{mM}^{-1} \mathrm{~s}^{-1}\right)\end{array}$ & $R^{2}$ \\
\hline 2 & 43 & $0.200 \pm 0.020$ & $4.44 \pm 0.08$ & 22.1 & 0.981 \\
2 & 89 & $0.224 \pm 0.015$ & $3.56 \pm 0.05$ & 15.9 & 0.991 \\
2 & 154 & $0.311 \pm 0.030$ & $2.81 \pm 0.06$ & 9.07 & 0.982 \\
2.5 & 89 & $0.129 \pm 0.014$ & $3.53 \pm 0.6$ & 27.3 & 0.996 \\
3 & 89 & $0.114 \pm 0.014$ & $3.33 \pm 0.11$ & 29.2 & 0.991 \\
3.5 & 96 & $0.102 \pm 0.041$ & $1.48 \pm 0.14$ & 14.5 & 0.963 \\
\hline
\end{tabular}

(b) Synthetic peptides as substrates. Z represents a benzyloxycarbonyl group, OEt represents a methoxy group, OP4P represents a C-terminal 3(4-pyridyl)propyl-1-oxy group, others are the one-letter abbreviations of amino acids. ${ }^{\mathrm{a}}$ Data from Hollands and Fruton (1968), pepsin concentration $2.8 \times 10^{-4} \mathrm{mM}$, temperature $37^{\circ} \mathrm{C}$. ${ }^{\mathrm{b}}$ Data from Sachdev and Fruton (1969). N.B. Some errors in the original articles concerning the power notation of the units were cross-referenced and corrected.

\begin{tabular}{llllll}
\hline $\mathrm{pH}$ & $\begin{array}{l}\text { Ionic } \\
\text { strength } \\
(\mathrm{mM})\end{array}$ & $K_{m}(\mathrm{mM})$ & $k_{\text {cat }}\left(\mathrm{s}^{-1}\right)$ & $\begin{array}{l}k_{\text {cat }} / K_{m} \\
\left(\mathrm{mM}^{-1} \mathrm{~s}^{-1}\right)\end{array}$ \\
\hline 1.0 & - & 0.26 & 0.1 & 0.39 & Z-H-F-F-OEt $^{\mathrm{a}}$ \\
1.5 & - & 0.37 & 0.13 & 0.35 & Z-H-F-F-OEt $^{\mathrm{a}}$ \\
2.0 & - & 0.33 & 0.11 & 0.31 & Z-H-F-F-OEt $^{\mathrm{a}}$ \\
2.5 & 8 & 0.37 & 0.14 & 0.37 & Z-H-F-F-OEt $^{\mathrm{a}}$ \\
3.0 & 17 & 0.28 & 0.15 & 0.53 & Z-H-F-F-OEt $^{\mathrm{a}}$ \\
3.5 & 29 & 0.21 & 0.21 & 0.99 & Z-H-F-F-OEt $^{\mathrm{a}}$ \\
4.0 & 35 & 0.17 & 0.33 & 1.90 & Z-H-F-F-OEt $^{\mathrm{a}}$ \\
4.5 & 39 & 0.18 & 0.47 & 2.65 & Z-H-F-F-OEt $^{\mathrm{a}}$ \\
5.0 & 39 & 0.09 & 0.28 & 2.95 & Z-H-F-F-OEt $^{\mathrm{a}}$ \\
5.5 & 43 & 0.04 & 0.08 & 2.65 & Z-H-F-F-OEt \\
2.0 & - & 0.7 & 0.49 & 0.70 & Z-F-F-OP4P \\
3.0 & - & 0.2 & 0.74 & 3.7 & Z-F-F-OP4P $^{\mathrm{b}}$ \\
2.0 & - & 1.1 & 2.2 & 2.0 & Z-G-F-F-OP4P $^{\mathrm{b}}$ \\
3.5 & - & 0.4 & 3.1 & 7.8 & Z-G-F-F-OP4P $^{\mathrm{b}}$ \\
2.0 & - & 0.8 & 56.5 & 70.6 & Z-G-G-F-F-OP4P \\
3.5 & - & 0.4 & 71.8 & 180 & Z-G-G-F-F-OP4P \\
\hline
\end{tabular}




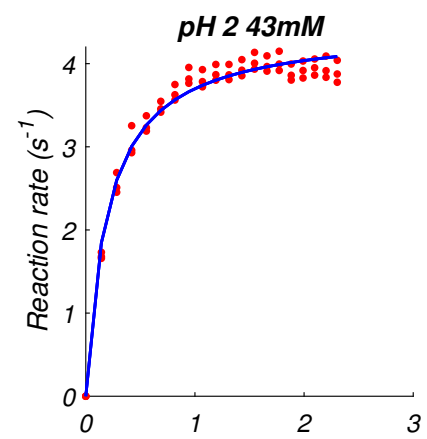

Substrate concentration (mM)

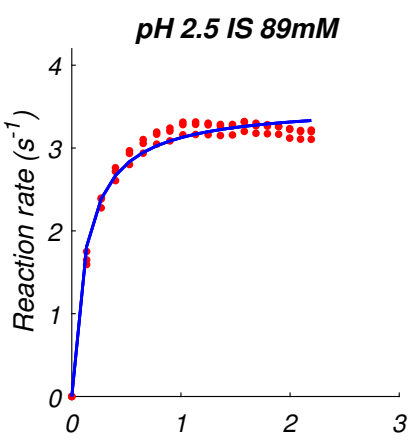

Substrate concentration ( $\mathrm{mM}$ )

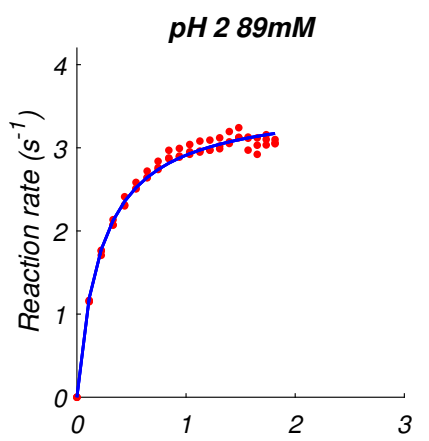

Substrate concentration ( $\mathrm{mM}$ )

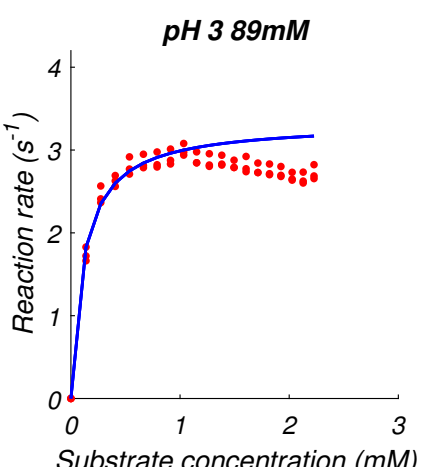

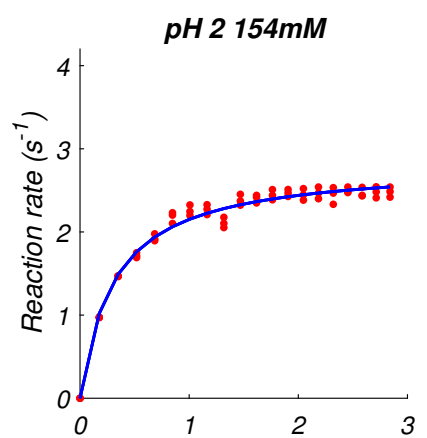

Substrate concentration (mM)

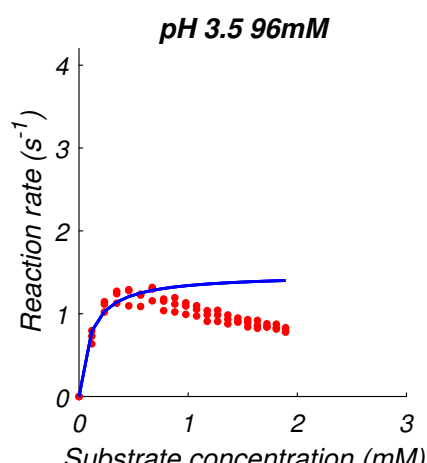

Figure 5.2: Reaction rate of BSA at varied concentrations in $1 \mu \mathrm{M}$ pepsin under different $\mathrm{pH}$ and ionic strength. The red dots are the data calculated from three repetitions of ITC experiments, the blue lines are the fitted prediction from the Michaelis-Menten model. The $\mathrm{pH}$ and ionic strength of all conditions are given above each graph. 


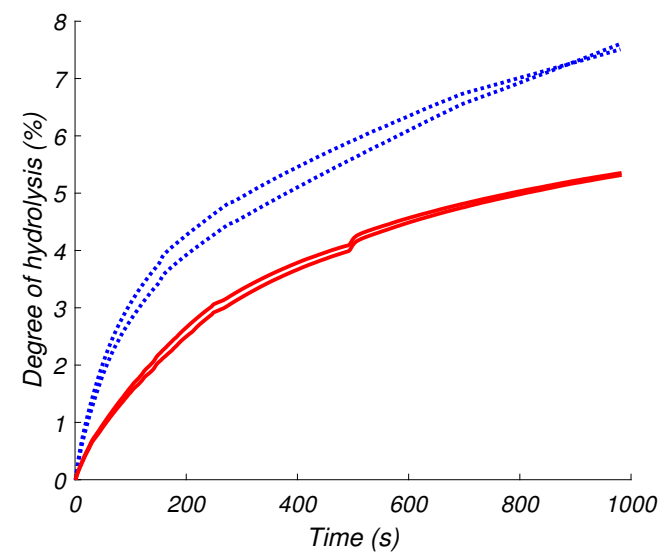

Figure 5.3: Examples of Hydrolysis curves of BSA hydrolyzed by pepsin, using ITC single injection data. Data from two experiments at two conditions were used: dotted blue lines are at $\mathrm{pH} 2$ and ionic strength $43 \mathrm{mM}$, the solid red lines are at $\mathrm{pH} 3.5$ and ionic strength $96 \mathrm{mM}$.

where $P(t)$ is the peptide bond cleavage at a certain time (Eq. 5.8), $S_{\text {protein }}$ is the protein concentration, $N_{p}$ is the number of peptide bonds in the protein substrate $\left(N_{p}=582\right.$ for BSA). Since the single injection experiments were designed to reach substrate depletion, the trends for the kinetics of all six conditions were similar. The data at $\mathrm{pH} 2$ (ionic strength $43 \mathrm{mM}$ ) and $\mathrm{pH} 3.5$ (ionic strength $96 \mathrm{mM}$ ) were the most contrasting, and are used as examples for this section. The degree of hydrolysis is plotted as a function of time in Fig. 5.3. The curves are typical for protein hydrolysis: the increase was rapid in the beginning of the reaction, and slowed down as the hydrolysis proceeded. The reaction reached a degree of hydrolysis of roughly $8 \%$ at 1000 s for $\mathrm{pH} 2$ and ionic strength $43 \mathrm{mM}$, and about $5 \%$ for $\mathrm{pH} 3.5$ and ionic strength $96 \mathrm{mM}$. This showed the potential application of ITC for studying the degree of hydrolysis, which may be applied to more studies of protein hydrolysis. The advantage of ITC still applies: time-saving and highlysensitive. The $\Delta H_{\text {bond }}$ needs to be determined by combining the ITC with a measurement of the total peptide bond cleavages, though a single measurement is sufficient.

Since the substrate concentration and the reaction rate at every mo- 


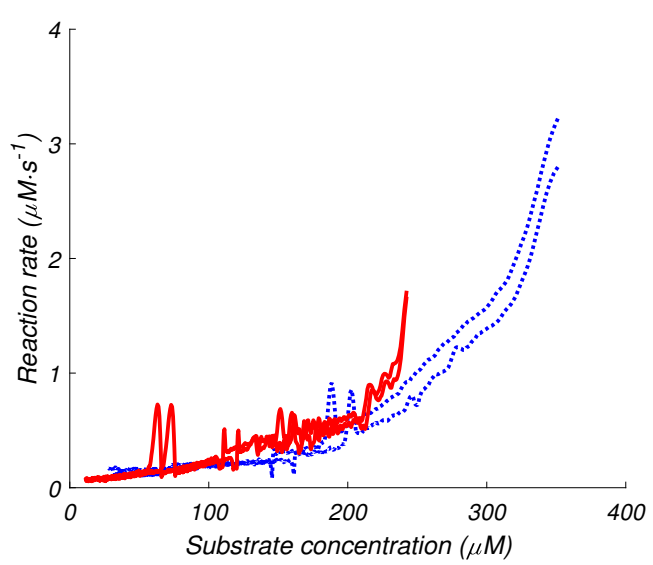

Figure 5.4: Reaction rate of pepsin-catalyzed hydrolysis of BSA, at different remaining substrate concentration during ITC single injection experiments. Duplicates at two conditions are shown: dotted blue lines are at $\mathrm{pH} 2$ and ionic strength $43 \mathrm{mM}$, the solid red lines are at $\mathrm{pH} 3.5$ and ionic strength $96 \mathrm{mM}$.

ment can be calculated, we can study the time-dependent kinetics of pepsin concerning substrate concentration. The reaction rate is plotted against the substrate concentration at that same moment (Fig. 5.4), the short delay before reaching the maximum reaction rate was neglected. The curve shape in Fig. 5.4 suggests that the decrease in reaction rate is not simply due to the reduction of substrate concentration like typical Michaelis-Menten kinetics. As the hydrolysis proceeded and the substrate concentration decreased (right to left), the reaction rate dropped rapidly in the beginning and leveled off as the reaction proceeded. In comparison, Todd and Gomez (2001) applied the same integration method on the data of trypsin-catalyzed hydrolysis and obtained typical Michaelis-Menten curves. Therefore, some form of enzyme inhibition had occurred during the pepsin catalyzed hydrolysis of protein.

Did substrate or product inhibition occur? Substrate inhibition cannot explain the rapid decrease of reaction rate during the single injection experiment (Fig. 5.4). It is unlikely that product inhibition occurred, since our preliminary experiments had shown that longer intervals between injections had little impact on the titration curves. This suggests 
that the hydrolysis was not inhibited by the higher quantity of accumulated final product.

We postulate that "intermediate peptide inhibition" may have occurred. What we observed in Fig. 5.4 was rapid hydrolysis of the more efficient substrate (the substrates that pepsin cleaves faster) in the early stage and slower hydrolysis of less efficient substrate in the later stage. As we showed in Table 5.2b, the pepsin catalyzed hydrolysis rate for different substrates ranged over three orders of magnitude. In the meantime, all substrates do not show large deviation in the $K_{m}$ values, thus pepsin will not selectively bind the efficient substrates. Once the less efficient substrates appear, they act as the competitive substrate and slow down the overall reaction rate. This phenomenon can be related to the Linderstrøm-lang protein hydrolysis model (Linderstrøm-Lang 1952; Adler-Nissen 1976). We previously showed that whey protein and egg white protein solutions were hydrolyzed by pepsin through a "zipper" type mechanism, where the denatured proteins were hydrolyzed rapidly into intermediate peptides, and the intermediate peptides were hydrolyzed at a slower rate, which causes an accumulation of the intermediate peptides (Q. Luo, Boom, and Janssen 2015). The slower hydrolysis of the intermediate peptides caused a slower overall reaction rate, which can be viewed as "intermediate peptide inhibition". This could also explain why the decrease of reaction rate after reaching maximum in Fig. 5.2 is more pronounce at higher $\mathrm{pH}$. Because the maximum reaction rate was reached earlier when the $\mathrm{pH}$ was higher (the $K_{m}$ values are lower), the inhibition by the accumulating intermediates can no longer be compensated by the increase of reaction rate from adding substrate.

\subsection{Conclusion}

Due to the limitation of methods and the complexity of protein substrate, previous studies on pepsin kinetics were mostly based on small synthetic peptides, which cannot represent the true kinetics of pepsin with naturally occurring substrates. ITC is a powerful and sensitive 
tool but challenging for studying the enzymatic hydrolysis of proteins. We combined ITC with the OPA method, and produced reliable kinetic parameters for the pepsin-catalyzed hydrolysis of BSA.

We investigated the effect of $\mathrm{pH}$ and ionic strength on the pepsin kinetics using ITC. Pepsin has higher activity at $\mathrm{pH} 2$ than at higher $\mathrm{pH}$ values, while its affinity to substrate is lower. At the same $\mathrm{pH}$, pepsin has lower activity and lower affinity when the ionic strength increases. We found contrasting pepsin kinetic parameters of BSA and of small synthetic peptides, and the reaction rate for intact protein is also drastically faster than intermediate peptides.

The data of ITC single injection experiments can be used to study the time-dependent kinetics of pepsin. The degree of hydrolysis can be followed continuously. The reaction rate versus substrate concentration plot (Fig. 5.4) did not show a typical Michaelis-Menten curve. We postulated that may be due to the lower efficiency of pepsin towards intermediate peptides during hydrolysis. The kinetic parameters of pepsin towards different substrates and the "intermediate peptide inhibition" both suggest the physiological function of the pepsin to be: stimulating the disintegration of the food bolus by fast hydrolysis of intact proteins, rather than finely digesting the proteins into absorption-ready peptides. 


\subsection{Supplementary information}
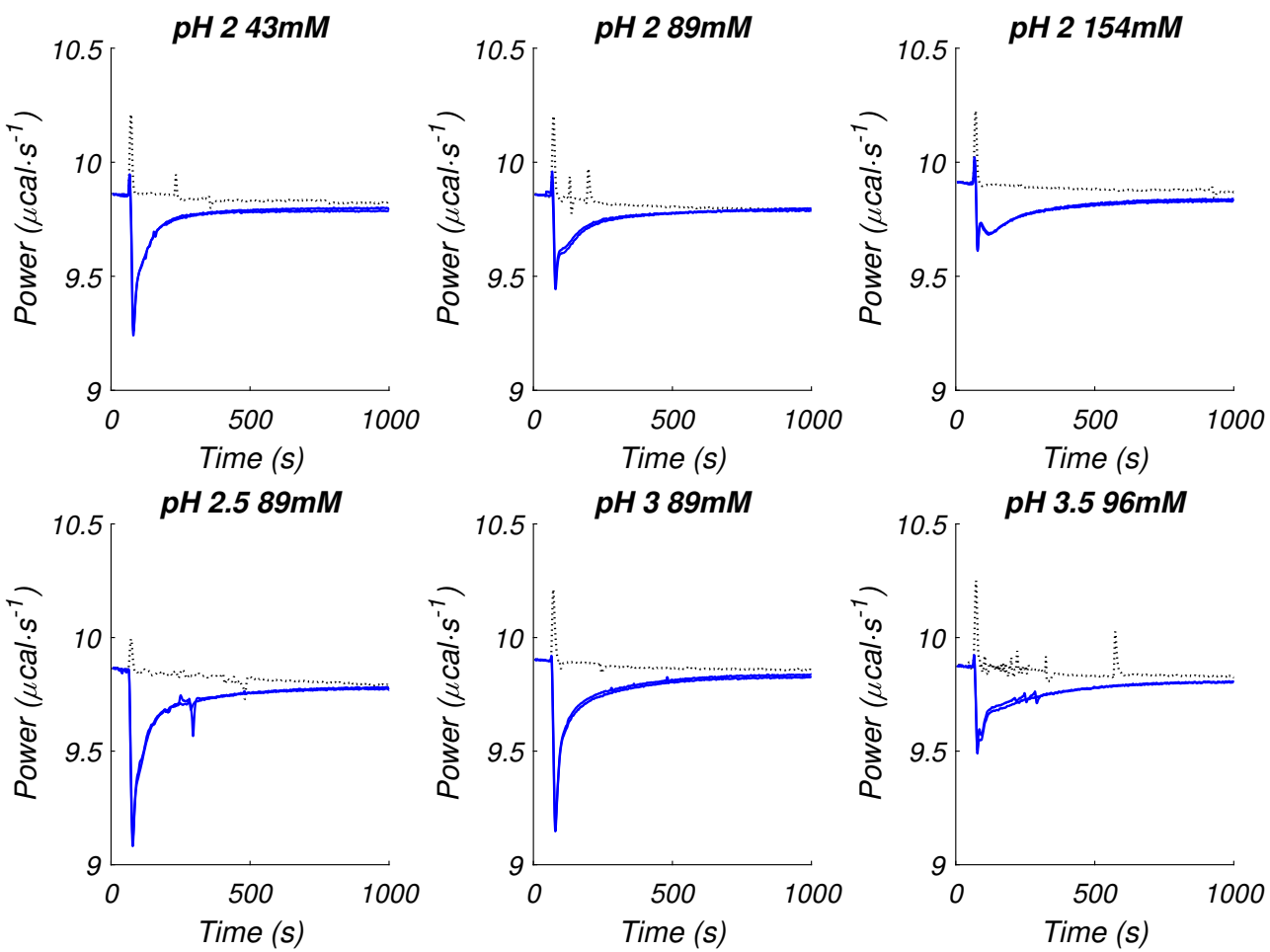

Figure 5.5: Supplementary information: isothermal tiration calorimetry single injection experiments under different $\mathrm{pH}$ and ionic strength. The solutions used are $300 \mathrm{mM}$ BSA and $1 \mu \mathrm{M}$ pepsin in $100 \mathrm{mM}$ phosphate buffers. The solid blue lines show, two repetitions of $5 \mu \mathrm{L}$ of BSA injected into $200 \mu \mathrm{L}$ of pepsin solution. The dotted black line shows the blank, where $5 \mu \mathrm{L}$ BSA solution was injected into the buffer solution without enzyme. The $\mathrm{pH}$ and ionic strength of all conditions are given above each graph.

\section{References}

Adler-Nissen, J. (Nov. 1, 1976). "Enzymic Hydrolysis of Proteins for Increased Solubility." In: Journal of Agricultural and Food Chemistry 24.6, pp. 1090-1093. Dor: 10. 1021/ j f60208a021. 
Ahn, J., M.-J. Cao, Y. Q. Yu, and J. R. Engen (June 1, 2013). “Accessing the Reproducibility and Specificity of Pepsin and Other Aspartic Proteases." In: Biochimica et Biophysica Acta (BBA) - Proteins and Proteomics 1834.6, pp. 1222-1229. DoI: 10 . 1016/ j . bbapap . 2012. 10.003.

Boirie, Y., M. Dangin, P. Gachon, M.-P. Vasson, J.-L. Maubois, and B. Beaufrere (Dec. 23, 1997). "Slow and Fast Dietary Proteins Differently Modulate Postprandial Protein Accretion." In: Proceedings of the National Academy of Sciences of the United States of America 94.26, pp. 14930-14935. pmid: 9405716.

Butré, C. I., P. A. Wierenga, and H. Gruppen (June 6, 2012). "Effects of Ionic Strength on the Enzymatic Hydrolysis of Diluted and Concentrated Whey Protein Isolate." In: Journal of Agricultural and Food Chemistry 60.22, pp. 5644-5651. DoI: 10.1021/ jf301409n.

Dale, B. E. and D. H. White (May 1, 1983). "Ionic Strength: A Neglected Variable in Enzyme Technology." In: Enzyme and Microbial Technology 5.3, pp. 227-229. DoI: 10 . 1016/0141-0229 (83 ) 90101-1. Denis, S., T. Sayd, A. Georges, C. Chambon, S. Chalancon, V. SantéLhoutellier, and S. Blanquet-Diot (June 15, 2016). "Digestion of Cooked Meat Proteins Is Slightly Affected by Age as Assessed Using the Dynamic Gastrointestinal TIM Model and Mass Spectrometry." In: Food E Function 7.6, pp. 2682-2691. DoI: 10.1039/C6F000120C.

Dunn, B. M. (2001). "Overview of Pepsin-like Aspartic Peptidases." In: Current protocols in protein science Chapter 21, Unit 21.3. DoI: 10. 1002/0471140864.ps2103s25.

Dunn, B. M. (Dec. 1, 2002). "Structure and Mechanism of the PepsinLike Family of Aspartic Peptidases." In: Chemical Reviews 102.12, pp. 4431-4458. Dor: 10. 1021/cr010167q.

Foltmann, B. (1981). “Gastric Proteinases-Structure, Function, Evolution and Mechanism of Action.” In: Essays Biochem 17, pp. 52-84.

Foltmann, B., A. L. Jensen, P. Lønblad, E. Smidt, and N. H. Axelsen (Jan. 1, 1981). "A Developmental Analysis of the Production of Chymosin and Pepsin in Pigs." In: Comparative Biochemistry and Physiology Part B: Comparative Biochemistry 68.1, pp. 9-13. Dor: 10.1016/ 0305-0491(81)90172-3. 
Freyer, M. W. and E. A. Lewis (2008). "Isothermal Titration Calorimetry: Experimental Design, Data Analysis, and Probing Macromolecule/Ligand Binding and Kinetic Interactions." In: Biophysical Tools for Biologists, Volume One: In Vitro Techniques. Vol. 84. Methods in Cell Biology. Academic Press, pp. 79-113.

Fruton, J. S. (1970). "The Specificity and Mechanism of Pepsin Action." In: Advances in Enzymology and Related Areas of Molecular Biology. Ed. by F. F. Nord. John Wiley \& Sons, Inc., pp. 401-443. Dor: 10 . 1002 / 9780470122785 . ch9.

Fruton, J. S. (1976). "The Mechanism of the Catalytic Action of Pepsin and Related Acid Proteinases." In: Advances in Enzymology and Related Areas of Molecular Biology. Ed. by A. Meister. John Wiley \& Sons, Inc., pp. 1-36. DoI: 10. 1002/9780470122891.ch1.

Hamuro, Y., S. J. Coales, K. S. Molnar, S. J. Tuske, and J. A. Morrow (Apr. 15, 2008). "Specificity of Immobilized Porcine Pepsin in H/D Exchange Compatible Conditions.” In: Rapid Communications in Mass Spectrometry 22.7, pp. 1041-1046. DoI: 10.1002/ rcm. 3467. Hollands, T. R. and J. S. Fruton (1968). "Kinetics of the Hydrolysis of Synthetic Substrates by Pepsin and by Acetyl-Pepsin.” In: Biochemistry 7.6, pp. 2045-2053.

Hsu, H. W., D. L. Vavak, L. D. Satterlee, and G. A. Miller (Sept. 1, 1977). "A Multienzyme Technique for Estimating Protein Digestibility.” In: Journal of Food Science 42.5, pp. 1269-1273. Dor: 10 . 1111/ j . 1365-2621 . 1977. tb14476 . x.

Johnson, K. A. and R. S. Goody (Oct. 4, 2011). “The Original Michaelis Constant: Translation of the 1913 Michaelis-Menten Paper.” In: Biochemistry 50.39, pp. 8264-8269. DoI: 10.1021/bi201284u.

Kageyama, T. (Apr. 30, 2014). "Pepsinogens, Progastricsins, and Prochymosins: Structure, Function, Evolution, and Development." In: Cellular and Molecular Life Sciences CMLS 59.2, pp. 288-306. DoI: 10. 1007/s00018-002-8423-9.

Kondjoyan, A., J.-D. Daudin, and V. Santé-Lhoutellier (Apr. 2015). "Modelling of Pepsin Digestibility of Myofibrillar Proteins and of Variations Due to Heating." In: Food Chemistry 172, pp. 265-271. DoI: 10.1016/ j . foodchem. 2014 .08.110. 
Kopper, R. A., N. Odum, M. Sen, R. M. Helm, J. Steve Stanley, and A. Wesley Burks (Sept. 2004). "Peanut Protein Allergens: Gastric Digestion Is Carried out Exclusively by Pepsin.” In: Journal of Allergy and Clinical Immunology 114.3, pp. 614-618. Dor: 10.1016/ j . jaci . 2004 .05. 012.

Linderstrøm-Lang, K. U. (1952). Lane Medical Lectures: Proteins and Enzymes. Stanford University Press. $132 \mathrm{pp}$.

Luo, Q., R. M. Boom, and A. E. M. Janssen (Sept. 2015). "Digestion of Protein and Protein Gels in Simulated Gastric Environment." In: LWT - Food Science and Technology 63.1, pp. 161-168. DoI: 10.1016/ j. lwt.2015.03.087.

Martin, R. B. (Apr. 15, 1998). "Free Energies and Equilibria of Peptide Bond Hydrolysis and Formation.” In: Biopolymers 45.5, pp. 351-353. DOI: 10 . 1002 / (SICI ) 1097-0282 (19980415) 45:5<351: :AID-BIP3> 3. 0 . C0 ; 2-K.

Michaelis, L. and M. L. Menten (1913). "Die Kinetik Der Invertinwirkung." In: Biochem Z 49 (February), pp. 333-369. Dor: 10.1021/ bi201284u.

Miller, B. G. and R. Wolfenden (2002). "Catalytic Proficiency: The Unusual Case of OMP Decarboxylase." In: Annual Review of Biochemistry 71.1, pp. 847-885. DoI: 10 . 1146 / annurev . biochem . 71 . 110601. 135446. pmid: 12045113.

Minekus, M., M. Alminger, P. Alvito, S. Ballance, T. Bohn, C. Bourlieu, F. Carrière, R. Boutrou, M. Corredig, D. Dupont, C. Dufour, L. Egger, M. Golding, S. Karakaya, B. Kirkhus, S. Le Feunteun, U. Lesmes, A. Macierzanka, A. Mackie, S. Marze, D. J. McClements, O. Ménard, I. Recio, C. N. Santos, R. P. Singh, G. E. Vegarud, M. S. J. Wickham, W. Weitschies, and A. Brodkorb (2014). "A Standardised Static in Vitro Digestion Method Suitable for Food - an International Consensus." In: Food E Function 5.6, p. 1113. Dor: 10.1039/c3fo60702 j.

Morin, P. E. and E. Freire (Aug. 27, 1991). "Direct Calorimetric Analysis of the Enzymatic Activity of Yeast Cytochrome c Oxidase." In: Biochemistry 30.34, pp. 8494-8500. pmid: 1653014.

Nielsen, P., D. Petersen, and C. Dambmann (2001). "Improved Method for Determining Food Protein Degree of Hydrolysis." In: Journal of 
Food Science 66.5, pp. 642-646. Dor: 10.1111/ j . 1365-2621. 2001. tb04614. $x$.

Nilsson, M., J. J. Holst, and I. M. Björck (Jan. 4, 2007). "Metabolic Effects of Amino Acid Mixtures and Whey Protein in Healthy Subjects: Studies Using Glucose-Equivalent Drinks." In: The American Journal of Clinical Nutrition 85.4, pp. 996-1004. pmid: 17413098.

Northrop, D. B. (Oct. 1, 2001). "Follow the Protons: A Low-Barrier Hydrogen Bond Unifies the Mechanisms of the Aspartic Proteases." In: Accounts of Chemical Research 34.10, pp. 790-797. DoI: 10.1021/ ar000184m.

Pletschke, B. I., R. J. Naudé, and W. Oelofsen (Dec. 1995). “Ostrich Pepsins I and II: A Kinetic and Thermodynamic Investigation." In: The International Journal of Biochemistry \& Cell Biology 27.12, pp. 1293-1302. DoI: 10.1016/1357-2725(95)00092-4.

Polovic, N., M. Blanusa, M. Gavrovic-Jankulovic, M. AtanaskovicMarkovic, L. Burazer, R. Jankov, and T. C. Velickovic (2007). “A Matrix Effect in Pectin-Rich Fruits Hampers Digestion of Allergen by Pepsin in Vivo and in Vitro." In: Clinical E Experimental Allergy 37.5, pp. 764-771. Dor: 10.1111/ j . 1365-2222.2007.02703 .x.

Powers, J. C., A. D. Harley, and D. V. Myers (1977). "Subsite Specificity of Porcine Pepsin." In: Acid Proteases:Structure, Function, and Biology. Advances in Experimental Medicine and Biology. Springer, Boston, MA, pp. 141-157. Dor: 10.1007/978-1-4757-0719-9_9.

Sachdev, G. P. and J. S. Fruton (1969). "Pyridyl Esters of Peptides as Synthetic Substrates of Pepsin.” In: Biochemistry 8.11, pp. 42314238.

Schmidt, D. G., R. J. Meijer, C. J. Slangen, and E. C. van Beresteijn (Oct. 1995). "Raising the $\mathrm{pH}$ of the Pepsin-Catalysed Hydrolysis of Bovine Whey Proteins Increases the Antigenicity of the Hydrolysates." In: Clinical and experimental allergy: journal of the British Society for Allergy and Clinical Immunology 25.10, pp. 1007-1017. pmid: 8556555. Todd, M. J. and J. Gomez (2001). "Enzyme Kinetics Determined Using Calorimetry: A General Assay for Enzyme Activity?" In: Analytical biochemistry 296.2, pp. 179-187. Dor: 10.1006/abio.2001.5218. 
Williams, B. A. and E. J. Toone (1993). "Calorimetric Evaluation of Enzyme Kinetic Parameters." In: The Journal of Organic Chemistry 58.13, pp. 3507-3510. 


\section{Chapter 6}

\section{Interactions between acid and proteins under in vitro gastric condition - a theoretical and experimental quantification}

This chapter is based on:

Q. Luo, W. Zhan, R. M. Boom, A. E. M. Janssen. "Interactions between acid and proteins under in vitro gastric condition - a theoretical and experimental quantification" Submitted for publication. 


\section{Abstract}

The gastric digestion of proteins is influenced by the $\mathrm{pH}$ and the gastric $\mathrm{pH}$ fluctuates after food consumption. However, the gastric $\mathrm{pH}$ dynamics still need to be quantitatively understood. Protein strongly influences the gastric $\mathrm{pH}$. Therefore, we studied the interaction between acid and proteins, including the buffer reaction and the acid diffusion in protein gels. In theory, the buffer capacity of proteins can be characterized by its content of ionizable amino acid side groups. We validated this by titrating protein solutions and gels with hydrochloric acid. Moreover, the liberated carboxyl and amino groups during enzymatic hydrolysis of protein can also contribute to the buffer capacity. While we expected protons to diffuse faster than pepsin, we found that the penetration distance of acid is comparable to that of pepsin. Moreover, buffer reaction caused the acid to concentrate tenfold in the gel compared to the bulk acid concentration. Therefore, we postulated that the buffer reaction reduces acid diffusivity in gels. 


\subsection{Introduction}

The gastric digestion kinetics of food proteins are influenced by the gastric $\mathrm{pH}$. Pepsin is the major enzyme in the stomach, it has maximum activity between pH 1.5 and 2.5 (Piper and Fenton 1965). Dekkers et al. (2016) studied the proteolytic digestion of mixed $\beta$ lactoglobulin-Xanthan gels and found a lower digestion rate when using a dynamic $\mathrm{pH}$ profile reflecting in vivo conditions than when using a conventional highly acidic ( $\mathrm{pH} 1.9)$ profile. Food structure may hinder the acid penetration into the food matrix. Mennah-Govela, Bornhorst, and R. P. Singh (2015) found the effective diffusivity of gastric juice into the rice bolus was greater in brown rice than in white rice. Starch hydrolysis by $\alpha$-amylase may continue in the stomach before the gastric acid penetrates the rice bolus. Floury et al. (2018) studied the breakdown of dairy protein gels during in vitro gastric digestion using time-lapse synchrotron deep-UV fluorescence microscopy. This methodology can follow both the protein content and the acidification of the dairy gel particles. The images of the gels during the digestion process indicated a synergy between acid diffusion and enzymatic reaction.

The gastric $\mathrm{pH}$ fluctuates in response to food consumption. When fasting, the human gastric pH is usually around 2 (Scarr et al. 1989; S. Phillips, Hutchinson, and Davidson 1993). After food ingestion, the gastric $\mathrm{pH}$ rises depending on the volume and content of the food. The gastric $\mathrm{pH}$ gradually decreases, as gastric fluid is being secreted and the food is being digested and emptied from the stomach. Malagelada et al. (1976) studied healthy volunteers after an ordinary meal consists of steak, bread, ice cream and water, gastric $\mathrm{pH}$ after ingesting of the meal approximated 5, then fell to $\mathrm{pH} 3$ after $1 \mathrm{~h}$ and to $\mathrm{pH} 2$ after $2 \mathrm{~h}$. Sullivan et al. (2014) studied the gastric digestion of $\alpha$-lactalbumin in healthy volunteers, after taking $250 \mathrm{~mL}$ of test drink containing sucrose and $\alpha$-lactalbumin, the gastric $\mathrm{pH}$ increased to nearly 7 but returned to about 2 within $10 \mathrm{~min}$. When the test drink contained oleic acid instead of $\alpha$-lactalbumin, the gastric $\mathrm{pH}$ remained stable. 
The influence and importance of buffer capacity of foods on the gastric $\mathrm{pH}$ has been discussed, while a quantification of such influence is yet absent. We aim here to quantify the buffer capacity of protein, and consequently to better understand the dynamic process of gastric $\mathrm{pH}$ change. We also hypothesize that the buffer capacity of protein also has a strong impact on the acid diffusion into the protein based foods.

\subsubsection{Theory basis of buffer capacity}

Buffer capacity is an important physico-chemical characteristic of proteins. Salaün, Mietton, and Gaucheron (2005) reviewed the buffer capacity of dairy products, while the buffer capacity of monoclonal antibody was also studied (Gokarn et al. 2008; Karow, Bahrenburg, and Garidel 2013). The buffer capacity of protein comes from the ionizable groups on the polypeptide chains, including the side chains of the amino acids, the terminal $\alpha$-amino groups, and the terminal $\alpha$ carboxyl groups. Thus, the protein solution can be considered as a buffer system composed of these ionizable groups. To simplify the calculation, we used the Brønsted-Lowry acid forms (proton donors) of all the ionizable groups. The acid dissociation constant is defined as:

$$
K_{a, i}=\frac{\left[H^{+}\right]\left[A_{i}^{-}\right]}{\left[H A_{i}\right]}
$$

where $K_{a, i}$ is the acid dissociation constants of the amino acids, and the square brackets denote the concentration of the corresponding components. The logarithmic constants of the acid dissociation ( $\mathrm{pKa}$ ) are most commonly given, rather than that of the base dissociation $(\mathrm{pKb})$. Some pKa values of amino acids are given in Table 6.1.

Assume the total concentration of each relevant amino acid is $c_{a, i}$ :

$$
c_{a, i}=\left[H A_{i}\right]+\left[A_{i}^{-}\right]=\frac{\left[H^{+}\right]\left[A_{i}^{-}\right]}{K_{a, i}}+\left[A_{i}^{-}\right]
$$


Table 6.1: Measured pKa values of the side chains of amino acids. Data from Thurlkill et al. (2006), measured in $0.1 \mathrm{M} \mathrm{KCl}$ at $25^{\circ} \mathrm{C}$.

\begin{tabular}{ccccccccc}
\hline Group & $\alpha$-carboxyl & Asp & Glu & His & $\alpha$-amino & Cys & Tyr & Lys \\
\hline $\mathrm{pKa}$ & 3.67 & 3.67 & 4.25 & 6.54 & 8.00 & 8.55 & 9.84 & 10.40 \\
\hline
\end{tabular}

$$
\left[A_{i}^{-}\right]=\frac{c_{a, i} K_{a, i}}{K_{a, i}+\left[H^{+}\right]}
$$

Buffers exhibit the highest resistance to $\mathrm{pH}$ changes when the $\mathrm{pH}$ equals to their $\mathrm{pKa}$, and the resistance decreases when the $\mathrm{pH}$ moves away from their $\mathrm{pKa}$. Therefore, when titrating a protein from its native $\mathrm{pH}$ (generally nearly neutral) to lower $\mathrm{pH}$, only the $\mathrm{pKa}$ values that are lower than the native $\mathrm{pH}$ need to be considered. These $\mathrm{pKa}$ values are those of terminal $\alpha$-carboxyl and side chains of Asp, Glu, and His. We regard the more basic side chains (Tyr, Lys, Arg, etc.) as completely dissociated ions, and assume their sum of concentration is $\left[B_{0}^{+}\right]$. At the native $\mathrm{pH}\left(\mathrm{pH}_{0}\right)$ of the protein, the initial charge balance is:

$$
\left[\mathrm{A}^{-}\right]+\left[\mathrm{OH}_{0}^{-}\right]=\left[\mathrm{B}_{0}^{+}\right]+\left[\mathrm{H}_{0}^{+}\right]
$$

Therefore, the concentration of $\left[B_{0}^{+}\right]$is:

$$
\left[B_{0}^{+}\right]=\sum_{i=1}^{n} \frac{c_{a, i} K_{a, i}}{K_{a, i}+\left[H_{0}^{+}\right]}+\frac{K_{w}}{\left[H_{0}^{+}\right]}-\left[H_{0}^{+}\right]
$$

where the upper bond of summation $n$ is dependent on the number of relevant amino acids species. During acid titration, when $\mathrm{n}$ mol/L of $\mathrm{HCl}$ is added into the solution, the charge balance gives:

$$
\left[\mathrm{A}^{-}\right]+\left[\mathrm{OH}^{-}\right]+\left[\mathrm{Cl}^{-}\right]=\left[\mathrm{B}_{0}^{+}\right]+\left[\mathrm{H}^{+}\right]
$$

Substitute the concentrations of the ions into the charge balance: 


$$
n=\left[B_{0}^{+}\right]-\sum_{i=1}^{n} \frac{c_{a, i} K_{a, i}}{K_{a, i}+\left[H^{+}\right]}-\frac{K_{w}}{\left[H^{+}\right]}+\left[H^{+}\right]
$$

The effective concentration of the buffer components still needs to be determined experimentally, since the side chains of amino acids can be hidden inside the protein structure and can not contribute to the buffer capacity of the protein unless the protein is completely unfolded.

\subsubsection{Buffer capacity}

First proposed by van Slyke 1922, $\beta$ is a quantitative measure of the resistance of a buffer solution to $\mathrm{pH}$ change on addition of hydrogen or hydroxide ions. It is defined as:

$$
\beta=\frac{d n}{d p H}
$$

where $\mathrm{dn}$ is an infinitesimal amount of added acid or base and $\mathrm{dpH}$ is the resulting infinitesimal change in the cologarithm of the hydrogen/hydrogen ion concentration.

The buffer capacity of a solution can be calculated based on titration experiment, or be predicted based on the composition of the buffer solution:

$$
\beta=\frac{d n}{d\left[H^{+}\right]} \frac{d\left[H^{+}\right]}{d p H}=2.303\left(\frac{K_{w}}{\left[H^{+}\right]}+\left[H^{+}\right]+\sum_{i=1}^{n} \frac{c_{a, i} K_{a, i}\left[H^{+}\right]}{\left(K_{a, i}+\left[H^{+}\right]\right)^{2}}\right)
$$

The derivative is calculated based on eq.6.5.

\subsubsection{Acid uptake during protein hydrolysis}

During protein hydrolysis, when a peptide bond is cleaved, a carboxyl and an amino group are released: 
$-\mathrm{CHR}^{\prime}-\mathrm{CO}-\mathrm{NH}-\mathrm{CHR}^{\prime \prime}-+\mathrm{H}_{2} \mathrm{O} \stackrel{\text { enzyme }}{\longrightarrow}-\mathrm{CHR}^{\prime}-\mathrm{COOH}+$ $\mathrm{NH}_{2}-\mathrm{CHR} "$

These two groups undergo ionization, which depends on the current $\mathrm{pH}$ of the reaction medium and the $\mathrm{pK}$ values of the carboxyl and amino groups:

$$
\begin{array}{r}
-\mathrm{CHR}^{\prime}-\mathrm{COO}-+\mathrm{H}^{+} \rightleftharpoons-\mathrm{CHR}^{\prime}-\mathrm{COOH} \\
\mathrm{NH}_{2}-\mathrm{CHR}^{\prime \prime}-+\mathrm{OH}^{-} \rightleftharpoons \mathrm{NH}_{2}-\mathrm{CHR}^{\prime \prime}-+\mathrm{H}_{2} \mathrm{O}
\end{array}
$$

The ionization status of these groups may cause a change in the $\mathrm{pH}$. This characteristic of protein hydrolysis has been utilized as a method to measure the degree of hydrolysis, namely the pH-STAT method (Rutherfurd 2010; Butré, Wierenga, and Gruppen 2012). The pHSTAT method keeps the $\mathrm{pH}$ constant during protein hydrolysis by adding a strong base or acid, depending on the reaction conditions. In the gastric situation, when food protein is being hydrolyzed, the released carboxyl and amino groups create additional buffer capacity. Thus more gastric acid is needed to decrease or maintain a low gastric $\mathrm{pH}$.

\subsection{Materials and method}

\subsubsection{Materials}

Whey Protein Isolate (WPI) (Bipro, lot no. JE 034-70-440-6) was purchased from Davisco Food International, Inc. (Le Sueur, USA). This batch of WPI was reported to have a protein content of $97.9 \mathrm{~g} / 100 \mathrm{~g}$ dry solid. Pepsin from porcine gastric mucosa (lyophilized powder, 3200 to 4500 units $/ \mathrm{mg}$ protein, $\mathrm{MW}=34.6 \mathrm{kDa}$ ), ovalbumin from chicken egg (purity $66 \%-88 \%$ ) and all other chemicals used were purchased from Sigma Aldrich (St. Louis, MO, USA). All the water used was obtained from a Milli-Q Integral Water Purification System (Merck Millipore, Billerica, MA, USA). 


\subsubsection{Gel preparation}

Whey protein gel and ovalbumin gel $(20 \mathrm{wt} \%)$ were prepared in Teflon tubes (diameter $2 \mathrm{~cm}$ ) incubated in a $90{ }^{\circ} \mathrm{C}$ water bath for $30 \mathrm{~min}$, as described previously (Q. Luo, Boom, and Janssen 2015).

The gel suspension for titration experiments was prepared by cutting the gels into small pieces, and ground with an analytical mill (A11 basic, IKA, Staufen im Breisgau, Germany), gel particles with a diameter of approximately $0.9 \mathrm{~mm}$ were obtained. The gel particles were then suspended in $25 \mathrm{~mL}$ water, with a protein content of $50 \mathrm{~g} \mathrm{~L}^{-1}$.

\subsubsection{Titration}

All titration experiments were performed on an 877 Titrino plus Titrator (Metrohm, Herisau, Switzerland). A titrant with $0.5 \mathrm{M} \mathrm{HCl}$ and $0.9 \mathrm{~g} \mathrm{~L}^{-1} \mathrm{NaCl}$ was prepared. Our preliminary experiments have shown that the $\mathrm{NaCl}$ can slightly influence the buffer capacity of the protein solution, and the enzymatic hydrolysis is also affected by ionic strength (Dale and White 1983). Therefore, $\mathrm{NaCl}$ of physiological concentration was added to the titrant.

\section{Buffer capacity}

The buffer capacity of the $50 \mathrm{~g} \mathrm{~L}^{-1}$ protein solutions and protein gel suspensions were determined by stepwise titration from their native $\mathrm{pH}$ (about 7-7.1 for whey protein solution, and 6.3-6.6 for ovalbumin solution) to $\mathrm{pH} 2$. During titration, the samples were stirred at 300 rpm, using a magnetic stirrer. The volume increment of the titrator was set at $0.05 \mathrm{~mL}$, and the titration only proceeds when signal drift is lower than $2.5 \mathrm{mV} \mathrm{min}{ }^{-1}$. Under this setting, the duration of each titration was approximately $10 \mathrm{~min}-20 \mathrm{~min}$. The experiments were performed in triplicate.

From eq. 6.5, the relation between added volume of acid and the $\mathrm{pH}$ of the solution can be calculated: 


$$
\frac{c_{H C l} \times v_{H C l}}{v_{0}+v_{H C l}}=\frac{v_{0}}{v_{0}+v_{H C l}} \times\left(\left[B_{0}^{+}\right]-\sum_{i=1}^{n} \frac{c_{a, i} K_{a, i}}{K_{a, i}+\left[H^{+}\right]}\right)-\frac{K_{w}}{\left[H^{+}\right]}+\left[H^{+}\right]
$$

where $c_{\mathrm{HCl}}$ is the concentration of the $\mathrm{HCl}, v_{\mathrm{HCl}}$ is the volume used in the titration, $v_{0}$ is the initial volume of the solution, $\mathrm{pH}$ is measured during titration.

Transform into an explicit function:

$$
v_{H C l}=\frac{v_{0}}{c_{H C l}-f(p H)} \times\left(\left[B_{0}^{+}\right]-\sum_{i=1}^{n} \frac{c_{a, i} K_{a, i}}{K_{a, i}+\left[H^{+}\right]}+f(p H)\right)
$$

where $f(p H)=\left[H^{+}\right]-K_{w} /\left[H^{+}\right]$

The pKa values of $\alpha$-carboxyl and Asp side chain are identical according to the measurement of Thurlkill et al. (2006) (table 6.1), although they differ slightly in other literature. For simplicity, their concentrations were combined and regarded as the total carboxyl groups in the calculation.

Acid uptake during protein hydrolysis

After performing the buffer capacity measurement, the protein solutions or protein gel suspensions were transferred to water-jacketed vessels to keep their temperature at $37^{\circ} \mathrm{C}$. Pepsin stock solution was added to the vessels, reaching a final enzyme activity of $2000 \mathrm{U} \mathrm{mL}^{-1}$. The same titrant was used to stabilize the $\mathrm{pH}$ at 2, using the $\mathrm{pH}$-STAT setup of the titrator where the time interval between two measurement points is $7.3 \mathrm{~s}$. The duration of the hydrolysis was $2 \mathrm{~h}$.

\subsubsection{Acid diffusion in protein gels}

For acid diffusion experiments, the gels were kept in the Teflon tubes. One cap of the tube was removed and the tube was suspended in 


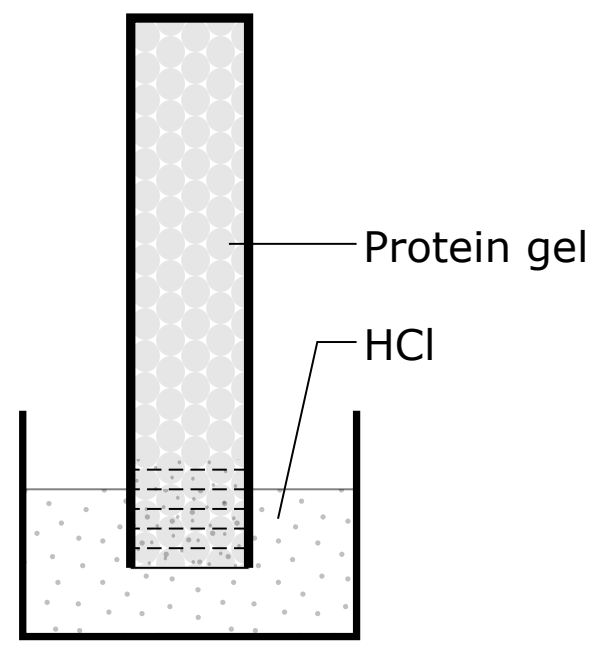

Figure 6.1: Illustration of acid diffusion experiment. Gels of $20 \mathrm{wt} \%$ in tubes were soaked in $\mathrm{HCl}(0.01 \mathrm{M})$ for $20 \mathrm{~h}$, then sliced and titrated.

$150 \mathrm{~mL}$ of $0.01 \mathrm{M} \mathrm{HCl}$ for $20 \mathrm{~h}$. Afterwards, the gels were cut perpendicularly to the axis of the tube (approximately $1 \mathrm{~mm}$ thick slices for each tube). $25 \mathrm{~mL}$ water was added to the slices and then homogenized using the Ultra-Turrax (Ika Works Inc., USA) at $10000 \mathrm{rpm}$ for $1 \mathrm{~min}$. The samples were left for 2 hours, and then titrated to $\mathrm{pH} 9$ with $0.1 \mathrm{M}$ $\mathrm{NaOH}$. After the titration, the samples were freeze-dried to measure their dry weight. The acid content in the gel was calculated on a dryweight basis:

$$
n_{p}=\frac{n_{\mathrm{NaOH}}}{m_{d}-m_{\mathrm{NaCl}}}
$$

where $n_{p}$ is the titratable acid per gram of protein, $n_{\mathrm{NaOH}}$ is the mole of $\mathrm{NaOH}$ used to titrate the gel from $\mathrm{pH} 2$ to $\mathrm{pH} 9 . m_{d}$ is the dry mass of the gel slice, $m_{\mathrm{NaCl}}$ is the mass of $\mathrm{NaCl}$ which was produced during titration. Here we approximated that all sodium in the dry matter presented as $\mathrm{NaCl}$. Then, the titratable acid in the gel slices can be calculated:

$$
n_{g e l}=\left(n_{p}-n_{p 0}\right) \times \frac{m_{d}}{m_{w}}
$$


where $n_{g e l}$ is the titratable acid per gram of gel, $n_{p 0}$ is the titratable acid per gram of protein in the blank sample, $m_{w}$ is the wet mass of the gel slice. The diffusion distance was also based on the wet mass of each gel slice:

$$
l=\frac{m_{a c c}}{\rho \pi r^{2}}
$$

where $m_{a c c}$ is the accumulated wet mass of the gel slices up to the center of the correspondent slice, $\rho$ is the density of the gel $\left(\rho=1 \mathrm{~g} \mathrm{~cm}^{-3}\right.$ for both gels, measured by water displacement), $r$ is the radius of the gel slices $(r=1 \mathrm{~cm})$.

\subsubsection{Data analysis}

Matlab R2016b (MathWorks, Natick, USA) was used for data analysis of the results. Model fitting was done using the nonlinear fitting function lsqcurvefit that solves fitting problems using a nonlinear leastsquares approach. The trust-region-reflective algorithm was chosen. The accuracy of fitting was analyzed by determining the coefficient of determination of the fit using the resnorm option of lsqcurvefit. The function nlparci was used to extract the $95 \%$ confidence interval of the parameters out of the Jacobian matrix.

\subsection{Results and discussions}

\subsubsection{Buffer capacity titration}

The buffer capacity of whey protein and ovalbumin solutions and gel suspensions were determined by titration. One example of the titration curve is shown in Fig. 6.2. The buffer capacity was calculated from the experimental data using eq. 6.6, the resulted buffer capacity at different $\mathrm{pH}$ were shown in Fig. 6.3. All experiments showed increased buffer capacity when approaching $\mathrm{pH} 2$, due to the water dissociation. For the whey protein solution, a single peak of buffer capacity is shown at approximately $\mathrm{pH}$ 3.5. For the ovalbumin solution, 


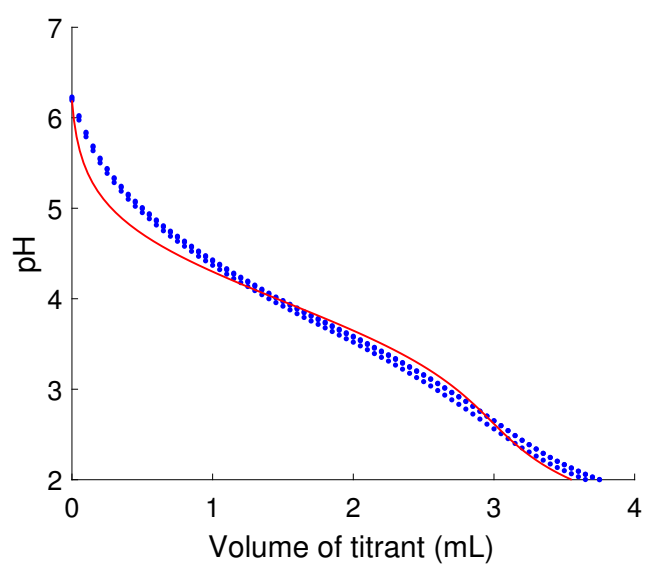

Figure 6.2: Example of buffer capacity titration curves. The blue dots are the data from 3 experiments of $50 \mathrm{~g} \mathrm{~L}^{-1}$ ovalbumin solution titrated by $0.5 \mathrm{M} \mathrm{HCl}$. The solid red line is the model prediction.

the peak is shown near $\mathrm{pH}$ 4. The data of the whey protein gel buffer capacity is more scattered. Compare to the ovalbumin solution, a shift of the buffer capacity can be observed in the ovalbumin gel: the slope became more gradual at the $\mathrm{pH}$ range from 7 to 4 and the peak shifted to a lower $\mathrm{pH}$. There may be two reasons for the lower reproducibility of the whey protein gel and the shift of buffer capacity of the ovalbumin gel. Firstly, heat denaturation and heat aggregation changed the accessibility of the ionizable side groups. Secondly, although the gels were ground to small particles, they still exhibited diffusion limitation for the protons. The protons took a longer time to access the ionizable side groups deep in the gel matrices. Therefore, the shift of the peak could be due to a delayed response to the addition of acid during titration. For these reasons, only the data of solution samples were used for the model fitting.

The titration data of whey protein and ovalbumin solutions were fitted into eq. 6.9. No obvious peak can be observed near $\mathrm{pH}$ 6.54, and preliminary fitting indicated that the His side groups did not contribute to the buffer capacity of the proteins. Therefore, only the carboxyls and Glu were used in the final fitting. The fitted molar concentrations of the ionizable groups were normalized with the mass concentration 

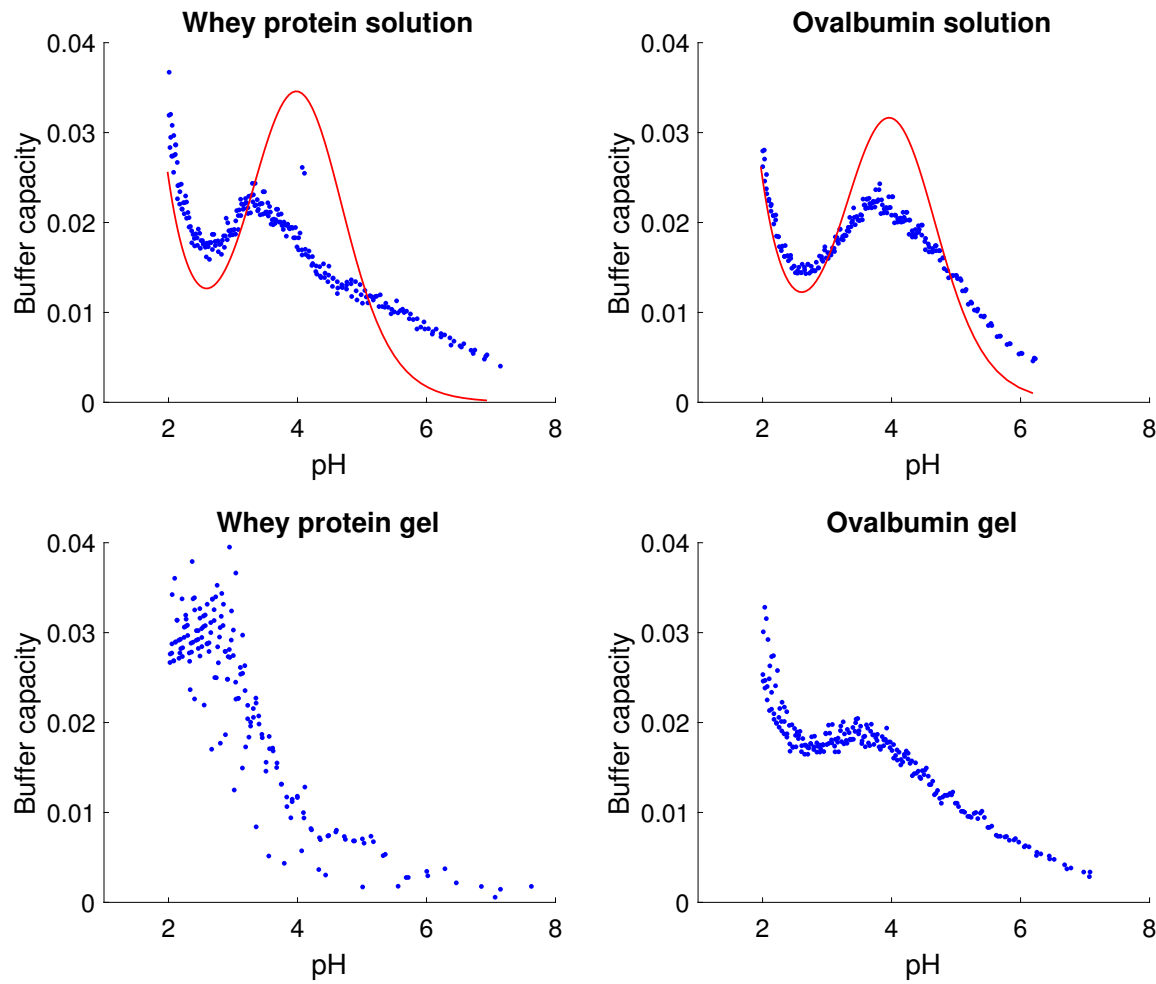

Figure 6.3: Buffer capacity of whey protein and ovalbumin, in solutions and in gels. The blue dots show data from 3 experiments. The red lines show the theoretical buffer capacity calculated from fitted parameters. 
of the proteins, which is shown in table 6.2. The fitted parameters were used to predict the theoretical buffer capacity using eq. 6.7, the predicted buffer capacities of the samples are shown in Fig. 6.3.

The buffer capacities of the carboxyl groups and the Glu side groups were joined into one single peak since their pKa values are close. The location of the predicted peak for ovalbumin corresponds to that of the experimental data, while there is a slight discrepancy for that of the whey protein solution. Due to the logarithmic nature of $\mathrm{pH}$ and the simplification of parameters, the prediction overestimated the buffer capacity of the protein at the peak, while underestimated the buffer capacity at other $\mathrm{pH}$ ranges. This implicates the possible presence of various other buffers in low amount. For example, citrate, lactate, carbonate, acetate, and propionate ions present in the milk, and some of them may remain in the whey protein isolate. Nonetheless, the side groups of Asp and Glu, and the terminal $\alpha$-carboxyl groups can represent the effective buffer components of whey protein and ovalbumin under gastric condition, which can be used to predict the buffer capacities of given proteins.

\subsubsection{Acid uptake during hydrolysis}

The protein solutions and protein gel suspensions were hydrolyzed under the $\mathrm{pH}$-STAT condition at $\mathrm{pH}$ 2. The acid uptake of ovalbumin

Table 6.2: The effective buffer concentration in whey protein and ovalbumin. The concentrations of the ionizable groups are presented as the mole of the buffering side groups per kilogram of protein. Carboxyls refers to the carboxyl groups on the side chain of Asp and the terminal $\alpha$-carboxyl groups of the polypeptide chains. Data from 3 titration experiments. The uncertainties are the $95 \%$ confidence intervals of the fitted parameters.

\begin{tabular}{lccc}
\hline & Whey protein & Ovalbumin & $R^{2}$ \\
\hline Carboxyls & $0.613 \pm 0.105$ & $0.591 \pm 0.051$ & 0.955 \\
Glu & $0.717 \pm 0.090$ & $0.626 \pm 0.043$ & 0.987 \\
\hline
\end{tabular}


is taken as the example (Fig. 6.4), the acid uptake of other samples also showed similar trends (Data not shown). These curves are typical for protein hydrolysis in $\mathrm{pH}$-STAT experiments. In the $\mathrm{pH}-\mathrm{STAT}$ method, the degree of hydrolysis (DH) can be calculated using the following equation:

$$
D H(\%)=\frac{V_{b} N_{b}}{\alpha M_{p} h_{t o t}}
$$

where $V_{b}$ is the volume of added titrant (strong acid or base), $N_{b}$ is the molar concentration of the titrant, $\alpha$ is the average degree of dissociation of $\alpha$-amino groups or $\alpha$-carboxylic groups in a protein, $M_{p}$ is the mass of protein, $h_{t o t}$ is the total number of peptide bonds per gram of protein substrate (Butré, Wierenga, and Gruppen 2012). Therefore, the acid uptake due to hydrolysis is proportional to the degree of hydrolysis.

The total acid uptake during $2 \mathrm{~h}$ of hydrolysis was compared with the total acid uptake during buffer capacity titration. The amount of acid uptake per kilogram of protein was presented in table 6.3, along with the degree of hydrolysis at $2 \mathrm{~h}$. Whey protein solution consumed $1.67 \mathrm{~mol} \mathrm{~kg}^{-1}$ of acid during the buffer capacity titration, but only consumed $0.37 \mathrm{~mol} \mathrm{~kg}^{-1}$ of acid during $2 \mathrm{~h}$ hydrolysis. The whey protein gel consumed $1.14 \mathrm{~mol} \mathrm{~kg}^{-1}$ acid during hydrolysis since heat denaturation eliminates the resistance of the native $\beta$-lactoglobulin to pepsin hydrolysis. Moreover, hydrolysis disintegrates the gel particles, which may increase the accessibility of some ionizable groups in the protein aggregates and is reflected in the acid uptake. The acid uptake of ovalbumin solution and gel did not show an obvious difference. They both consumed $1.5 \mathrm{~mol} \mathrm{~kg}^{-1}$ of acid during buffering, and approximately half the amount of acid during hydrolysis. Therefore, buffering reaction and enzymatic hydrolysis both influence the acid uptake and gastric $\mathrm{pH}$ during digestion in the stomach. 


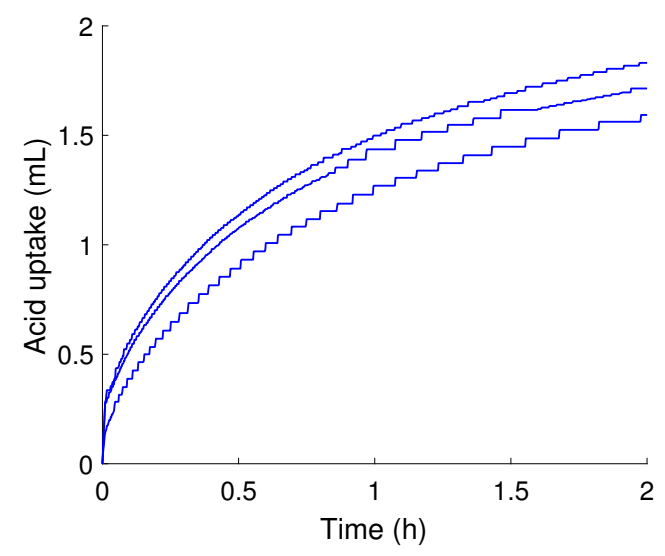

Figure 6.4: Example of acid uptake during $2 \mathrm{~h}$ pH-STAT hydrolysis of ovalbumin by pepsin at $\mathrm{pH}$ 2. Data from 3 experiments of $50 \mathrm{~g} \mathrm{~L}^{-1}$ ovalbumin solution titrated by $0.5 \mathrm{M} \mathrm{HCl}$.

Table 6.3: Total acid uptake during buffering reaction till $\mathrm{pH} 2$ and $2 \mathrm{~h}$ enzymatic hydrolysis. The concentrations are presented as the mole of needed monoprotic strong acid per kilogram of protein. Data from 3 experiments, the uncertainties are the standard deviations.

\begin{tabular}{lcc}
\hline & Buffering $\left(\mathrm{mol} \mathrm{kg}^{-1}\right)$ & Hydrolysis $\left(\mathrm{mol} \mathrm{kg}^{-1}\right)$ \\
\hline Whey protein solution & $1.67 \pm 0.01$ & $0.37 \pm 0.03$ \\
Whey protein gel & $1.37 \pm 0.02$ & $1.14 \pm 0.13$ \\
Ovalbumin solution & $1.50 \pm 0.02$ & $0.69 \pm 0.04$ \\
Ovalbumin gel & $1.49 \pm 0.03$ & $0.72 \pm 0.07$ \\
\hline
\end{tabular}




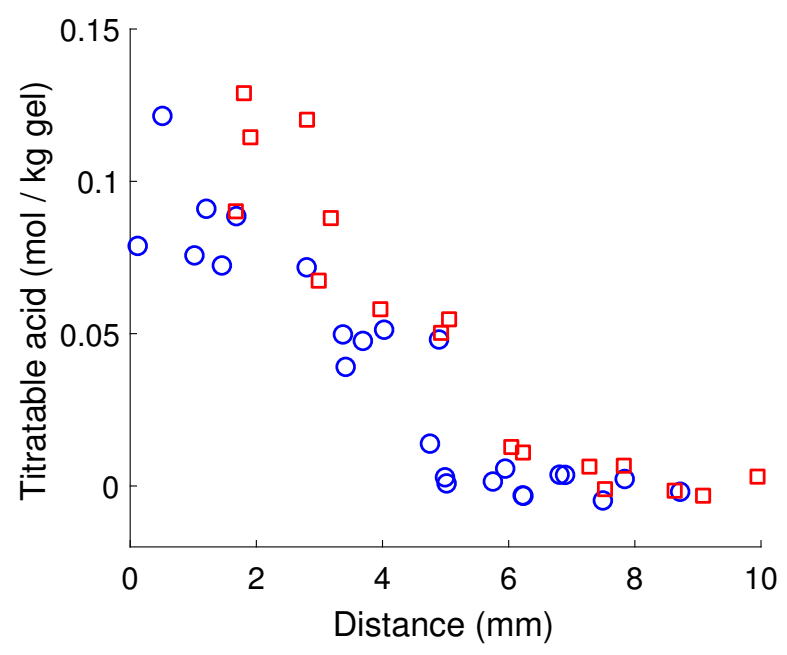

Figure 6.5: Titratable acid content in $20 \mathrm{wt} \%$ whey protein gel (blue circles) and $20 \mathrm{wt} \%$ ovalbumin gel (red square) after $20 \mathrm{~h}$ soaking in $0.01 \mathrm{M} \mathrm{HCl}$. The titratable acid content are presented as the mol of titratable acid per $\mathrm{kg}$ of gel wet mass. Distance were adjusted based on the wet mass of the slices. Data from 4 experiments of whey protein gel and 3 experiments of ovalbumin gel.

\subsubsection{Acid diffusion}

Acid diffusion was assessed by soaking the gels in $0.01 \mathrm{M} \mathrm{HCl}$. After $20 \mathrm{~h}$ soaking, the gels were swollen to different extents and expanded over the edge of the Teflon tube. We regarded the swollen slice as the first slice and counted it in the diffusion distance. The acid content in the gels was determined by end-point titration. The result is presented in Fig. 6.5.

We observed a concentration gradient of the acid content, which decreased rapidly along the distance. The acid content dropped to zero at about $5 \mathrm{~mm}$ distance in whey protein gels and at $6 \mathrm{~mm}$ in ovalbumin gel. We previously found that pepsin can only reach the first $2 \mathrm{~mm}$ of the $20 \mathrm{wt} \%$ whey protein gels after $6 \mathrm{~h}$ (Q. Luo, Borst, et al. 2017). While we expected protons diffuse faster than pepsin, the acid could not penetrate much deeper into the protein gels. Thus, the acid diffusion may also be a limiting factor for pepsin activity inside the protein 
gel particles. Mennah-Govela, Bornhorst, and R. P. Singh (2015) found that acid reached the deep regions in rice bolus in a $78.4 \mathrm{~mm}$-long syringe after a similar time span, which corresponds to an effective diffusivity of approximately $0.5 \times 10^{-8} \mathrm{~m}^{2} \mathrm{~s}^{-1}-4 \times 10^{-8} \mathrm{~m}^{2} \mathrm{~s}^{-1}$. The acid diffusion is therefore more significantly hindered in the protein gels than in the rice bolus. We believe this is due to the different buffer capacity of the matrices.

The acid content in the outer gel slices almost reached $0.1 \mathrm{M}$ in the whey protein gel and $0.13 \mathrm{M}$ in the ovalbumin gel. These concentrations are higher than the concentration of $\mathrm{HCl}$ solution used to soak the gels, which is $0.01 \mathrm{M}$. The concentrated acid content in gels is related to the buffer reaction of the proteins. A proportion of the protons is combined with the ionizable groups and thus fixated on the proteins. This proportion of protons does not contribute to the chemical potential regarding the diffusion process. Therefore, the Fick's law of diffusion cannot be simply applied to the gel matrices with buffer capacity.

To understand the effect of buffer capacity to the acid diffusion in gel matrices, we derived a variation of the Fick's law with the assumption that the buffer reaction of protons with the protein is very fast (the detailed derivation is shown in the electronic supplementary information):

$$
\frac{\partial}{\partial t}\left(c_{1}+\frac{c_{1} c_{a}}{c_{1}+K_{a}}\right)=D \frac{\partial^{2} c_{1}}{\partial x^{2}}
$$

where $c_{1}$ is the concentration of the diffusing proton, $c_{1} c_{a} /\left(c_{1}+K_{a}\right)$ is the concentration of the fixated protons, $D$ is the diffusion coefficient of the protons, and $x$ is the diffusion distance. For a simplified demonstration, here we only considered one species of ionizable group.

When $c_{1}$ is small compared to $K_{a}$, that is when the $\mathrm{pH}$ is higher than or close to the $\mathrm{pKa}$ values, we can approximate that:

$$
\frac{c_{1} c_{a}}{c_{1}+K_{a}} \approx c_{1} \frac{c_{a}}{K_{a}}
$$


then,

$$
\frac{\partial c_{1}}{\partial t}=\frac{D}{1+c_{a} / K_{a}} \frac{\partial^{2} c_{1}}{\partial x^{2}}
$$

This modified diffusion coefficient indicates that the buffer reaction has a negative influence on the diffusivity of protons, and a higher $c_{a}$ results in slower diffusion.

As the diffusion proceeds, the local $\mathrm{pH}$ in the gel may decrease to lower than the $\mathrm{pKa}$ values. When $c_{1} \gg K_{a}$, then we have:

$$
\frac{c_{1} c_{a}}{c_{1}+K_{a}} \approx c_{a}
$$

Since $c_{a}$ is a constant, eq. 6.14 will be equivalent to the original Fick's second law, the buffer reaction will no longer have effects on the diffusion process. Therefore, if the initial $\mathrm{pH}$ of the gel is higher than the $\mathrm{pKa}$ value of the buffering ionizable group, the buffer reaction will hinder the diffusion of protons, and there will be a gradual shift to lower hindrance, till no hindrance when $p H<<p K a$ in the gel.

\subsection{Conclusion}

We quantified the buffer capacity of proteins both theoretically and experimentally. The side groups of Asp and Glu, and the terminal $\alpha$-carboxyl groups are the effective buffer components of whey protein and ovalbumin under gastric condition. We also demonstrated that the hydrolysis of protein can also influence the acid uptake. The quantification of buffer capacity can be used to predict the acid uptake of the proteins and the $\mathrm{pH}$ change during gastric digestion even though the buffer capacity and the hydrolysis kinetic parameters of certain proteins need to be determined experimentally.

The acid diffusion in protein gel can be strongly hindered by the buffer reaction of the ionizable groups. Along with pepsin diffusion, the acid diffusion can also be a limiting factor for the enzyme activity in food matrices during gastric digestion. 
The buffer reaction is one of the multi-scale dynamic processes in gastric digestion. By mechanistically quantifying the interaction of acid and proteins under the gastric condition, we can be one step closer to fully understand the gastric digestion of food.

\section{Supplementary information}

To understand the effect of buffer capacity to the acid diffusion in gel matrices, we derived a variation of the Fick's law. We assume the buffer reaction of protons with the protein is instant, and consider the proton balance in a thin slab $A \Delta x$ :

$($ accumulation $)=($ diffusion in - diffusion out $)-($ consumed by reaction $)$

For the diffusing protons $\left(c_{1}\right)$ :

$$
\frac{\partial c_{1}}{\partial t}=D \frac{\partial^{2} c_{1}}{\partial x^{2}}-r
$$

where $r$ is the rate of buffer reaction. D is the diffusion coefficient of proton in water. For the protons that have reacted with the protein $\left(c_{2}\right)$ :

$$
\frac{\partial c_{2}}{\partial t}=r
$$

There is no diffusion term because the reacted protons are immobilized by the protein network. Combining eq. 6.18 and eq. 6.19 yields:

$$
\frac{\partial}{\partial t}\left(c_{1}+c_{2}\right)=D \frac{\partial^{2} c_{1}}{\partial x^{2}}
$$

The correlation between $c_{1}$ and $c_{2}$ can be calculated from the equilibrium of buffer reaction $\left(K_{a}=\left[H^{+}\right]\left[A_{i}^{-}\right] /[H A]\right)$. For a simplified 
demonstration, here we use one species of ionizable group:

$$
K_{a}=\frac{\left(c_{a}-c_{2}\right) c_{1}}{c_{2}}
$$

where $c_{a}$ is the total concentration of the ionizable group $\left(c_{a}=\left[A_{i}^{-}\right]+\right.$ $[H A])$. Therefore:

$$
c_{2}=\frac{c_{1} c_{a}}{c_{1}+K_{a}}
$$

Substitute into eq. 6.20:

$$
\frac{\partial}{\partial t}\left(c_{1}+\frac{c_{1} c_{a}}{c_{1}+K_{a}}\right)=D \frac{\partial^{2} c_{1}}{\partial x^{2}}
$$

When $c_{1}$ is small in comparison with $K_{a}$, that is when the $\mathrm{pH}$ is higher than or close to the $\mathrm{pKa}$ values, an approximation can be done:

$$
\begin{gathered}
c_{2}=\frac{c_{1} c_{a}}{c_{1}+K_{a}}=c_{1} \frac{c_{a}}{K_{a}} \frac{1}{1+c_{1} / K_{a}} \approx c_{1} \frac{c_{a}}{K_{a}} \\
D \frac{\partial^{2} c_{1}}{\partial x^{2}}=\frac{\partial}{\partial t}\left(c_{1}+\frac{c_{1} c_{a}}{c_{1}+K_{a}}\right) \approx\left(1+\frac{c_{a}}{K_{a}}\right) \frac{\partial c_{1}}{\partial t}
\end{gathered}
$$

This results in a modified diffusion coefficient:

$$
D^{\prime}=\frac{D}{1+c_{a} / K_{a}}
$$

Therefore, the buffer reaction has a negative influence on the diffusivity of protons, and a higher $c_{a}$ result in slower diffusion.

As the diffusion proceeds, the local $\mathrm{pH}$ in the gel may decrease to lower than the pKa values, which gives a $c_{1}$ that is higher than the $K_{a}$ value. When $c_{1} \gg K_{a}$, then we have:

$$
c_{2}=\frac{c_{1} c_{a}}{c_{1}+K_{a}} \approx c_{a}
$$

Since $c_{a}$ is a constant here, the buffer reaction will no longer have effects on the diffusion process. 


\section{References}

Butré, C. I., P. A. Wierenga, and H. Gruppen (June 6, 2012). "Effects of Ionic Strength on the Enzymatic Hydrolysis of Diluted and Concentrated Whey Protein Isolate." In: Journal of Agricultural and Food Chemistry 60.22, pp. 5644-5651. Dor: 10.1021/ jf301409n.

Dale, B. E. and D. H. White (May 1, 1983). "Ionic Strength: A Neglected Variable in Enzyme Technology." In: Enzyme and Microbial Technology 5.3, pp. 227-229. DoI: 10. 1016/0141-0229 (83)90101-1.

Dekkers, B. L., E. Kolodziejczyk, S. Acquistapace, J. Engmann, and T. J. Wooster (Jan. 20, 2016). "Impact of Gastric pH Profiles on the Proteolytic Digestion of Mixed Blg-Xanthan Biopolymer Gels." In: Food E Function 7.1, pp. 58-68. Dor: 10.1039/C5F001085C.

Floury, J., T. Bianchi, J. Thévenot, D. Dupont, F. Jamme, E. Lutton, M. Panouillé, F. Boué, and S. Le Feunteun (Jan. 15, 2018). "Exploring the Breakdown of Dairy Protein Gels during in Vitro Gastric Digestion Using Time-Lapse Synchrotron Deep-UV Fluorescence Microscopy." In: Food Chemistry 239, pp. 898-910. Dor: 10 . 1016 / j . foodchem. 2017.07.023.

Gokarn, Y. R., E. Kras, C. Nodgaard, V. Dharmavaram, R. M. Fesinmeyer, H. Hultgen, S. Brych, R. L. Remmele Jr., D. N. Brems, and S. Hershenson (Aug. 1, 2008). "Self-Buffering Antibody Formulations." In: Journal of Pharmaceutical Sciences 97.8, pp. 3051-3066. DoI: 10.1002 / jps. 21232.

Karow, A. R., S. Bahrenburg, and P. Garidel (Mar. 1, 2013). "Buffer Capacity of Biologics - from Buffer Salts to Buffering by Antibodies." In: Biotechnology Progress 29.2, pp. 480-492. DoI: 10 . 1002 / btpr . 1682.

Luo, Q., R. M. Boom, and A. E. M. Janssen (Sept. 2015). "Digestion of Protein and Protein Gels in Simulated Gastric Environment." In: LWT - Food Science and Technology 63.1, pp. 161-168. DoI: 10.1016/ j. Iwt.2015.03.087.

Luo, Q., J. W. Borst, A. H. Westphal, R. M. Boom, and A. E. M. Janssen (May 2017). "Pepsin Diffusivity in Whey Protein Gels and Its Effect 
on Gastric Digestion." In: Food Hydrocolloids 66, pp. 318-325. DoI: 10.1016/ j. foodhyd.2016.11.046.

Malagelada, J.-R., G. F. Longstreth, W. H. J. Summerskill, and V. L. W. Go (Feb. 1, 1976). "Measurement of Gastric Functions During Digestion of Ordinary Solid Meals in Man." In: Gastroenterology 70.2, pp. 203-210. DOI: 10. 1016/S0016-5085 (76 ) 80010-8.

Mennah-Govela, Y. A., G. M. Bornhorst, and R. P. Singh (2015). “Acid Diffusion into Rice Boluses Is Influenced by Rice Type, Variety, and Presence of $\alpha$-Amylase." In: Journal of Food Science. Dor: 10 . $1111 /$ 1750-3841. 12750.

Phillips, S., S. Hutchinson, and T. Davidson (1993). "Preoperative Drinking Does Not Affect Gastric Contents." In: BJA: British Journal of Anaesthesia 70.1, pp. 6-9.

Piper, D. and B. H. Fenton (1965). "pH Stability and Activity Curves of Pepsin with Special Reference to Their Clinical Importance." In: Gut 6.5, pp. 506-508.

Rutherfurd, S. M. (2010). "Methodology for Determining Degree of Hydrolysis of Proteins in Hydrolysates: A Review." In: Journal of AOAC International 93.5, pp. 1515-1522.

Salaün, F., B. Mietton, and F. Gaucheron (Feb. 1, 2005). "Buffering Capacity of Dairy Products." In: International Dairy Journal 15.2, pp. 95-109. Dor: 10.1016/ j . idairy j .2004.06.007.

Scarr, M., J. R. Maltby, K. Jani, and L. R. Sutherland (Dec. 1, 1989). "Volume and Acidity of Residual Gastric Fluid after Oral Fluid Ingestion before Elective Ambulatory Surgery." In: CMAJ: Canadian Medical Association Journal 141.11, pp. 1151-1154. pmid: 2819633.

Sullivan, L. M., J. J. Kehoe, L. Barry, M. J. M. Buckley, F. Shanahan, K. H. Mok, and A. Brodkorb (Aug. 2014). "Gastric Digestion of $\alpha$ Lactalbumin in Adult Human Subjects Using Capsule Endoscopy and Nasogastric Tube Sampling." In: British Journal of Nutrition 112.4, pp. 638-646. Dor: 10.1017/S0007114514001196.

Thurlkill, R. L., G. R. Grimsley, J. M. Scholtz, and C. N. Pace (May 1, 2006). "pK Values of the Ionizable Groups of Proteins." In: Protein Science 15.5, pp. 1214-1218. Dor: 10.1110/ps.051840806. 
Van Slyke, D. D. (1922). “On the Measurement of Buffer Values and on the Relationship of Buffer Value to the Dissociation Constant of the Buffer and the Concentration and Reaction of the Buffer Solution." In: Journal of Biological Chemistry 52.2, pp. 525-570. 
Chapter 7

General discussion 
In this thesis, we mechanistically studied the gastric digestion of protein-based food matrices. This included several physicochemical aspects of the gastric digestion. In this general discussion, these results will be systematically reviewed and interpreted, and the directions for further research will be explored.

\subsection{Main findings and conclusions}

In Chapter 2, we used protein gels as models to study the protein digestion of solid food. Compared to the digestion of protein in solution, we found that the digestion of protein gels was strongly affected by its microstructure. This was evident not only in a slowing down of the hydrolysis, but also in a qualitative change of the apparent enzyme kinetics. In addition, the hydrolytic action of pepsin enhances the disintegration of the protein gels. Since the indiffusion of the pepsin is much slower in a denser matrix, this also leads to qualitatively different attrition and gel collapse. These findings demonstrate the importance of food structure, enzymatic kinetics and diffusion processes in the gastric digestion.

The mutual influence between pepsin action and food structure was further explored in Chapter 3, by quantifying the diffusivity of pepsin in whey protein gels. The measured diffusion rates of pepsin in the gels showed that in an inert gel network, the pepsin will be constrained within a thin layer from the gel surface, and is not able to diffuse very fast into the gel. However, scanning electron microscopy indicated that the hydrolytic action of pepsin loosens the microstructure of the whey protein gel surfaces, which accelerates pepsin diffusion. Consequently, the gel disintegration is enhanced by higher pepsin concentrations.

To obtain more understanding of the diffusive behaviour of pepsin, we characterized the diffusivity of pepsin in various protein gel matrices and used existing diffusion models to describe the diffusivity (Chapter 4). These models elucidate the phenomena that underlie the 
diffusivity of pepsin in any protein gel and show us which the structural parameters of the protein gels are relevant.

The enzyme kinetics of pepsin were characterized at different $\mathrm{pH}$ and ionic strengths, using bovine serum albumin as protein substrate (Chapter 5). The results at different $\mathrm{pH}$ were in accordance with previous studies. While influence of the ionic strength is generally less studied, we showed that this also has a strong impact on the reaction kinetics of pepsin. By comparing with literature data, we found that pepsin is more efficient towards intact protein than towards smaller peptides.

The gastric $\mathrm{pH}$ is an important parameter in the digestion, yet a quantitative understanding of the dynamics of the gastric $\mathrm{pH}$ is still missing. Among the macronutrients, protein has the strongest influence on the gastric $\mathrm{pH}$ change, since it generally contains a high density of charged groups, which may become undissociated when exposed to a low $\mathrm{pH}$. This leads to an effective increase of the $\mathrm{pH}$ by the ingested proteins. Therefore, we investigated the buffer capacity of proteins and the acid diffusion in protein gels, both theoretically and experimentally (Chapter 6). The acid diffusion into the protein gels was very slow compared to that in water, which is due to the reactive front of the acid that diffuses in, and which first has to react with the locally available charged groups, before the diffusive front can advance.

In summary, this thesis mainly studied some of the physicochemical of gastric digestion, including the enzyme diffusion, enzymatic hydrolysis, buffer reaction, and acid diffusion. The findings show that these processes are interrelated and are all contributing to the disintegration and digestion of food. 


\subsection{Connecting the functionality of pepsin to the physiology of stomach}

Although we focused on the physicochemical processes of gastric digestion, to thoroughly understand the mechanism of digestion, the physiological relevance of these processes should be considered as well.

Stevens and Hume (2004) systematically compared the digestive system of vertebrates, including the stomach physiology. Although the stomach has a similar function in most vertebrates, it is adapted to the diet of the animal. Fig. 7.1 from their book shows the variation of gastric regions based on their epithelial lining. Pepsinogen and $\mathrm{HCl}$ are secreted by the proper gastric region. The proper gastric region covers the largest area in the human stomach, just as in the canine stomach. In contrast, the stomachs of ox and llama are dominated by the region of nonglandular stratified squamous epithelium, while their proper gastric regions are minimal. Pig, horse, and rat have proper gastric regions that occupy approximately $1 / 2$ to $1 / 3$ of the stomach. This different distribution of pepsin-secreting glands suggests that pepsin is more important for a carnivorous and omnivorous diet, rather than for a herbivorous diet. This could be due to the different protein content and food structure in the diets.

Why is pepsin responsible for this task in the digestion processes? There could be several reasons. First, pepsin has a large active-site cleft that can facilitate large substrate (Kageyama 2014). Second, pepsin is more efficient towards protein while less efficient towards smaller peptides when compared to the intestinal proteases. For example, Maximova and Trylska (2015) found very low $k_{\text {cat }}$ for trypsincatalyzed hydrolysis of casein $\left(0.01 \mathrm{~s}^{-1}\right)$ as the substrate, which is very low compared to our measurement of BSA catalyzed by pepsin in Chapter 5, even if considering that we corrected the $k_{\text {cat }}$ with the conversion factor of 'susceptible peptide bonds'. Other studies reported high $k_{\text {cat }}$ values for trypsin-catalyzed hydrolysis of certain syn- 


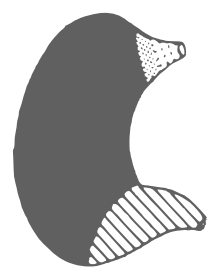

human

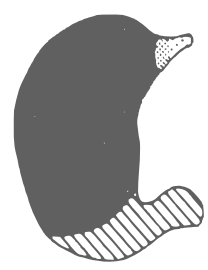

$\operatorname{dog}$

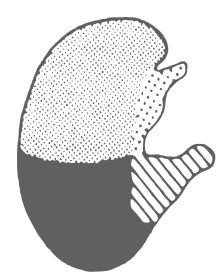

pig

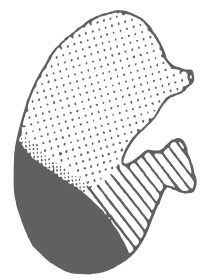

horse
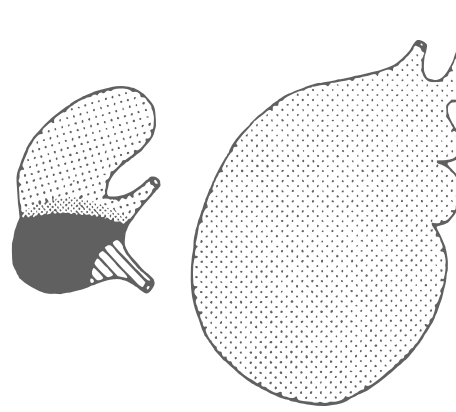

ox

rat

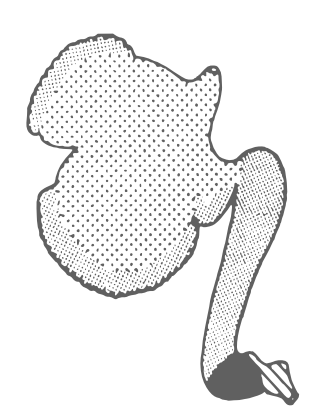

llama

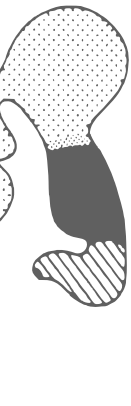

\section{Stratified squamous region \\ Cardiac gland region \\ Proper gastric region \\ Pyloric gland region}

Figure 7.1: Distribution of gastric mucosa in some mammals. The regions are defined by their epithelial lining. Stomachs are not represented on same scale. Taken from Stevens and Hume (2004)

thetic peptides (Tsunematsu, Imamura, and Makisumi 1983; Sears and Clark 1993). This difference in kinetics shows the division of functionality and synergy of pepsin and the intestinal proteases. Pepsin roughly cleaves the proteins into smaller polypeptides, which can then be further cleaved by the intestinal protease cocktail which includes trypsin, chymotrypsin, and several peptidases. The resulted tripeptides, dipeptides, and amino acids are ready to be absorbed by the intestine cells (Whitney and Rolfes 2011).

The varied demand of pepsin secretion in animals with different diets, the contrasting kinetics of pepsin and trypsin, along with the effect of pepsin in the digestion process that we found, all suggest the division of physiological function for pepsin to be the rapid modification of 
the protein-based food structures for further digestion and absorption, thus maximize the protein utilization. Therefore its digestive role is very tightly coupled to the role of the structure of the food, which is most prominently important in the stomach.

\subsection{Towards modeling the gastric digestive processes}

With the finding of this thesis, we validated that the physicochemical processes are important in the gastric digestion of food. With a better understanding of the underlying mechanism, models to predict such processes became possible. Here we propose two model concepts on the gastric $\mathrm{pH}$ and food disintegration.

\subsubsection{Simulation of gastric $\mathrm{pH}$ change after food ingestion}

In Chapter 6, we demonstrated the influence of food proteins on the gastric $\mathrm{pH}$. The gastric $\mathrm{pH}$ change during food ingestion and digestion can be predicted, when the experimentally measured data of protein buffer capacity and the physiological conditions are known.

Fig. 7.2 shows the processes involved in the gastric $\mathrm{pH}$ change. During fasting, there is only a small amount of residual gastric fluid in the stomach, it ranges from $0 \mathrm{~mL}-80 \mathrm{~mL}$ for different individuals and conditions, with an average of $20 \mathrm{~mL}$ (S. Phillips, Hutchinson, and Davidson 1993). After ingestion, food is mixed with the residual gastric fluid. The buffering components in the food react with the $\mathrm{HCl}$ in the residual gastric fluid, which will increase the gastric $\mathrm{pH}$. These buffering components are mostly the ionizable groups in the proteins and some other electrolytes. If the food is protein-rich, the buffer capacity of the food is mostly determined by the proteins.

After food ingestion, the stomach starts to secrete more gastric fluid. The exact composition and flow rate varies according to the phase of 


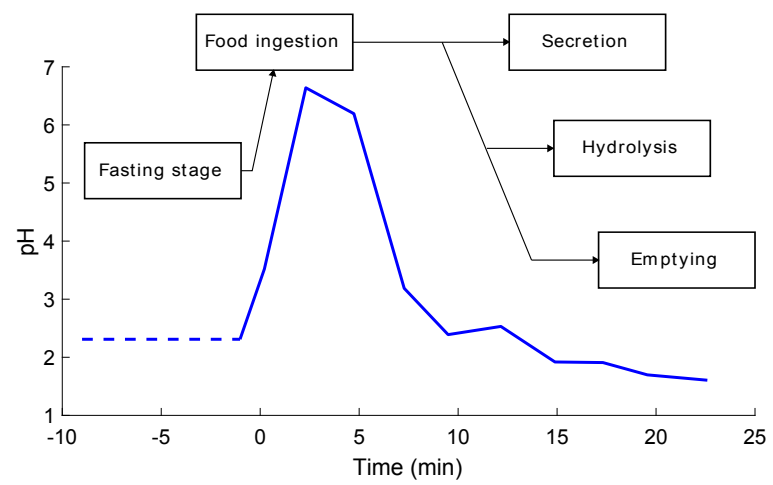

Figure 7.2: Flowchart of the processes involved in the gastric $\mathrm{pH}$ change. The solid line shows the gastric $\mathrm{pH}$ levels in healthy human subjects after the ingestion of $\alpha$-lactalbumin test drinks, the dashed line is the average value of the fasting $\mathrm{pH}$ level. Gastric $\mathrm{pH}$ data from Sullivan et al. (2014).

food ingestion and digestion. Bellmann et al. (2016) estimated the average secretion rate based on literature as $1 \mathrm{~mL} \mathrm{~min}^{-1}$ and the stimulated secretion rate as $3.9 \mathrm{~mL} \mathrm{~min}^{-1}$. They also reported the average pepsin concentration $\left(1 \mathrm{mg} \mathrm{mL}^{-1} ; 2500 \mathrm{U} \mathrm{mg}^{-1}\right)$ and $\mathrm{HCl}(0.1 \mathrm{M})$. The secreted $\mathrm{HCl}$ will react with the buffer components and gradually decrease the gastric $\mathrm{pH}$ again.

In the meantime, the proteins in food are hydrolysed by pepsin. The activity of pepsin is limited by increase of the gastric $\mathrm{pH}$, since it has its optimum activity at relatively low $\mathrm{pH}$. In addition, the hydrolysis of the proteins by pepsin liberates $\alpha$-carboxyl groups which also contribute to the buffer capacity, and thus prolong the period that the gastric $\mathrm{pH}$ is relatively high. Due to gastric secretion and gastric emptying, the pepsin concentration itself is time dependent. Last but not least, gastric emptying affects the gastric $\mathrm{pH}$, by changing the amount of acid, buffer components, pepsin, and substrate present.

By combining all these effects, the gastric $\mathrm{pH}$ can be quantitatively and dynamically predicted. For fluid foods, one may assume that mixing and transfer is fast; for solid and semi-solid foods, this clearly cannot be assumed, and requires further investigation. 


\subsubsection{Towards a mechanistic model of protein gel disintegra- tion}

As proposed in the objective of this thesis, we aimed to mechanistically understand the gastric digestion of food by studying the physicochemical processes during the digestion. Apart from the empirical models we discussed in Chapter 1, some literature on drug release studied the effects of acid diffusion, enzyme diffusion and reaction, and swelling effect (Li et al. 2009; H. Ye et al. 2017). However, they are focused on the release of drugs from the polymer network, rather than the disintegration of the gel networks. The findings of this thesis showed the possibility of a model that use the enzymatic reaction and mass transfer processes to predict the disintegration of protein-based food. Here, the approach to connect these processes will be discussed.

\section{Enzyme concentration}

The local pepsin concentration is dependent on the diffusion process, the diffusion is hindered by the gel matrices, which was discussed in Chapter 3 and Chapter 4 . The hindered diffusion coefficient in a given matrix can be calculated using the physics-based models in Chapter 4.

\section{Reaction kinetics}

If the local enzyme concentration and the substrate concentration are known, the reaction kinetics can be calculated. We showed that acid diffusion can also be a limiting factor for the enzyme activity in food matrices during gastric digestion in Chapter 6. Therefore, the local $\mathrm{pH}$ should be considered when calculating the enzyme kinetics in the food matrices.

It should be noted that the enzyme reaction is based on peptide bond cleavage, and the breakdown of the network is dependent on the remaining protein concentration on the network. This conversion 
from peptide bond cleavage to network breakdown need to be determined.

Breakdown of the network

The formation of polymer gels requires the protein to minimally have a critical gelation concentration $c_{g}$. We assume there is a corresponding critical disintegration concentration $c_{d}$ in the digestion process of protein gels. Thus, the disintegration rate of the gel particle could be determined by the local concentration of the gel network. When the local concentration of the protein in the gel network dropped to the critical concentration $c_{d}$, that layer will dissolve into the environment.

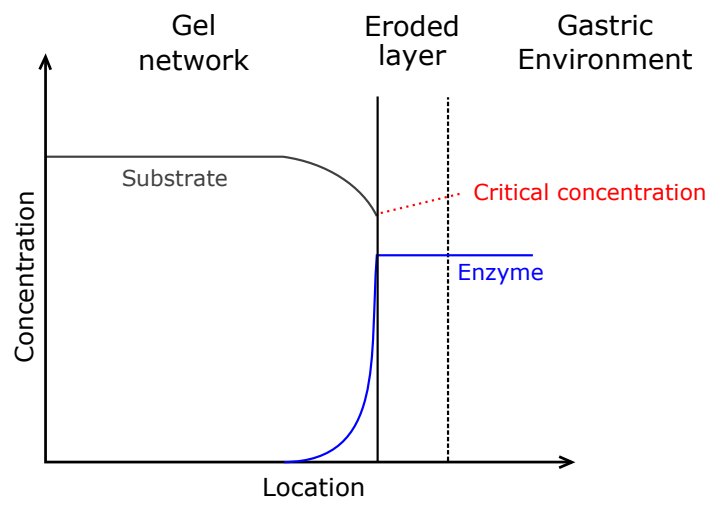

Figure 7.3: Illustration of the proposed protein gel disintegration model.

To sum up, the proposed model used physico-chemical theories along with experimentally measurable parameters. This model can predict the enzyme concentration gradient, the local reaction kinetics, and the substrate concentration gradient in the gel matrices, and finally the disintegration rate of the protein gel. By predicting the disintegration rate, we could have a direct indication of the digestibility of a protein gel based on its physico-chemical properties. 


\subsection{Other aspects of the gastric digestion pro- cesses}

There are some other aspects of the gastric digestion process that are worth investigation. Firstly, the swelling of the gel will influence the disintegration process. When the gel swells, it becomes more accessible for the enzyme and its mechanical strength decreases, which makes the gel more susceptible to disintegration. There are theories that address the swelling effects. For example, van der Sman (2015) analysed the swelling of biopolymer gels using scaling laws. H. Ye et al. (2017) considered the swelling effect in a multi-physics model for drug release from a hydrogel.

Secondly, as we discussed in Chapter 6, the acid diffusion can also be a limiting factor for the protein hydrolysis inside the gel matrices. Therefore, when considering the enzyme kinetics, both the gastric $\mathrm{pH}$ at the macroscale and the $\mathrm{pH}$ at the microscale in the food matrices should be taken into account.

Thirdly, the electrostatic interaction in the food matrix and digestion process should also be considered. Both acid diffusion and pepsin diffusion can be influenced by their electrostatic interaction with the gel network. The electrostatic effect in diffusion processes can be addressed by the Nernst-Planck equation (Jasielec et al. 2012; H. Ye et al. 2017).

Lastly, the digestion processes of other food component can be studied using the similar approach. For instance, the digestion of starchbased food matrices can be predicted by studying the diffusion of $\alpha$ amylase into the matrix, with consideration of the $\mathrm{pH}$ influence on the $\alpha$-amylase activity. Mennah-Govela, Bornhorst, and R. P. Singh (2015) demonstrated that the salivary $\alpha$-amylase can significantly modify the structure of rice bolus and influence the acid diffusion until the gastric acid inactivates the enzyme. 


\subsection{Outlook of digestion research}

By using the physical chemistry concepts and process engineering approaches, we could better understand the digestion at both the microscale and macroscale. Since most food matrices are complex systems, it is challenging to distinguish the important aspects in the simultaneous and dynamic processes. By following the individual physicochemical processes analytically, we can gain insight on their individual effect on the digestion and then consider their interactions systematically. With better knowledge of these individual processes, physic-based predictive models become possible.

Using mechanistic models has many advantages including costefficiency and predictive capability (Datta 2008), but mostly for being able to establish causal relations in complex systems. By following the underlying mechanistic processes and using measurable parameters, these models can confirm whether indeed causal relations between individual phenomena, for example between microscopic processes and macroscopic dynamics, are present. These causal relations will give us not just understanding, but also the capacity to predict out of the range of experimentally assessed conditions.

The ultimate goal of food digestion research is to design better food products in nutritional value, sensory attractiveness, and populationspecific functionality. In silico models can be useful tools in such designing: rather than trial and error, the properties of the product can be better defined and tweaked before it is produced.

\section{References}

Bellmann, S., J. Lelieveld, T. Gorissen, M. Minekus, and R. Havenaar (Oct. 1, 2016). "Development of an Advanced in Vitro Model of the Stomach and Its Evaluation versus Human Gastric Physiology." In: Food Research International. The 4th International Conference on 
Food Digestion 88, pp. 191-198. Dor: $10.1016 /$ j . foodres . 2016 . 01.030.

Datta, A. K. (Jan. 1, 2008). "Status of Physics-Based Models in the Design of Food Products, Processes, and Equipment." In: Comprehensive Reviews in Food Science and Food Safety 7.1, pp. 121-129. DoI: 10.1111/ j.1541-4337.2007.00030.x.

Jasielec, J., R. Filipek, K. Szyszkiewicz, J. Fausek, M. Danielewski, and A. Lewenstam (Oct. 2012). "Computer Simulations of Electrodiffusion Problems Based on Nernst-Planck and Poisson Equations." In: Computational Materials Science 63, pp. 75-90. DoI: 10 . 1016/ j . commatsci.2012.05.054.

Kageyama, T. (Apr. 30, 2014). "Pepsinogens, Progastricsins, and Prochymosins: Structure, Function, Evolution, and Development." In: Cellular and Molecular Life Sciences CMLS 59.2, pp. 288-306. Dor: 10. 1007/s00018-002-8423-9.

Li, H., R. Luo, E. Birgersson, and K. Y. Lam (Feb. 1, 2009). “A ChemoElectro-Mechanical Model for Simulation of Responsive Deformation of Glucose-Sensitive Hydrogels with the Effect of Enzyme Catalysis." In: Journal of the Mechanics and Physics of Solids 57.2, pp. 369-382. Dor: 10.1016/ j . jmps .2008.10.007.

Maximova, K. and J. Trylska (Oct. 1, 2015). "Kinetics of TrypsinCatalyzed Hydrolysis Determined by Isothermal Titration Calorimetry." In: Analytical Biochemistry 486, pp. 24-34. Dor: 10.1016/ j . ab.2015.06.027.

Mennah-Govela, Y. A., G. M. Bornhorst, and R. P. Singh (2015). “Acid Diffusion into Rice Boluses Is Influenced by Rice Type, Variety, and Presence of $\alpha$-Amylase." In: Journal of Food Science. Dor: 10 . $1111 /$ 1750-3841. 12750.

Phillips, S., S. Hutchinson, and T. Davidson (1993). "Preoperative Drinking Does Not Affect Gastric Contents." In: BJA: British Journal of Anaesthesia 70.1, pp. 6-9.

Sears, P. S. and D. S. Clark (June 5, 1993). "Comparison of Soluble and Immobilized Trypsin Kinetics: Implications for Peptide Synthesis." In: Biotechnology and Bioengineering 42.1, pp. 118-124. Dor: 10 . 1002 /bit. 260420116. 
Stevens, C. E. and I. D. Hume (Nov. 25, 2004). Comparative Physiology of the Vertebrate Digestive System. 2nd. Cambridge: Cambridge University Press. 424 pp.

Sullivan, L. M., J. J. Kehoe, L. Barry, M. J. M. Buckley, F. Shanahan, K. H. Mok, and A. Brodkorb (Aug. 2014). "Gastric Digestion of $\alpha-$ Lactalbumin in Adult Human Subjects Using Capsule Endoscopy and Nasogastric Tube Sampling." In: British Journal of Nutrition 112.4, pp. 638-646. DoI: 10.1017/S0007114514001196.

Tsunematsu, H., T. Imamura, and S. Makisumi (July 1983). "Kinetics of Hydrolysis of Na-Benzoyl-p-Guanidino-L-Phenylalanine pNitroanilide by Trypsin." In: Journal of Biochemistry 94.1, pp. 123128. pmid: 6619104.

Van der Sman, R. G. M. (June 2015). "Biopolymer Gel Swelling Analysed with Scaling Laws and Flory-Rehner Theory." In: Food Hydrocolloids 48, pp. 94-101. Dor: 10.1016/ j . foodhyd.2015.01.025.

Whitney, E. N. and S. R. Rolfes (2011). Understanding Nutrition. 12th ed. Belmont, CA: Wadsworth, Cengage Learning. 1 p.

Ye, H., Y. Liu, L. Gao, T. Du, and Y. Jia (July 28, 2017). "Effects of Solution $\mathrm{pH}$ on Ion Distribution and Drug Release Behaviors of a Weak Polyelectrolyte Hydrogel: Effects of $\mathrm{pH}$ on Behaviors of Weak Polyelectrolyte Hydrogel." In: Polymer International. Dor: 10 . 1002 / pi . 5429. 

Summary 


\section{Summary}

The impact of food on health is not only from the sum of the ingredients, but also from its digestive process in the human body. To better design food, scientists need to better understand the underlying mechanisms of digestion. However, food digestion research is challenging due to the complexity of both food and digestion. To tackle this complexity, we can regard food digestion as a series of processes, and investigate it from an engineering perspective.

The aim of the thesis is to study the physicochemical processes in the gastric digestion of protein-based food matrices, to gain quantitative insight and mechanistic understanding of the gastric digestion of protein food. We first explored the overall digestion kinetics of egg white protein and whey protein in solutions and in gels in a static simulated environment (Chapter 2). The dry matter loss, degree of hydrolysis and peptide distribution of the proteins in solutions and in gels were followed. The results show that both the action of pepsin and hydrodynamic force are important in the disintegration of protein gels, and the gel microstructure hinders the digestion of protein. These findings showed the importance of food structure, diffusion processes and enzyme kinetics in the gastric digestion, which defined the further exploration of this thesis.

We determined the diffusivity of pepsin in water and in whey protein isolate (WPI) gels by fluorescence correlation spectroscopy (FCS) (Chapter 3). The measured pepsin diffusivity indicates that the pepsin is constrained within a thin layer from the gel surface during digestion. Gel composition analysis confirmed this constraint: hydrolysis was observed only in a short distance from the gel surface. Scanning electron microscopy indicated that the surface of whey protein gels was loosened by pepsin, which may accelerate pepsin diffusion and consequently enhance the disintegration of gel surface. To quantitatively characterize the hindrance of the microstructure in the diffusive mobility of the enzyme, we used enhanced green fluorescent protein (EGFP) as the probe to study the diffusivity of proteins in varied pro- 
tein gel matrices by FCS (Chapter 4). The gels with the same volume fraction but different texture do not show differences in protein diffusivity. We tested mathematical models to describe diffusion in protein gel matrices, some models yield good description and offer the possibility to predict enzyme diffusion in diverse food matrices. However, to yield more accurate predictions, electrostatic and enzyme-substrate interaction also need to be considered.

The kinetic parameters of pepsin with its naturally occurring substrate had not been systematically quantified. Therefore, we used isothermal titration calorimetry to study the enzymatic kinetics of pepsin with bovine serum albumin as the substrate (Chapter 5). We found that pepsin has a higher activity at $\mathrm{pH} 2$, while its affinity to the substrate is lower. At the same $\mathrm{pH}$, pepsin has lower activity and affinity at higher ionic strengths. Compare to small peptides, pepsin is more efficient towards larger substrates such as proteins. The enzyme kinetics of pepsin suggested its physiological function to be: fast hydrolysis of intact proteins to enhance the disintegration of food.

The gastric digestion kinetics of food proteins is influenced by the gastric $\mathrm{pH}$, and the gastric $\mathrm{pH}$ fluctuates in response to food consumption. However, a quantitative understanding of the gastric $\mathrm{pH}$ dynamics is missing. Among the macronutrients, protein has the strongest influence on the gastric $\mathrm{pH}$ change. Therefore, we investigated the buffer capacity of proteins and the acid diffusion in protein gels, both theoretically and experimentally (Chapter 6). In theory, the buffer capacity of proteins can be characterized by its content of ionizable amino acid side groups, which was validated by titrating protein solutions and gels with hydrochloric acid. Moreover, the liberated carboxyl and amino groups during enzymatic hydrolysis of protein can also contribute to the buffer capacity. While we expected protons to diffuse faster than pepsin, we found that the penetration distance of acid is comparable to that of pepsin. The acid concentrated tenfold in the gel comparing to the bulk acid concentration, which was caused by the buffer reaction. Therefore, we postulated that the acid diffusivity reduction is due to the buffer reaction. With the quantitative knowledge of buffer capacity, the $\mathrm{pH}$ change during gastric digestion can be 
predicted, which was discussed in Chapter 7.

Chapter 7 also reviews and reflects on the previous chapters. The physicochemical processes studied are interrelated and are all contributing to the gastric digestion of food. The physicochemical characteristics of pepsin were relevant to its physiological functionality. A qualitative overall model was proposed. By integrating the physicochemical processes involved, this model has the potential to predict the disintegration and digestion kinetics of protein-based food matrices. 


\section{Acknowledgments}

After I finished this dissertation and looked back at the four years I spent as a PhD student, I am truly grateful for the people who went through this together with me. I would like to take the opportunity to express my gratitude for these people.

First and foremost, I want to thank my promotor and co-promotor. Remko, since your lectures during my MSc study, your enthusiasm and erudition rekindled my passion for science. During my PhD project, every meeting had been inspiring and I learned a lot from you. Anja, you were there for me since early in my MSc study, my internship and my MSc thesis, you led me down the path. In my PhD project, you gave me the freedom and trust to explore many of the research interests, as well as the guidance and encouragement to get things done.

Secondly, I want to thank my colleagues in FPE. Marjan, Ilona, and Martin, thank you for the help and patience on the financial matter and other things. I had been a troublemaker for a few times. Maurice, Jos, and Jarno, thank you for helping me in and out of the lab. Jan-Eise, thank you for the help with Matlab. My officemates: Kevin, Alime, Dimitri, and Juliana, thank you for the company. To all colleagues, thank you for the coffee breaks, the lunches, the dinners, the movies, the parties, the PhD trips and all the activities we had together. You all made these tough years enjoyable.

I would like to thank my BSc and MSc students for your contribution to the project, including experimental work, literature study, new 
ideas and more. My co-authors, Jan Willem and Adrie, I enjoyed the collaboration with you.

Many thanks to my family and friends. 爸爸妈妈, 谢谢你们的抚养 和教育, 谢谢你们无条件的支持和理解。在家的各位亲人, 我在外仍 然时常承蒙你们的关照。My holiday park friends and my MSc study mates, I will always keep those good memories we shared. My Haarweg 71 corridor mates, with you guys I felt at home and I 'socially' grew up a bit more. Also, you are the reason I became so Dutch!

Last but not least, to my dearest 梦希。谢谢你陪伴我走过这一段艰 难而美好的时光, 谢谢你的关心和照顾, 谢谢你换着花样喂饱挑食的 我:) 


\section{About the author}

\section{Curriculum Vitae}

Qi Luo was born on 24th July, 1989 in Yanling, Hunan province, China. After studying in Yanling No. 1 Middle School, he started his bachelor study of Food Science and Engineering at Beijing Forestry University in 2006. In 2011, Qi started his Master program of Food Technology at Wageningen University. He finished his MSc thesis at Food Process Engineering group on the performance of pepsin in simulated gastric digestion, under the supervision of Dr. Anja Janssen. His MSc internship was performed at Danone Research, on the enzymatic Hydrolysis of $\beta$-lactoglobulin and $\alpha$-lactalbumin, under the supervision of Dr. Sergio Oliveira and Dr. Anja Janssen. After obtaining his MSc degree in August 2013, he started his PhD research at Food Process Engineering group under the supervision of Dr. Anja Janssen and Prof. dr. Remko Boom. The results of his $\mathrm{PhD}$ research are presented in this thesis.

E-mail: luoqi1989@gmail.com 


\section{List of publications}

Q. Luo, R. M. Boom, and A. E. M. Janssen. "Digestion of Protein and Protein Gels in Simulated Gastric Environment." In: LWT - Food Science and Technology 63.1, pp. 161-168.

Q. Luo, J. W. Borst, A. H. Westphal, R. M. Boom, A. E.M. Janssen. "Pepsin Diffusivity in Whey Protein Gels and Its Effect on Gastric Digestion." In: Food Hydrocolloids 66, pp. 318-325.

Q. Luo, E. Sewalt, J. W. Borst, A. H. Westphal, R. M. Boom, A. E.M. Janssen. "Analysis and modeling of enhanced green fluorescent protein diffusivity in whey protein gels." Submitted for publication.

Q. Luo, D. Chen, R. M. Boom, A. E. M. Janssen. "Revisiting the enzymatic kinetics of pepsin using isothermal titration calorimetry." Submitted for publication.

Q. Luo, W. Zhan, R. M. Boom, A. E. M. Janssen. "Interactions between acid and proteins under in vitro gastric condition - a theoretical and experimental quantification" Submitted for publication. 


\section{Overview of completed training activities}

\section{Discipline specific activities}

Courses

- Reaction kinetics in food science, VLAG, Wageningen, NL, 2014

- Han-sur-lesse Physical Chemistry Winter School, WUR / TU Delft, Han-sur-lesse, BE, 2014

- Advanced Food Analysis, VLAG, Wageningen, NL, 2015

- Programming with Python, MolMed Erasmus MC, Rotterdam, NL, 2016

Conferences and meetings

- 3rd Interantional Conference on Food Digestion, Infogest, Wageningen, NL, 2014

- 4th Interantional Conference on Food Digestion ${ }^{1}$, Infogest, Naples, IT, 2015

- The 7th International Symposium on Food Rheology and Structure $^{2}$, ETH Zurich, Zurich, CH, 2015

- 2nd Food Structure and Functionality Forum Symposium², Elsevier, Singapore, SG, 2016

- 2nd Wageningen PhD Symposium², VLAG, Wageningen, NL, 2015

- 16th Food Colloids Conference ${ }^{1}$, WUR/TNO, Wageningen, NL, 2016

- 5th International Conference on Food Digestion ${ }^{1}$, Infogest, Rennes, FR, 2017

\footnotetext{
${ }^{1}$ Poster

${ }^{2}$ Presentation
} 


\section{General courses}

- VLAG PhD week, VLAG, Baarlo, NL, 2014

- PhD carousel, WGS, Wageningen, NL, 2014

- Scientific Writing, WGS, Wageningen, NL, 2014

- Voice and Presentation Skill Training, WUR Library, Wageningen, NL, 2015

- Career Perspectives, WGS, Wageningen, NL, 2016

- Teaching and supervising Thesis Student, Educational support, Wageningen, NL, 2016

\section{Additional activities}

- Preparation of Research Proposal, FPE, Wageningen, NL, 2014

- PhD study tour to Chile and Brazil, FPE, CL/BR, 2014

- PhD study tour to Denmark and Switzerland, FPE, DE/CH, 2016

- Weekly group meetings, FPE, Wageningen, NL, 2014 - 2016 

Print by: Digiforce || ProefschriftMaken

Cover inspired by Fritz Kahn's Man as Industrial Palace (1926), designed by Lu Zhang. 